Portland State University

PDXScholar

1984

\title{
A numerical solution for three dimensional beam columns in the elastic region
}

Hamid Reza Afghan

Portland State University

Follow this and additional works at: https://pdxscholar.library.pdx.edu/open_access_etds

Part of the Civil Engineering Commons

Let us know how access to this document benefits you.

\section{Recommended Citation}

Afghan, Hamid Reza, "A numerical solution for three dimensional beam columns in the elastic region" (1984). Dissertations and Theses. Paper 3422.

https://doi.org/10.15760/etd.5300

This Thesis is brought to you for free and open access. It has been accepted for inclusion in Dissertations and Theses by an authorized administrator of PDXScholar. Please contact us if we can make this document more accessible: pdxscholar@pdx.edu. 
AN ABSTRACT OF THE THESIS OF Hamid Reza Afghan for the Master of Science in Engineering-Civil presented June 1, 1984.

Title: A Numerical Solution for Three Dimensional Beam Columns in the Elastic Region.

APPROVED BY MEMBERS OF THE THESIS COMMITTEE:

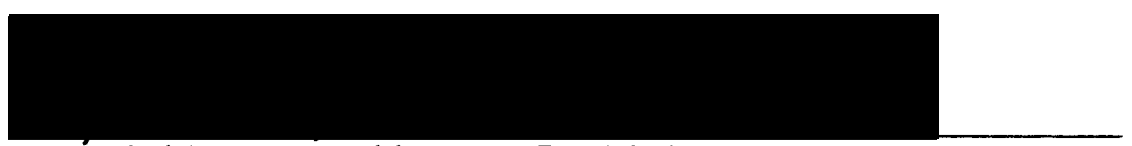

Wendelin H. Mueller, III, Advisor

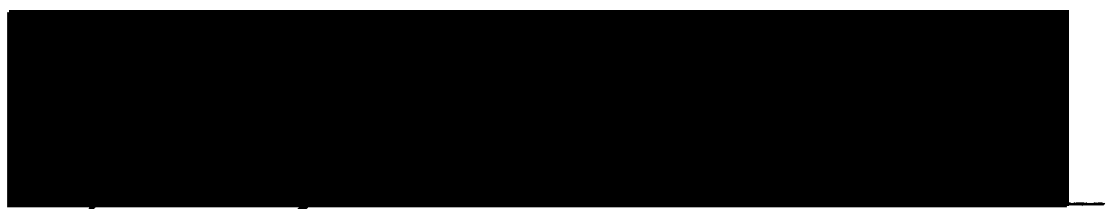

Hącik Erzuryerlu
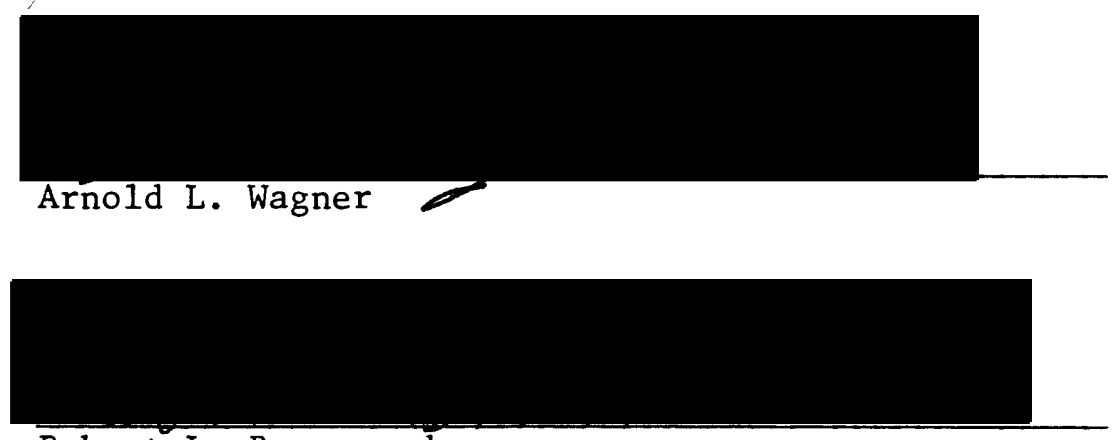

Robert L. Broussard

The three differential equations describing the behavior of the beam columns in three dimensions are derived and presented in finite difference form. A computer model is developed to solve the simultaneous equations in the elastic regions and predict the member behavior. 
The computer program is checked by comparing the results obtained from the program with data from other investigators, and classical analytical techniques. 
A NUMERICAL SOLUTION FOR

THREE DIMENSIONAL BEAM COLUMNS

IN THE ELASTIC REGION

by

HAMID REZA AFGHAN

A thesis submitted in partial fulfillment of the requirements for the degree of

MASTER OF SCIENCE

in

ENGINEERING AND APPLIED SCIENCE

Portland State University

1985 
TO THE OFFICE OF GRADUATE STUDIES AND RESEARCH:

The members of the Committee approve the thesis of Hamid Reza Afghan presented June 1, 1984.

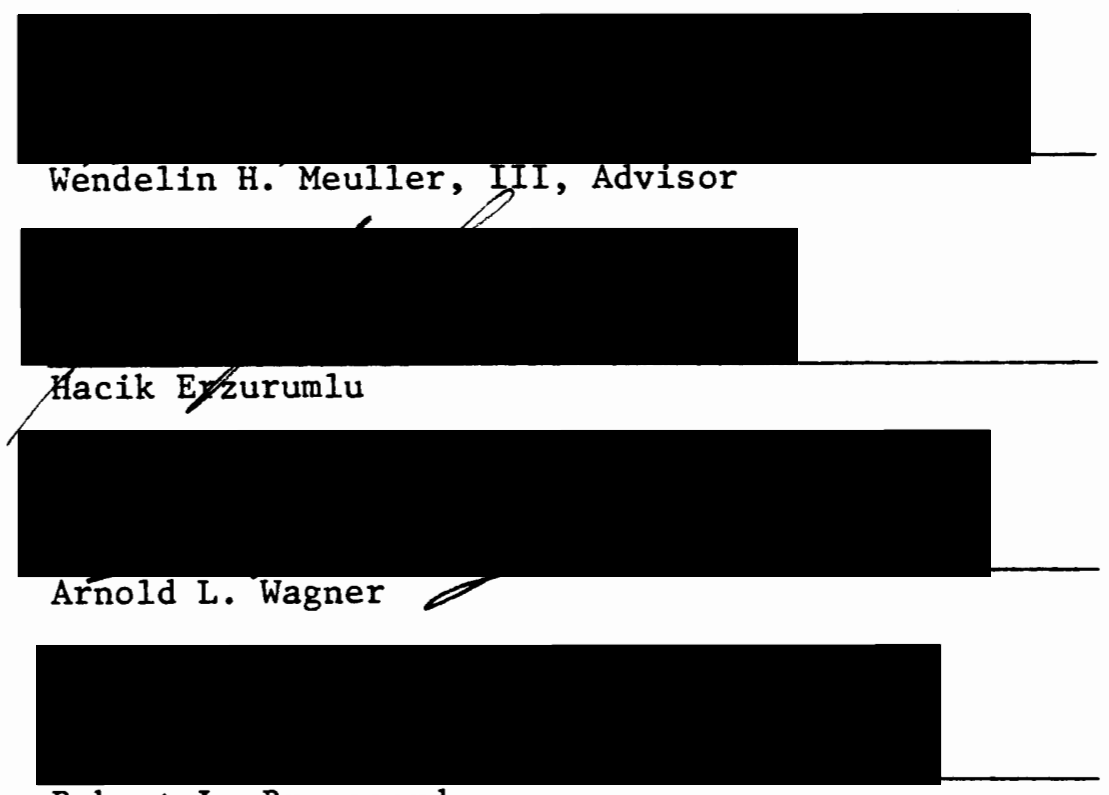

Robert L. Broussard

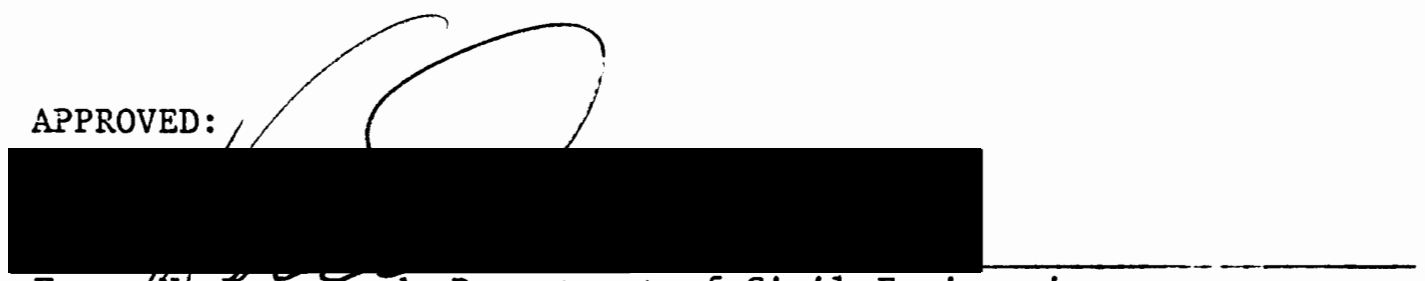

Franz/N: Kad, Head, Department of Civil Engineering

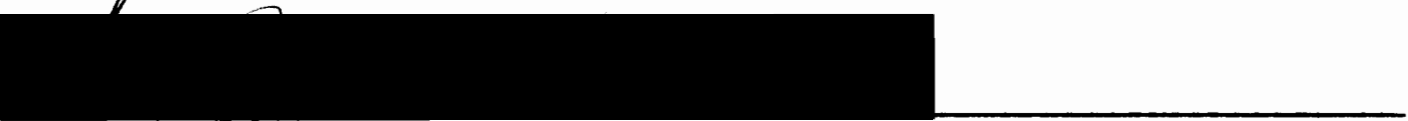

Jim F, Heath, Dean, Graduate Studies and Research 
DEDICATED TO MY LOVING MOTHER 


\section{ACKNOWLEDGMENTS}

The author is very thankful to $\mathrm{Dr}$. Wendelin H. Mueller for his guidance, help and support throughout this study. Gratitude is also expressed to Dr. Hacik Erzumulu for his advice and comments during the graduate and undergraduate study. The author would also like to express his appreciation to Mr. Arnold Wagner for his assistance and comments. Financial assistance in the form of a research grant from Bonneville Power Administration is gratefully appreciated. The author would especially like to thank Mr. Thomas Mackenzie for his support throughout the course of study.

The author would like to extend his appreciation to Ms. Beverly Meier for typing this thesis. Appreciation is also due to Mr. Bahman Daniali for his assistance in drawing the figures. Finally, the author would like to thank his brothers for their patience throughout the graduate work. 
TABLE OF CONTENTS

PAGE

DEDICATION . . . . . . . . . . . . . . . iii ACKNOWLEDGMENTS ................. . . iv LIST OF FIGURES . . . . . . . . . . . . . . vil CHAPTER

I INTRODUCTION ..................... 1

II REVIEW OF LITERATURE ........... 3

III COMPUTER MODEL ................... 5

Overview ............... 5

Recursive solution for an elastic beam column. 7

Derivation of the equilibrium equations

Recursive solution of the beam column

Starting and reversing the recursion process

Specifying desired deflections

Buckling and instability of the beam column

IV COMPARING WITH OTHER ANALYTICAL TECHNIQUES . . • 38

Concentrated moments . . . . . . 38

Three concentrated loads . . . . . . 39

Applied torques ......... . . 39

Flexural buckling about $\mathrm{x}$ axis ...... 41 
IV (Cont'd)

Flexural buckling about y axis . . . . . 43

Torsional buckling . . . . . . . . . . . 44

Flexural torsional buckling . . . . . . . 46

V EXPANSION POSSIBILITIES . . . . . . . . . 49

Specified slopes and fixed end condition . . 49

Specified external torques . . . . . . . 49

Spring supports . . . . . . . . . 50

Q - Delta effect.......... . . 56

References............. . 58

APPENDIX A . . . . . . . . . . . . . . . 60

APPENDIX B . . . . . . . . . . . . . . 71

APPENDIX C . . . . . . . . . . . . . 75

APPENDIX D . . . . . . . . . . . . . . 145 


\section{LIST OF FIGURES}

FIGURE

PAGE

1 Beam of variable cross section subjected to general loading condition . . . . . . . . . . 6

2 Displacement of the cross section . . . . . . . . 9

3 Infintesimal beam increment in the yz plane . . . . . 11

4 Infintesimal beam increment in the $x z$ plane . . . . 16

5 Infintesimal beam increment in three dimensions . . . 19

6 Load vs. lateral deflection . . . . . . . . . 33

7 Two pass recursive method for three dimensional beam column . . . . . . . . . . . . . . . 37

8 Simple beam with concentrated moments . . . . . . . 40

9 Simple beam with three point loads. . . . . . . . . 40

10 Applied torques . . . . . . . . . . . . . 42

11 Flexural buckling about $\mathrm{x}$ axis. . . . . . . . . 42

12 Flexural buckling about y axis. . . . . . . . . 45

13 Torsional buckling about $\mathrm{z}$ axis . . . . . . . . . 45

14 Flexural torsional buckling of 3 "x3"x1/4" angle. . . 47

15 Infintesimal beam column increment in the $\mathrm{yz}$ plane with springs attached . . . . . . . . . 51

16 Infintesimal beam column increment in the $\mathrm{xz}$ plane with springs attached . . . . . . . . 53 
17 Cross section of the beam column with springs attached (xy plane) . . . . . . . . . 55

18 Q - Delta effect in a cantilever beam . . . . . . . 57

19 General beam column with positive loads and moments . . . . . . . . . . . . . . 72

20 Displacement of the center of gravity . . . . . . . 146 


\section{CHAPTER I}

\section{INTRODUCTION}

A beam column that is loaded through its center of gravity can buckle in three modes of failure, flexural buckling about its principal axes, torsional buckling, or flexural torsional buckling. If the shear center does not coincide with the center of gravity and the cross section has no axis of symmetry, the column will buckle in flexural torsional buckling. If the shear center and the center of gravity coincide, it will fail in pure torsional buckling or pure flexural buckling about one of its principal axes.

The member behavior of angle sections is of special interest to the engineers involved in design and analysis of the transmission towers. The transmission towers are highly indeterminate and once a member reaches its critical load and it buckles, the loads are redistributed in the tower. The buckled member will sustain some load equal to or less than the critical axial load.

In the design of the transmission towers, two concepts are used: The elastic strength and the ultimate strength concept. The elastic concept uses the yielding as the failure criteria; however, in the ultimate strength concept collapse is considered as the failure criteria. The behavior of the member in the elastic, inelastic, and post buckling is required in the ultimate strength concept. 
The three differential equations describing the behavior of the beam columns are complex for routine use. These equations are fourth degree differential equations and $c$ an be solved by using a finite difference approach.

It is necessary to develope an analytical technique that can treat the beam column in the elastic region. Using this solution package, an open form technique can be formulated to handle the inelastic and post buckling regions.

The general differential equations are derived and presented in finite difference form. A computer model is developed to solve the simultaneous equations in the elastic region and predict the member behavior. The validity of the computer model is checked by solving general example problems using both the computer model and classical solution techniques. 
CHAPTER II

\section{REVIEW OF LITERATURE}

The behavior of the beam column in the elastic and inelastic regions of the symmetrical cross sections has been intensively investigated in the past. These investigations, due to the symmetry of the cross section, have been performed in only two dimension and the torsional effect has not been included.

Galambos and Ketter (5) and Ketter, Kaminsky and Beedle (8) have done a great deal of work on wide flange members loaded as beam columns. Ellis (4) has performed some work on the plastic behavior of the compression members both analytical and experimental. Dwyer and Galambos (3) have reported a study of the plastic behavior of square tubes. The emphasis of this report was the comparison of the relative strength of the square tubes and wide flanges.

Wagner (14) has investigated the combined effect of bending and axial load on round steel tubes in the elastic and inelastic regions using an open form solution. He has used Matlock's recursive technique for analyzing the beam column. This technique had been previously modified by others to perform inelastic beam column analysis. For example, Mueller (12) modified the technique for treating beam columns on non linear foundations. 
Timoshinko and Gere (13) have derived the general beam column equations in three dimensions. Chajes, Fang and Winter (2) have simplified these equations for the beam columns with one axis of symmetry. The emphasis of their study is on axially loaded cold formed thin walled columns in elastic and inelastic regions. 


\section{CHAPTER III}

COMPUTER MODEL

This investigation directs itself to the study of a member subjected to axial loads and bendings about the two principal axes.

\section{OVERVIEW}

The differential equations are derived and expanded into finite difference form. It is assumed that the member is divided into $m$ increments. Therefore there are $\mathrm{m}+1$ real stations (including station zero) and six imaginary stations as illustrated in Figure 1. Each station has three possible displacements, two translations $u$ and $v$, and one rotation $\not$. Hence there are $3(m+3)$ unknown displacements including stations -1 and +1 and $3(m+3)$ equations. A computer program is developed to solve these simultaneous equations. A listing of the computer program is available in Appendix C.

The beam column method that is presented here can conveniently handle a wide range of support and loading conditions and also takes into account the P-Delta amplification in bending moment. The cross sectional properties of the member can vary along its length in any conceivable configuration and the center of gravity does not necessarily have to coincide with the shear center. The line which goes through the shear center of the member is taken as the $z$ axis (See Figure 1). 


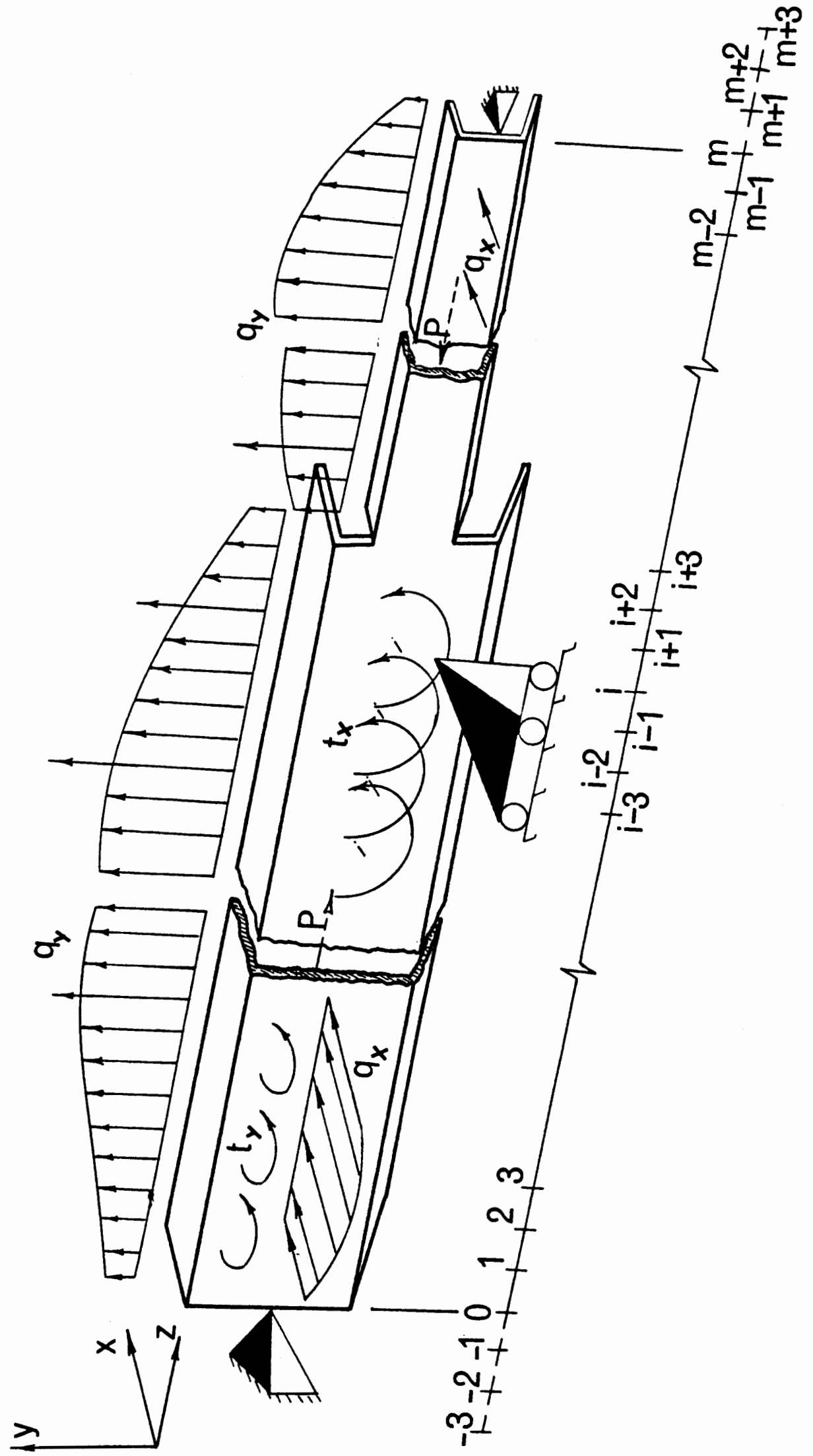

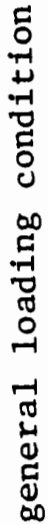

우

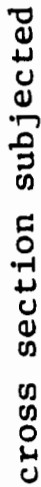

章

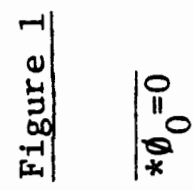




\section{RECURSIVE SOLUTION FOR AN ELASTIC BEAM COLUMN}

A recursive solution technique first used by Matlock to solve beam columns with one translational degree of freedom is employed for solving the simultaneous equations. After the three equations are defined in finite difference form and applied to each station, two passes are performed on the member. The first pass, from left to right, three coefficients are calculated for each station which are functions of the parameters at the two previous stations. On the return pass, from right to left, the deflections at each station are computed by using the calculated coefficients of that station and the deflections at the two preceding stations. This technique is expanded in the following discussion.

The following assumptions are made in this method of beam column analysis :
a. Hook's Law is valid
b. Plane sections before bending remain plane after bending
c. Deflections and rotations are small
d. Loads are applied in the plane of the vertical and hori- zontal axes of the member and through the center of gravity of the cross section

The following discussion is divided into five major sections:

1. Derivation of the equilibrium equations

2. Recursive solution of the beam column

3. Starting and reversing the recursion process

4. Specifying desired deflections

5. Buckling and instability of the beam column 


\section{Derivation of the Equilibrium Equations}

A beam column is considered with the general load and support configuration In Figure 1. The most general type of displacement possible for this member consists of bending about the principal axes and twisting about the $z$ axis through the shear center. The cross section of this member, Figure 2, undergoes trnaslations $u$ and $v$ in the $x$ and $y$ directions and a rotation $\varnothing$ about the shear center. An infintesimal increment of this member is considered in two planes yz and $x z$, Figures 3 and 4 , and in three dimension $x y z$, Figure 5. All quantities in Figures 3,4 , and 5 are positive as shown and are defined as follows:

Symbol

$\mathbf{P}$

$M_{\mathbf{X}}$

$\mathrm{M}_{\mathrm{y}}$

$\mathrm{v}_{\mathbf{x}}$

$\mathrm{v}_{\mathrm{y}}$

$q_{\mathbf{x}}$

qy

$t_{x}$

$t_{y}$

$\mathrm{M}_{\mathbf{z}}$

$\mathrm{m}_{\mathbf{z}}$
Description

Axial load on cross section through the center of gravity

Bending moment on cross section about $x$ axis

Bending moment on cross section about $y$ axis

Total shear on cross section in $\mathrm{x}$ direction

Total shear on cross section in y direction

Transverse load in $x$ direction through the center of gravity

Transverse load in $y$ direction through the center of gravity

Externally applied moment about $\mathrm{x}$ axis

Externally applied moment about $y$ axis

Torque on beam column about $z$ axis

Torque per unit length of the beam column about the $z$ axis
Dimension

$$
\begin{aligned}
& \text { F } \\
& \text { F.L } \\
& \text { F.L } \\
& \text { F } \\
& \text { F } \\
& \text { F/L } \\
& \text { F/L } \\
& \text { F.L/L } \\
& \text { F.L } / L \\
& \text { F.L } \\
& \text { F.L /L }
\end{aligned}
$$




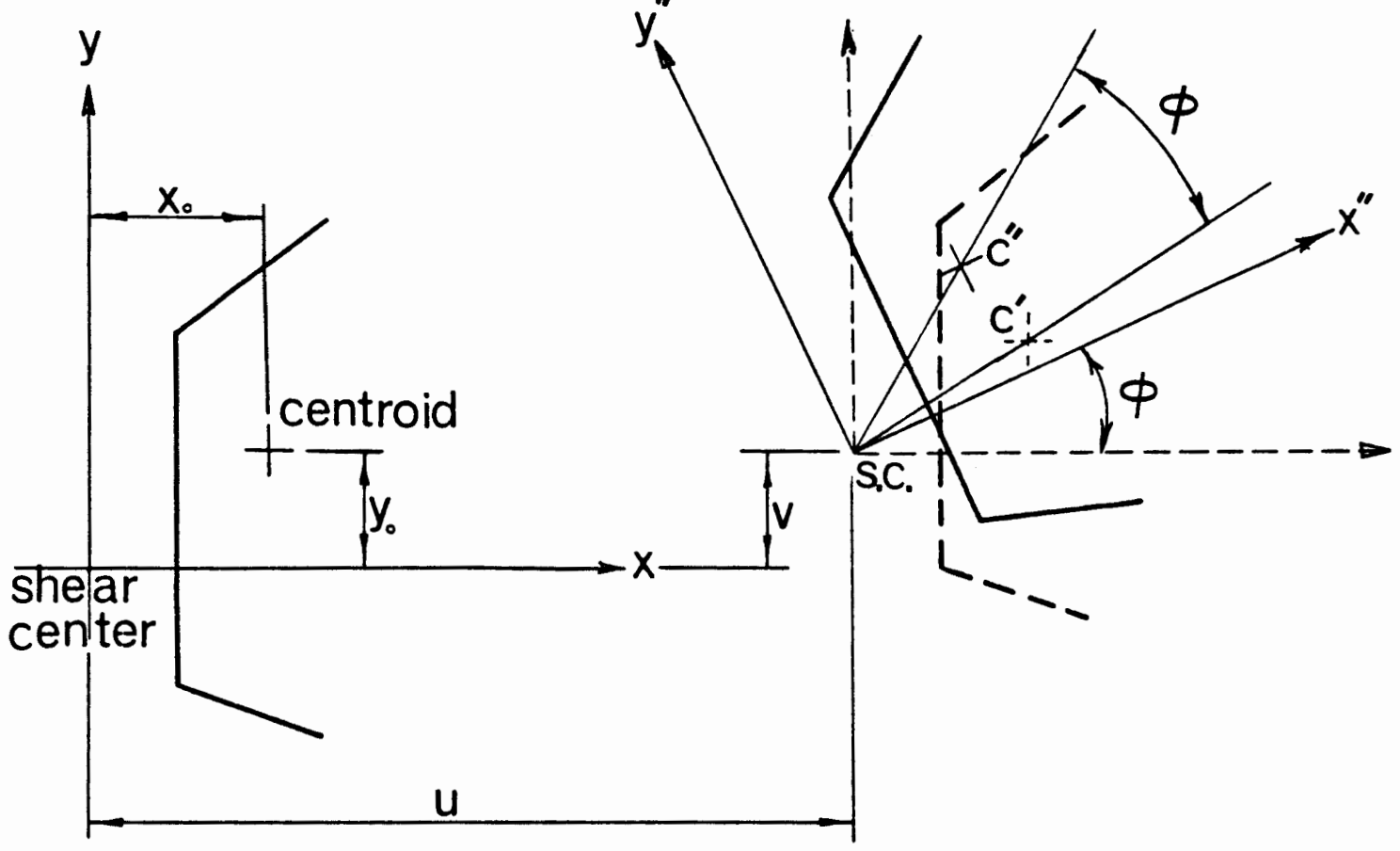

Figure 2 Displacement of the cross section 
It should be noted that $q_{x}, q_{y}, t_{x}$ and $t_{y}$ are assumed to be uniformly distributed over $d z$ increment, and the cross section is constant for each increment. Consider this element in the yz plane. Since the element is in equilibrium, the moment at point $A$ about the $x$ axis is zero, i.e,

$$
M_{x}-\left(M_{x}+d M_{x}\right)+P d y+v_{y} d z+q_{y} \frac{d z^{2}}{2}+t_{x} d z=0
$$

or

$$
-d M_{x}+P d y+V_{y} d z+q_{y} \frac{d z^{2}}{2}+t_{x} d z=0
$$

Neglecting the second order differentials and dividing Eq. (3.2) by dz results in:

$$
\frac{d M}{d z}=v_{y}+t_{x}+P \frac{d y}{d z}
$$

The vertical deflection of center of gravity, $y$, is equal to $v-x_{0} \varnothing$ (See App. D), therefore $d y=d v-x_{0} d \emptyset$.

Replacing dy in Eq. (3.3) and taking the derivative of Eq. (3.3) once with respect to $z$ gives:

$$
\frac{d^{2} M}{d z^{2}}=\frac{d V}{d z}+\frac{d}{d z}\left(t_{x}+P \frac{d v}{d z}-P x_{0} \frac{d \not}{d z}\right)
$$

When considering the equilibrium of the vertical forces on the element in the $y$ direction,

$$
v_{y}+q_{y}(d z)-\left(v_{y}+d v_{y}\right)=0
$$




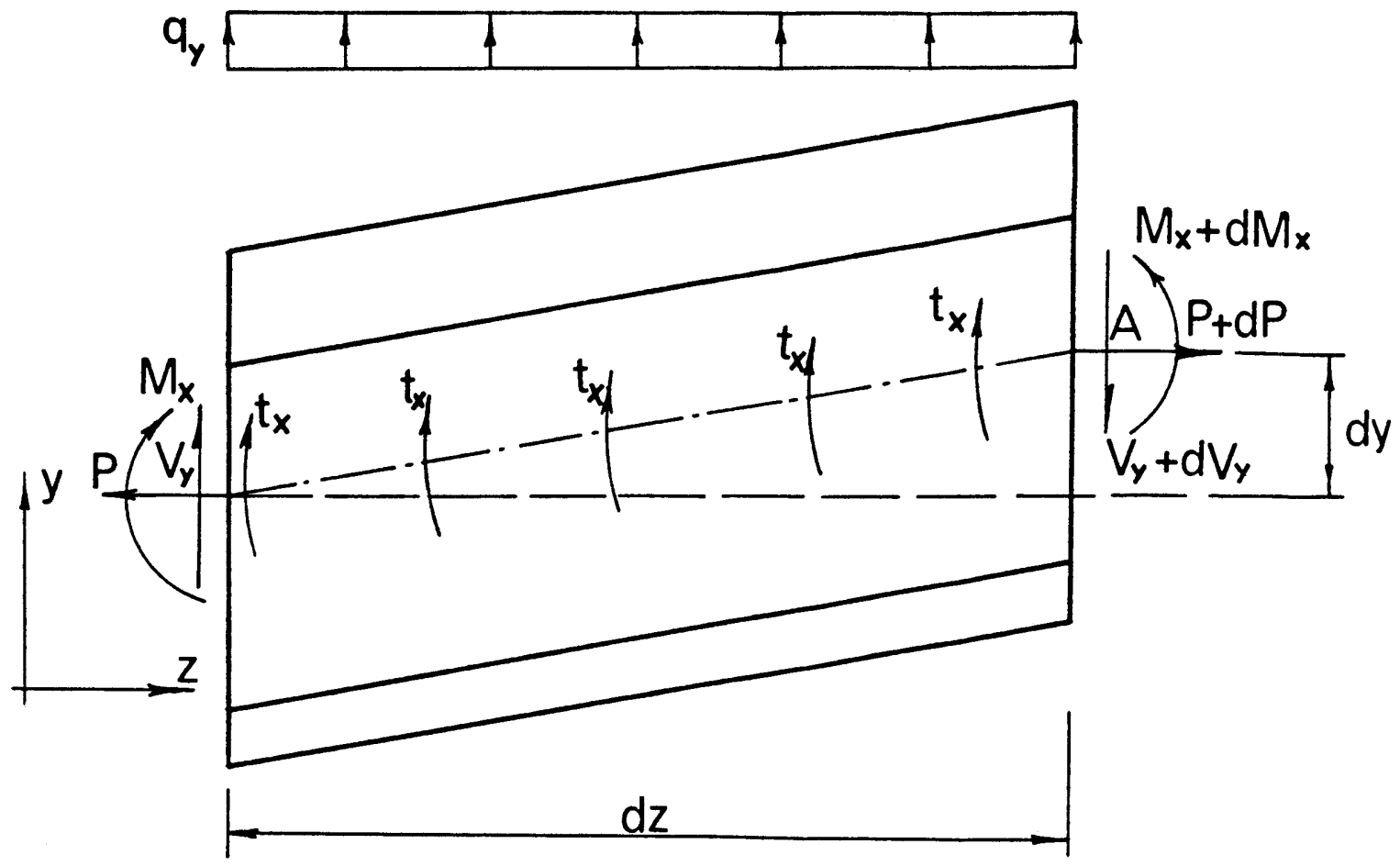

Figure 3 Infintesimal beam increment in the yz plane 
yields :

$$
\frac{d v}{d z}=q_{y}
$$

substituting: $\frac{d V_{y}}{d z}=q_{y}$ into Eq. (3.4) gives:

$$
\frac{d^{2} M}{d z^{2}}=q y+\frac{d}{d z}\left(t x+P \frac{d v}{d z}-P x_{0} \frac{d \emptyset}{d z}\right)
$$

The left side of Eq. (3.6) in finite difference form is:

$$
\frac{d^{2} M}{d z^{2}}=\frac{1}{h^{2}}\left(M_{i-1}-2 M_{i}+M_{i+1}\right)
$$

Where $i$ is the number defining the start and end of a particular finite increment. The member is divided into m equal finite increments and the length of each increment is equal to $h$. The value $i$ will hereafter be referred to as the station or station number.

The differential equation of the deflected elastic beam from the strength of materials is:

$$
M_{x}=F_{x} \frac{d^{2} v}{d z^{2}}
$$

$F_{x}$ is the flexural stiffness of the member in the $y$ direction (EI $x$ ) and $\frac{d^{2} v}{d z^{2}}$ is the curvature in the $y$ direction. Eq. (3.8) in the finite difference form at station $i$ is:

$$
M_{x_{i}}=F_{x_{i}}\left(v_{i-1}-2 v_{i}+v_{i+1}\right) \frac{1}{h^{2}}
$$


Applying Eq. (3.9) at station $i-1$ and $i+1$ gives,

$$
\begin{aligned}
& M_{x_{i-1}}=F_{x_{i-1}}\left(v_{i-2}-2 v_{i-1}+v_{i}\right) \frac{1}{h^{2}} \\
& M_{x_{i+1}}=F_{x_{i+1}}\left(v_{i}-2 v_{i+1}+v_{i+2}\right) \frac{1}{h^{2}}
\end{aligned}
$$

Substituting $M_{i-1}, M_{i}$ and $M_{i+1}$ in Eq. (3.7) results in:

$$
\begin{aligned}
\frac{d^{2} M}{d z^{2}} & =\frac{1}{h^{4}}\left[F_{x_{i+1}} v_{i+2}-2\left(F_{x_{i+1}}+F_{x_{i}}\right) v_{i+1}+\left(F_{x_{i+1}}+4 F_{x_{i}}+F_{x_{i-1}}\right) v_{i}\right. \\
& \left.-2\left(F_{x_{i}}+F_{x_{i-1}}\right) v_{i-1}+F_{x_{i-1}} v_{i-2}\right]
\end{aligned}
$$

Assuming $F_{x_{i-1}}, F_{x_{i}}$ and $F_{x_{i+1}}$ are each constant through the length of their respective increments $i-1, i$ and $i+1$. Eq. (3.10) represents the left side of Eq. (3.6) in finite difference form.

Now consider the right side of Eq. (3.6) and write the differential inside the bracket in finite difference form:

$$
\begin{aligned}
& \frac{d^{2} M}{d z^{2}}=q_{y_{i}}+\frac{d}{d z}\left[t_{x_{i}}+P_{i}\left(v_{i+1}-v_{i-1}\right)-P_{i} x_{o_{i}}\left(\frac{\varnothing_{i+1}-\varnothing_{i-1}}{2 h}\right)\right] \\
& \text { or } \\
& \frac{d^{2} M_{x}}{d z^{2}}=q_{y_{i}}+\frac{d}{d z}\left[t_{x_{i}}+\frac{P_{i}}{2 h} v_{i+1}-\frac{P_{i}}{2 h} v_{i-1}-\frac{P_{i} x_{o}}{2 h} \phi_{i+1}+\frac{P_{i} x_{i}}{2 h} \phi_{i-1}\right]
\end{aligned}
$$

The whole right side in finite difference form is: 


$$
\begin{aligned}
\frac{d^{2} M_{x}}{d z^{2}}= & q_{y_{i}}+\frac{1}{2 h}\left[\left(t_{x_{i+1}}-t_{x_{i-1}}\right)+\left(\frac{P_{i+1}}{2 h} v_{i+2}-\frac{P_{i+1}}{2 h} v_{i}\right)\right. \\
& -\left(\frac{P_{i-1}}{2 h} v_{i}-\frac{P_{i-1}}{2 h} v_{i-2}\right)-\left(\frac{P_{i+1} x_{i+1}}{2 h} \varnothing_{i+2}-\frac{P_{i+1} x_{i+1}}{2 h} \varnothing_{i}\right) \\
& \left.+\frac{P_{i-1} x_{i-1}}{2 h} \varnothing_{i}-\frac{P_{i-1} x_{i-1}}{2 h} \varnothing_{i-2}\right]
\end{aligned}
$$

Removing a factor of $\frac{1}{h^{4}}$ and collecting terms give:

$$
\begin{aligned}
\frac{d^{2} M}{d z^{2}}= & \frac{1}{h^{4}}\left[h^{4} q_{y_{i}}+\frac{1}{2} h^{3} t_{x_{i+1}}-\frac{1}{2} h^{3} t_{x_{i-1}}+\frac{h^{2}}{4} P_{i+1} v_{i+2}\right. \\
& -\left(\frac{h^{2} P_{i+1}}{4}+\frac{h^{2} P_{i-1}}{4}\right) v_{i}+\frac{h^{2} P_{i-1}}{4} v_{i-2}-\frac{h^{2} P_{i+1}}{4} x_{o_{i+1}} \phi_{i+2}+ \\
& \left.\left(\frac{h^{2} P_{i+1}}{4} x_{o_{i+1}}+\frac{h^{2} P_{i-1}}{4} x_{o_{i-1}}\right) \varnothing_{i}-\frac{h^{2} P_{i-1}}{4} x_{o_{i-1}} \varnothing_{i-2}\right]
\end{aligned}
$$

Equation (3.14) is the right side of Eq.(3.6). After combining the two Equations (3.10) and (3.14), the following equation results:

$$
\begin{gathered}
\left(F_{x_{i-1}}-P_{i-1}\right) v_{i-2}-2\left(F_{x_{i-1}}+F_{x_{i}}\right) v_{i-1}+\left(F_{x_{i-1}}+4 F_{x_{i}}+F_{x_{i+1}}+\right. \\
\left.\quad \mathrm{PH}_{i-1}+\mathrm{PH}_{i+1}\right) v_{i}-2\left(F_{x_{i}}+F_{x_{i+1}}\right) v_{i+1}+\left(F_{x_{i+1}}-P H_{i+1}\right) v_{i+2}+ \\
\left(P H_{i-1} x_{o_{i-1}}\right) \varnothing_{i-2}+\left(P H_{i-1} x_{o_{i-1}}+P H_{i+1} x_{o_{i+1}}\right) \varnothing_{i}+ \\
\left(P H_{i+1} x_{o_{i+1}}\right) \varnothing_{i+2}=Q_{y y}+T_{x_{i+1}}-T_{x_{i-1}}
\end{gathered}
$$


in which:

$$
\begin{aligned}
& \mathrm{PH}_{i}=\frac{1}{4} h^{2} \mathrm{P}_{i} \\
& \mathrm{Q}_{y_{\mathrm{i}}}=h^{4} \mathrm{q} \mathrm{y}_{i} \\
& \mathrm{~T}_{\mathrm{x}_{i}}=\frac{1}{2} h^{3} \mathrm{t}_{\mathrm{x}_{i}}
\end{aligned}
$$

Equation (3.15) is one of the three equations for the deflected shape of the beam colurn in finite difference form. It represents the deflection of the shear center in the $y$ direction.

In Figure 4, the moment about the $y$ axis at Point $A$ is also zero, i.e.,

$$
M_{y}-\left(M_{y}+d M_{y}\right)+P d x+v_{x} d z+q_{x} \frac{d z^{2}}{2}-t_{y} d z=0
$$

Neglecting higher order differential and dividing Eq. (3.17) by $d z$ results in:

$$
\frac{d M}{d z}=v_{x}-t_{y}+p \frac{d x}{d z}
$$

The deflection of the center of gravity in the $x$ direction is $u+y_{0} \varnothing$ (see App. D). Thus :

$$
d x=d u+y_{0} d \phi
$$

Substituting $\mathrm{dx}$ into Eq. (3.18) and taking the derivative once with respect to $z$ gives: 

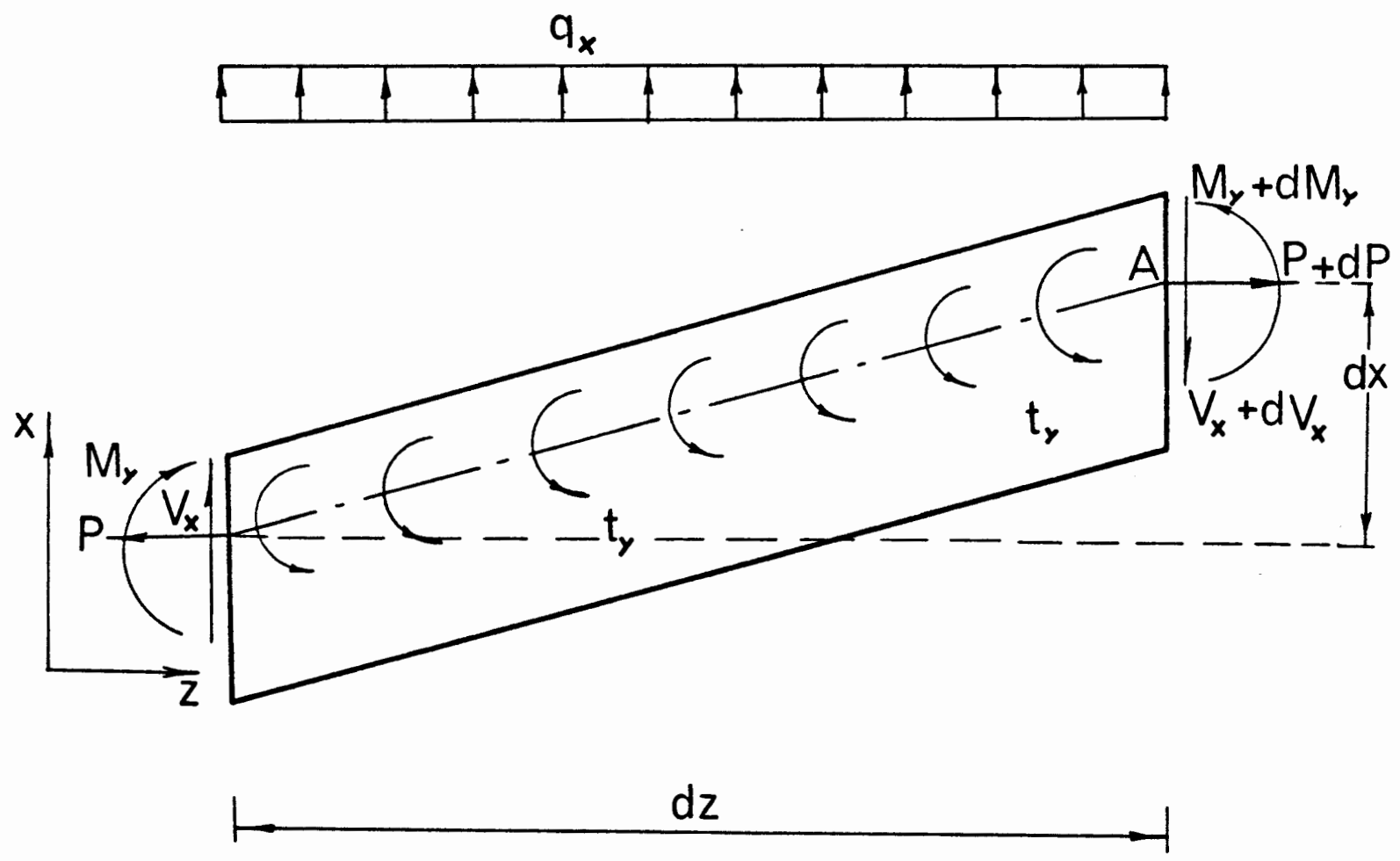

Figure 4 Infintesimal beam increment in the $x z$ plane 


$$
\frac{d^{2} M}{d z^{2}}=\frac{d V_{x}}{d z}+\frac{d}{d z}\left(-t y+P \frac{d u}{d z}+P y_{0} \frac{d \varnothing}{d z}\right)
$$

The equilibrium of the forces in the $x$ direction in Figure 4 gives:

$$
\frac{d V_{x}}{d z}=q_{x}
$$

Replacing $\frac{d V_{x}}{d z}$ by $q_{x}$ in Eq. (3.19A) results in:

$$
\frac{d^{2} M}{d z^{2}}=q_{x}+\frac{d}{d z}\left(-t_{x}+p \frac{d u}{d z}+P y_{0} \frac{d \emptyset}{d z}\right)
$$

Equation (3.20) is similar to Eq. (3.6). However, they are in two different directions, $x$ and $y$. It should be noted that $P x_{0} \frac{d \emptyset}{d z}$ in Eq. (3.6) has a negative sign and $P y_{0} \frac{d \emptyset}{d z}$ has a positive sign in Eq. (3.20). As the cross section translates and rotates about shear center, the new location of the center of gravity in the $x$ and $y$ directions becomes $u-y_{0} \varnothing$ and $v+x_{0} \varnothing$ (see App. D). The sign difference in the above expressions is reflected in Equations (3.6) and (3.20) by $\left(-P x_{0} \frac{d \phi}{d z}\right)$ and $\left(+P y_{0} \frac{d \phi}{d z}\right)$.

Performing the same operation for Eq. $(3.20)$ as was done in Eq. (3.6) gives the following equation in finite difference form. This is the second equation for the deflected shape of the general beam column of Figure (3.1). 


$$
\begin{aligned}
\left(F_{y_{i-1}}-P_{i-1}\right) u_{i-2}-2\left(F_{y_{i-1}}+F_{y_{i}}\right) u_{i-1}+\left(F_{y_{i-1}}+4 F_{y_{i}}+F_{y_{i+1}}\right. \\
\left.+P_{i-1}+P H_{i+1}\right) u_{i}-2\left(F_{y_{i}}+F_{y}\right) u_{i+1}+\left(F_{y_{i+1}}-P H_{i+1}\right) u_{i+2} \\
-\left(P H_{i-1} y_{o}\right) \emptyset_{i-2}+\left(P H_{i-1} y_{o}+P H_{i+1} y_{o}\right) \emptyset_{i} \\
-\left(P H_{i+1} y_{o}\right) \varnothing_{i+2}=Q_{x x_{i}}+T_{y_{i-1}}-T_{y_{i+1}}
\end{aligned}
$$

in which :

$$
\begin{aligned}
& Q_{x x_{i}}=h^{4} q_{x_{i}} \\
& T_{y_{i}}=\frac{1}{2} h^{3} t_{y_{i}}
\end{aligned}
$$

Equation (3.21) represents the deflection of the shear center in the $x$ direction in finite difference form.

Now consider equilibrium about the $z$ axis through the shear center as in Figure 5, i.e.,

$$
-M_{z}+\left(M_{z}+d M_{z}\right)+\left(m_{z}\right) d z+\left(q_{y} d z\right) x_{0}-\left(q_{x} d z\right) y_{0}=0
$$

or

$$
d M_{z}+\left(m_{z}\right) d z+\left(q_{y} d z\right) x_{0}-\left(q_{x} d z\right) y_{0}=0
$$

dividing Eq. (3.24) by dz results in:

$$
\frac{d M_{z}}{d z}+m_{z}+q_{y} x_{0}-q_{x} y_{0}=0
$$

or

$$
-\frac{d M_{z}}{d z}-m_{z}=q_{y} x_{0}-q_{x} y_{0}
$$




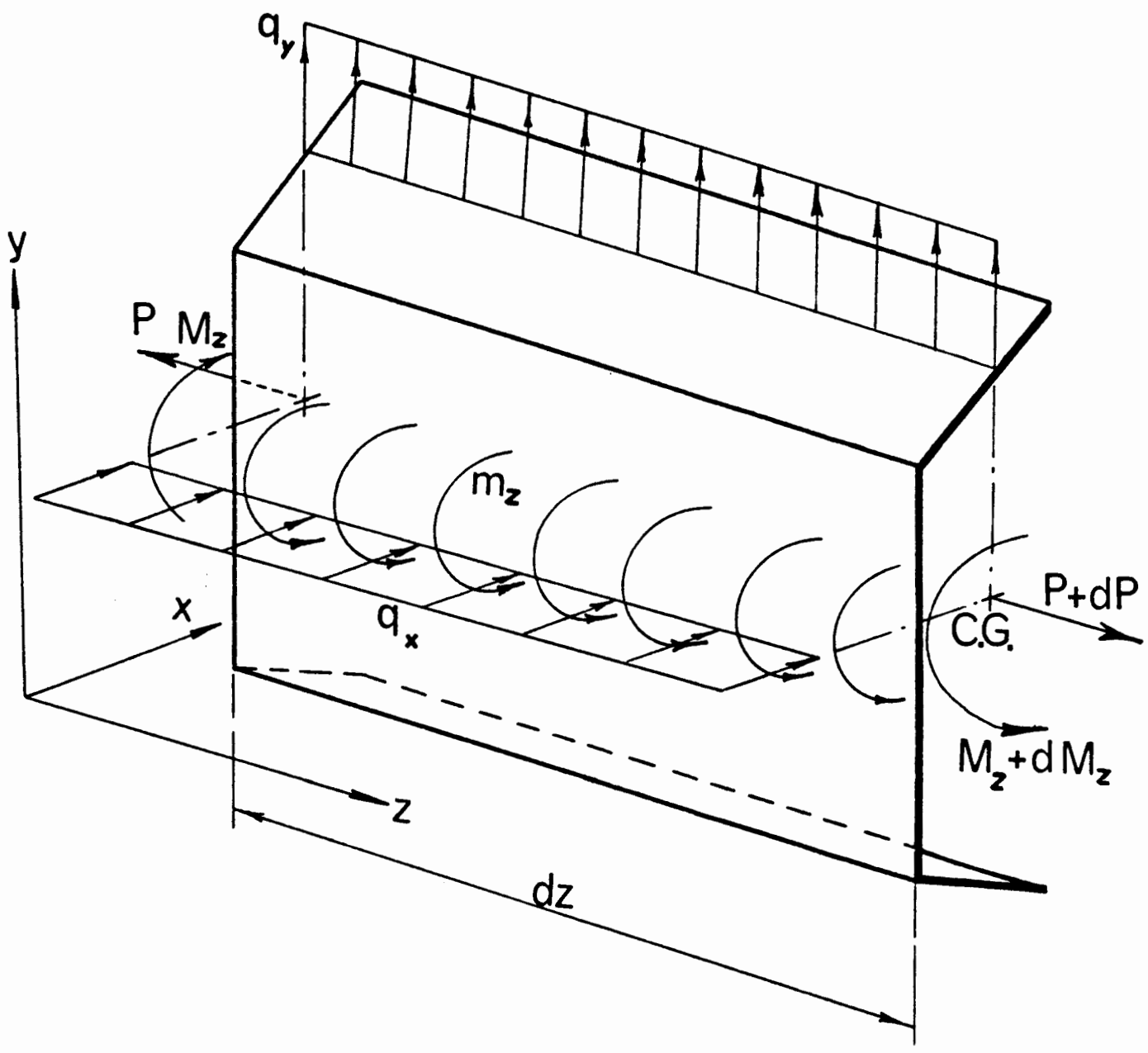

Figure 5 Infintesimal beam increment in three dimensions 
The torque, $M_{z}$, is resisted by a combination of shearing stress due to pure torsion and by the warping torsion. In differential form, $M_{z}$ for non-uniform torsion is:

$$
M_{z}=C \frac{d 0}{d z}-K \frac{d^{3} \emptyset}{d z^{3}}
$$

Equation (3.26) applies to any bar of thin walled open cross section. The first term of Eq. (3.26) represents the resistance of the section to twist and the second term the resistance to warping. As pointed out by McGuire (11), it is important to keep in mind that the second term is caused not by the warping of the member, but by its resistance to warp. If the member is allowed to warp, the second terms of Eq. (3.26) will become zero.

In Eq. (3.26), C is the torsional rigidity of the cross section which can be represented as GJ. $G$ is the shearing modulus of elasticity and $J$ is the torsion constant. The constant $K$ is called the warping rigidity and can be expressed as $E C_{w^{*}} E$ is the modulus of elasticity and $\mathrm{C}_{\mathrm{w}}$ is the warping constant.

The second term in Eq. (3.25), $\mathrm{m}_{z}$, denotes the torque per unit length of the bar due to the axial load on slightly rotated cross sections and it equals to:

$$
m_{z}=\frac{I_{0}}{A} P \frac{d^{2} \emptyset}{d z^{2}}-P\left(x_{0} \frac{d^{2} v}{d z^{2}}-y_{0} \frac{d^{2} u}{d z^{2}}\right)
$$

in which $I_{0}$ is the polar moment of inertia about the shear center and is equal to $I_{x}+I_{y}+A\left(x_{0}^{2}+y_{0}^{2}\right)$. Timoshenko and Gere 
21

present the derivation of $M_{z}$ and $m_{z}$. It should be emphasized that Timoshenko (13) uses positive sign convention for compressive load and here positive sign is used for tensile force.

Writing Eq. (3.26) in finite difference form for half increments :

$$
\begin{array}{r}
M_{z_{i}}=\frac{c_{i+\frac{1}{2}}+c_{i-\frac{1}{2}}}{2 h}\left(\varnothing_{i+\frac{1}{2}}-\phi_{i-\frac{1}{2}}\right)-\frac{k_{i+\frac{1}{2}}+k_{i-\frac{1}{2}}}{2 h} \\
\left(\varnothing_{i+1 \frac{1}{2}}-3 \phi_{i+\frac{1}{2}}+3 \phi_{i-\frac{1}{2}}-\varnothing_{i-1 \frac{1}{2}}\right)
\end{array}
$$

where

$$
\begin{aligned}
& \frac{c_{i+\frac{1}{2}}+c_{i-\frac{1}{2}}}{2}=c_{i} \\
& \frac{k_{i+\frac{1}{2}}+k_{i-\frac{1}{2}}}{2}=k_{i}
\end{aligned}
$$

$\frac{\mathrm{dM}}{\mathrm{dz}}$ in finite difference form for half increments is:

$$
\frac{d M_{z}}{d z}=\frac{M_{z}+\frac{1}{2}-M_{z}-\frac{1}{2}}{h}
$$

The right side of Eq. (3.30) can be determined from Eq. (3.28).

$$
\begin{aligned}
& M_{z_{i+\frac{1}{2}}} \text { and } M_{z_{i-}} \text { are: } \\
& M_{z_{i+\frac{1}{2}}}=\frac{c_{i+1}+c_{i}}{2 h}\left(\phi_{i+1}-\phi_{i}\right)-\frac{k_{i+1}+k_{i}}{2 h^{3}}\left(\phi_{i+2}-3 \phi_{i+1}+3 \phi_{i}-\phi_{i-1}\right) \\
& M_{z_{i-\frac{1}{2}}}=\frac{c_{i}+c_{i-1}}{2 h}\left(\phi_{i}-\phi_{i-1}\right)-\frac{k_{i}+k_{i-1}}{2 h^{3}}\left(\phi_{i+1}-3 \phi_{i}+3 \phi_{i-1}-\phi_{i-2}\right)
\end{aligned}
$$


substituting $M_{z_{i+\frac{1}{2}}}$ and $M_{z_{i-} \frac{1}{2}}$ from Eq. (3.31) into Eq. (3.30) yields: $\frac{d M_{z}}{d z}=\left[-\left(\frac{1}{2} \frac{K_{i-1}}{h^{4}}+\frac{1}{2} \frac{K_{i}}{h^{4}}\right) \varnothing_{i-2}+\left(\frac{3}{2} \frac{K_{i-1}}{h^{4}}+2 \frac{k_{i}}{h^{4}}+\frac{1}{2} \frac{K_{i+1}}{h^{4}}+\frac{1}{2} \frac{C_{i-1}}{h^{2}}+\frac{1}{2} \frac{C_{i}}{h^{2}}\right) \varnothing_{i-1}\right.$

$$
\begin{aligned}
& -\left(\frac{3}{2} \frac{k_{i-1}}{h^{4}}+3 \frac{k_{i}}{h^{4}}+\frac{3}{2} \frac{k_{i+1}}{h^{4}}+\frac{1}{2} \frac{C_{i-1}}{h^{2}}+\frac{C_{i}}{h^{2}}+\frac{1}{2} \frac{C_{i+1}}{h^{2}}\right) \varnothing_{i}+ \\
& +\left(\frac{1}{2} \frac{k_{i-1}}{h^{4}}+2 \frac{k_{i}}{h^{4}}+\frac{3}{2} \frac{k_{i+1}}{h^{4}}+\frac{1}{2} \frac{C_{i}}{h^{2}}+\frac{C_{i+1}}{h^{2}}\right) \varnothing_{i+1} \\
& \left.-\left(\frac{1}{2} \frac{k_{i}}{h^{4}}+\frac{1}{2} \frac{k_{i+1}}{h^{4}}\right) \varnothing_{i+2}\right)
\end{aligned}
$$

$m_{z}$ in finite difference form is:

$$
\begin{aligned}
m_{z_{i}}= & \left(\frac{I_{0}}{A}\right)_{i} P_{i}\left(\frac{\phi_{i+1}-2 \not \phi_{i}+\varnothing_{i-1}}{h^{2}}\right)-P_{i} x_{o_{i}}\left(\frac{v_{i+1}-2 v_{i}+v_{i-1}}{h^{2}}\right) \\
& +P_{i} y_{o_{i}}\left(\frac{u_{i+1}-2 u_{i}+u_{i-1}}{h^{2}}\right)
\end{aligned}
$$

Multipling both sides of Eq. (3.25B) by $h^{4}$ and replacing $\frac{d{ }^{2}}{d z}$ and $m_{z}$ as defined in Eq. (3.32) and (3.33), gives the following finite difference form :

$$
\begin{aligned}
& -P Y_{i} u_{i-1}+2 P Y_{i} u_{i}-P Y_{i} u_{i+1}+P X_{i} v_{i-1}-2 P X_{i} v_{i}+P X_{i} v_{i+1}+ \\
& \left(K A_{i-1}+K A_{i}\right) \varnothing_{i-2}-\left(3 K A_{i-1}+4 K A_{i}+K A_{i+1}+C A_{i-1}+C A_{i}+P R_{i}\right) \varnothing_{i-1} \\
& +\left(3 \mathrm{KA}_{\mathrm{i}-1}+6 \mathrm{KA}_{\mathrm{i}}+3 \mathrm{KA}_{\mathrm{i}+1}+\mathrm{CA}_{\mathrm{i}-1}+2 \mathrm{CA}_{\mathrm{i}}+\mathrm{CA}_{\mathrm{i}+1}+2 \mathrm{PR}_{\mathrm{i}}\right) \emptyset_{\mathrm{i}}-
\end{aligned}
$$




$$
\begin{aligned}
& \left(\mathrm{KA}_{i-1}+4 \mathrm{KA}_{i}+3 \mathrm{KA}_{i+1}+\mathrm{CA}_{i}+\mathrm{CA}_{i+1}+\mathrm{PR}_{i}\right) \varnothing_{i+1} \\
& +\left(\mathrm{KA}_{i}+\mathrm{KA}_{i+1}\right) \varnothing_{i+2}=Q_{y i}-Q_{x i}
\end{aligned}
$$

where

$$
\begin{aligned}
& \mathrm{PX}_{i}=h^{2} \mathrm{P}_{i} \mathrm{x}_{\mathrm{oi}} \\
& \mathrm{PY}_{i}=h^{2} \mathrm{P}_{i} \mathrm{y}_{\mathrm{o} i} \\
& \mathrm{PR}_{i}=h^{2}\left(\frac{\mathrm{I}}{\mathrm{A}}\right)_{i} \mathrm{P}_{i} \\
& \mathrm{CA}_{i}=\frac{h^{2}}{2} \mathrm{C}_{i} \\
& \mathrm{KA}_{i}=\frac{\mathrm{K}_{i}}{2} \\
& \mathrm{Q}_{\mathrm{x}_{i}}=h^{4} \mathrm{q}_{\mathrm{x}_{i}} \mathrm{y}_{\mathrm{o}} \\
& \mathrm{Q}_{\mathrm{y}_{i}}=h^{4} \mathrm{q}_{\mathrm{y}_{i}} \mathrm{x}_{\mathrm{o}_{i}}
\end{aligned}
$$

Equation ( 3.34$)$ is the third equilibrium equation for the elastic beam column of Figure 1. This represents the rotation of the member about the $z$ axis.

The three equilibrium equations (3.15), (3.21) and (3.34) can be written in a matrix form as follows:

$$
A A_{i} w_{i-2}+B B_{i} w_{i-1}+C C_{i} w_{i}+D D_{i} w_{i+1}+E E_{i} w_{i+2}=G G_{i}
$$


where

$$
\mathrm{AA}_{i}=\left[\begin{array}{cccc}
{ }^{\left(\mathrm{F}_{\mathrm{y}-1}-\mathrm{PH}_{\mathrm{i}-1}\right)} & 0 & -\left(\mathrm{PH}_{\mathrm{i}-1} \mathrm{y}_{\mathrm{O}-1}\right) \\
0 & \left(\mathrm{~F}_{\mathrm{x}_{\mathrm{i}-1}}-\mathrm{PH}_{\mathrm{i}-1}\right) & \left(\mathrm{PH}_{\mathrm{i}-1} \mathrm{x}_{\mathrm{o}-1}\right) \\
0 & 0 & \left(\mathrm{KA}_{\mathrm{i}-1}+\mathrm{KA}_{\mathrm{i}}\right)
\end{array}\right]
$$

$B B_{i}=\left[\begin{array}{ccc}-2\left(F_{y_{i-1}}+F_{y_{i}}\right) & 0 & 0 \\ 0 & -2\left(F_{x_{i-1}}+F_{x_{i}}\right) & 0 \\ -P_{y_{i}} & P_{x_{i}} & -\left(3 K_{i-1}+4 K A_{i}+K A_{i+1}+\right. \\ & & \left.C A_{i-1}+C A_{i}+P R_{i}\right)\end{array}\right]$

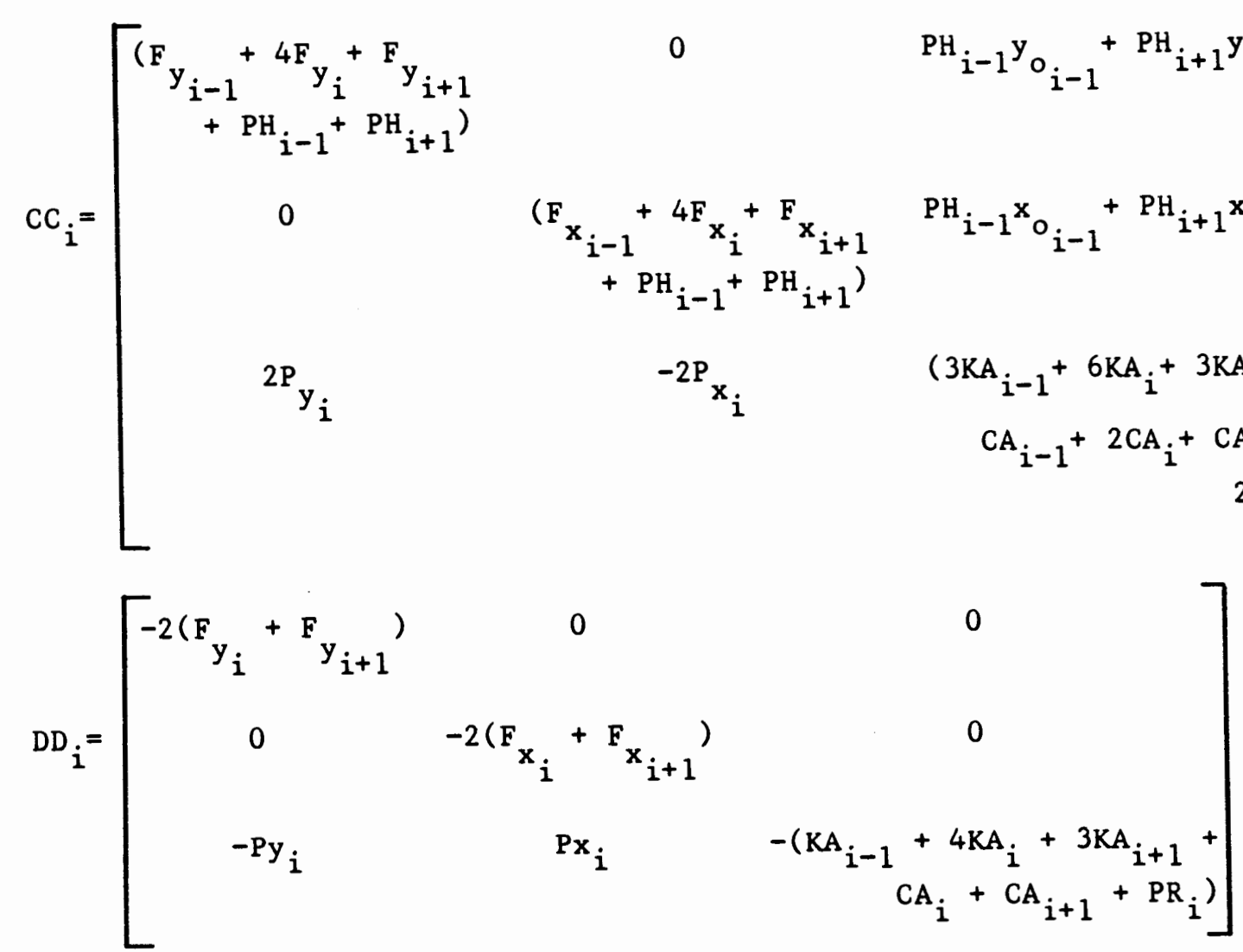


$E E_{i}=\left[\begin{array}{ccc}\left(F_{y_{i+1}}-\mathrm{PH}_{i+1}\right) & 0 & -\left(\mathrm{PH}_{i+1} \mathrm{y}_{\mathrm{o}_{i+1}}\right) \\ 0 & \left(\mathrm{~F}_{\mathrm{x}_{i+1}}-\mathrm{PH}_{i+1}\right) & \left(\mathrm{PH} \mathrm{H}_{i+1} \mathrm{x}_{\left.\mathrm{o}_{i+1}\right)}\right) \\ 0 & 0 & \left(\mathrm{KA}_{i}+\mathrm{KA}_{i+1}\right)\end{array}\right]$

$G G_{i}=\left\{\begin{array}{l}Q_{x x_{i}}+T_{y_{i-1}}-T_{y_{i+1}} \\ Q_{y y_{i}}-T_{x_{i-1}}+T_{x_{i+1}} \\ Q_{y_{i}}-Q_{x_{i}}\end{array}\right\}$

$w_{i}=\left\{\begin{array}{l}u_{i} \\ v_{i} \\ \phi_{i}\end{array}\right\}$

Equations $(3.16),(3.22)$ and (3.35) define the terms of the above matrices. Coefficients $A A, B B, C C, D D$ and $E E$ in Eq. (3.37) are $3 \times 3$ matrices and they are functions of the sectional properties of the beam column and the applied axial loads. Coefficient GG is a $3 \times 1$ matrix and it is a function of the applied loads. W is also a $3 \times 1$ matrix and it represents the deflection of the beam column, two translations $u$ and $v$, and one rotation $\varnothing$, at a particular station $i$.

In matrix structural analysis, the coefficients $A A, B B, C C, D D$ and EE make up the stiffness matrix for the structure with a band width of five and the coefficients GG make up the load matrix. 
2. SOLUTION OF THE BEAM COLUMN EQUATIONS

Assume the beam column is divided into $m$ increments of length $h$ and designate the increment points as stations. Let the left end of the beam column be station zero and the right end be station m. At each station $i$, the general beam column equation (3.36) can be applied (the cross sectional properties at each station is taken as the average of the distribution which exists on the beam column). Therefore there is a system of simultaneous equations whose solution gives the deflected shape of the beam column.

In order to solve these equations, Matlock (10) suggests a back and forth recursive process which is presented here. This technique was conceived by Tucher* who felt that by using "partitioned" matrices, a matrix of five diagonal sub-matrices could be solved in a recursive technique analogous to Matlock's method of solving beams and columns. A similar technique has been used by Hudson and Stelzer ( 7 ) for slabs on foundation.

Assume that the deflection of the beam column at a given station can be expressed as a linear function of the deflection at the two following stations, i.e.,

$$
w_{i}=A_{i}+B_{i} W_{i+1}+C_{i} W_{i+2}
$$

where $A, B$, and $C$ are constants to be determined. Coefficients $B$ and $C$ are $3 \times 3$ matrices and coefficient $A$ is $3 \times 1$ matrix. Applying Equation (3.38) to stations $i-1$ and $i-2$ results in:

*Tucher, Richard L., personal communication to Hudson Matlock concerning a technique for solving large, sparsely populated matrices, June $15,1965$. 


$$
\begin{aligned}
& w_{i-1}=A_{i-1}+B_{i-1} W_{i}+C_{i-1} w_{i+1} \\
& w_{i-2}=A_{i-2}+B_{i-2} W_{i-1}+C_{i-2} w_{i}
\end{aligned}
$$

substituting Eq. (3.39) and (3.40) in Eq. (3.38) gives

$$
\mathrm{w}_{i}=\mathrm{A}_{i}+\mathrm{B}_{i} \mathrm{w}_{i+1}+\mathrm{C}_{i} \mathrm{w}_{i+2}
$$

where

$$
\begin{aligned}
& A_{i}=-\frac{1}{D_{i}}\left(E_{i} A_{i-1}+A_{i} A_{i-2}-G_{i}\right) \\
& B_{i}=-\frac{1}{D_{i}}\left(E_{i} C_{i-1}+D D_{i}\right) \\
& C_{i}=-\frac{1}{D_{i}}\left(E E_{i}\right)
\end{aligned}
$$

in which

$$
\begin{aligned}
& D_{i}=C_{i}+E_{i} B_{i-1}+A_{i} C_{i-2} \\
& E_{i}=A_{i} B_{i-2}+B_{i}
\end{aligned}
$$

Therefore, it is seen that the assumptions of Eq. (3.38) and (3.39) are correct. It should be noted that $B_{i}, C_{i}, D_{i}$ and $E_{i}$ are all $3 \times 3$ matrices and $A_{i}$ is $3 \times 1$ matrix.

According to Eq. (3.42A) and (3.42B), constants $A_{i}, B_{i}$ and $C_{i}$, the continuity coefficients, are functions of these same three constants at two previous stations $i-2$ and $i-1$ and the known coefficients $A A-G G$ at station $i$. The recursive technique is performed in two passes. This is done by moving along the member from the left end and calculating $A_{i}, B_{i}$ and $C_{i}$ at each station on the first pass. Then deflection $w_{i}$ is calculated by substituting $w_{i+1}$ and $w_{i+2}$ 
into Eq. (3.41) on the return pass (Fig. 1).

Haliburton (6) considers this as a special form of the Gaussian elimination in which on the first pass, for all stations $i$, deflections $W_{i-2}$ and $W_{i-1}$, to the left of the main diagonal, are eliminated. This is called triangularizing the matrix. Therefore, the band width of five becomes three. On the return pass the deflections are calculated by back substitution. The resulting W's are the deflection of the member in $x$ and $y$ and the rotation $\phi$ about the $z$ axis.

\section{STARTING AND REVERSING THE RECURSIVE PROCESS}

In order to start the recursive process at station zero, the values of $A, B$ and $C$ at two previous stations are required. It is assumed that there are three immaginary stations preceeding station zero and three imaginary stations beyond station $m$. The imaginary stations have no stiffness and no load or restraints (Figure 1).

Assume the beam column is free to warp $\left(\mathrm{KA}_{i}=0\right)$. Therefore, according to Eq. (3.37), at station $-1, \mathrm{AA}_{-1}=0$ and $\mathrm{BB}_{-1}=0$. Values $A_{-1}, B_{-1}$ and $C_{-1}$ can be calculated by Eq. (3.42A) and (3.42B) at imaginary station -1 , i.e.,

$$
\begin{aligned}
& \mathrm{E}_{-1}=(0) \mathrm{B}_{-3}+0=0 \\
& \mathrm{D}_{-1}=\left[\mathrm{CC} \mathrm{C}_{-1}+(0) \mathrm{B}_{-2}+(0) \mathrm{C}_{-3}\right]=\mathrm{CC}_{-1} \\
& \mathrm{C}_{-1}=-[\mathrm{CC}]_{-1}^{-1}\left[\mathrm{EE}_{-1}\right] \\
& \mathrm{B}_{-1}=\left[-\mathrm{CC}_{-1}\right]^{-1}\left[(0) \mathrm{C}_{-2}+\mathrm{DD}_{-1}\right]=-[\mathrm{CC}]_{-1}^{-1}\left[\mathrm{DD}_{-1}\right] \\
& \mathrm{A}_{-1}=\left[-\mathrm{CC}_{-1}\right]^{-1}\left[(0) \mathrm{A}_{-2}+(0) \mathrm{A}_{-3}-\mathrm{GG}_{-1}\right]=-[\mathrm{CC}]_{-1}^{-1}[\mathrm{GG}]
\end{aligned}
$$


The values of $A_{0}, B_{0}$ and $C_{0}$ at station zero can be computed without any knowledge of $\mathrm{A}_{-2}, \mathrm{~B}_{-2}$ and $\mathrm{C}_{-2}$. Looking at Eq. (3.42A) and Eq. (3.42B) reveals that $\mathrm{A}_{-2}, \mathrm{~B}_{-2}$ and $\mathrm{C}_{-2}$ are multiplied by $\mathrm{AA}_{0}$ which is zero at station zero according to Eq. (3.37). Values $A_{i}, B_{i}$ and $C_{i}$ can be determined by starting at station zero and proceeding down the beam column to station $\mathrm{m}+1$. Station -1 was choosen as a starting point because nothing before it affects the beam as discussed above. Likewise, nothing beyond station $\mathrm{m}+1$ affects the beam column. This becomes evident in the following explanation.

On the return pass, the deflection at station $\mathrm{m}^{+1}$ is computed first without any knowledge about the deflections at stations $m+2$ and $\mathrm{m}+3$, i.e.,

$$
W_{m+1}=A_{m+1}+B_{m+1} W_{m+2}+C_{m+1} W_{m+3}
$$

Coefficient $E E_{m}$ is equal to zero at station $m$. Therefore, value $c_{m}$ which is equal to $-E E_{m} / D_{m}$ becomes zero. Since at station $m, C_{m}=0$ and at station $m^{+1}, D D_{m+1}$ and $E_{m+1}$ are equal to zero, the values $\mathrm{C}_{\mathrm{m}+1}$ and $\mathrm{B}_{\mathrm{m}+1}$ also become zero, i.e.,

$$
\begin{aligned}
& C_{m+1}=-\frac{1}{D_{m+1}}(0)=0 \\
& B_{m+1}=-\frac{1}{D_{m+1}}\left[E_{m+1}(0)+(0)\right]=0
\end{aligned}
$$

Therefore, Eq. (3.44) becomes:

$$
w_{m+1}=A_{m+1}+(0) W_{m+2}+(0) w_{m+3}=A_{m+1}
$$


Since $C_{m}$ is zero, the deflection at station $m$ can also be calculated without $\mathrm{w}_{\mathrm{m}+2}$, i.e.,

$$
\mathrm{W}_{\mathrm{m}}=\mathrm{A}_{\mathrm{m}}+\mathrm{B}_{\mathrm{m}} \mathrm{W}_{\mathrm{m}+1}+(0) \mathrm{W}_{\mathrm{m}+2}
$$

Therefore, deflections can be computed on the return pass by Eq. (3.41) starting at station $\mathrm{m}+1$.

The primary purpose of this investigation was its application to angle section in which the resistance to warping is very close to zero. However, in order to be able to start the recursive process and to reverse it for a section in which warping constant is specified, the following changes in Eq. (3.37) are suggested:

$$
\begin{aligned}
& \mathrm{AA}_{\mathrm{i}}(3,3)=2 \mathrm{KA}_{\mathrm{i}-1} \\
& \mathrm{BB}_{\mathrm{i}}(3,3)=-\left(3 \mathrm{KA}_{\mathrm{i}-1}+5 \mathrm{KA}_{\mathrm{i}}+\mathrm{CA}_{\mathrm{i}-1}+\mathrm{CA}_{\mathrm{i}}+\mathrm{PR}_{\mathrm{i}}\right) \\
& \mathrm{DD}_{\mathrm{i}}(3,3)=-\left(5 \mathrm{KA}_{i}+3 \mathrm{KA}_{\mathrm{i}+1}+\mathrm{CA}_{\mathrm{i}}+\mathrm{CA}_{\mathrm{i}+1}+\mathrm{PR}_{\mathrm{i}}\right) \\
& \mathrm{EE}_{\mathrm{i}}(3,3)=2 \mathrm{KA}_{\mathrm{i}+1}
\end{aligned}
$$

\section{SPECIFYING DESIRED DEFLECTIONS}

The deflection of a beam column is usually known at one or more points along the member. For example, the deflection at each end of a simple beam is zero or perhaps the settlement of one or more supports of a continuous beam is known. These conditions need to be introduced into the recursive solution.

Eq. (3.41) is repeated here for convenience.

$$
W_{i}=A^{\prime}{ }_{i}+B^{\prime}{ }_{i} w_{i+1}+C^{\prime}{ }_{i} w_{i+2} \text { * }
$$

*Primes are used to designate specially determined coefficients. 
In order to specify the deflection at some point on the beam column, say at station $i, A_{i}^{\prime}$ should be set equal to desired deflection and $B^{\prime}{ }_{i}$ and $C^{\prime}{ }_{i}$ equal to zero, i.e.:

$$
W_{i}=A_{i}^{\prime}+(0) W_{i+1}+(0) W_{i+2}
$$

The coefficients must be set at the special value before one proceeds to calculate the coefficients for the following stations. This is necessary because the coefficients at the following stations are functions of preceding ones.

There are three types of deflection at a station that may be specified. Each should be treated separately. For example, assume the deflection at station $i$ is specified in the $x$ direction only. In this case $A^{\prime}{ }_{i}(1,1)$ which pertains to the $x$ direction is set equal to the specified deflection and the respective rows of $B^{\prime}{ }_{i}$ and $C^{\prime}{ }_{i}$ matrices are set equal to zero, i.e.,

$$
\begin{aligned}
& B^{\prime}{ }_{i}(1,1)=B^{\prime}{ }_{i}(1,2)=B^{\prime}{ }_{i}(1,3)=0 \\
& C^{\prime}{ }_{i}(1,1)=C^{\prime}{ }_{i}(1,2)=C^{\prime}{ }_{i}(1,3)=0
\end{aligned}
$$

The same is true for the specified $y$ and 0 deflections. For example, for specified $y$ deflection the second rows of $B^{\prime}{ }_{i}$ and $C^{\prime}{ }_{i}$ are set equal to zero and $A^{\prime}{ }_{i}(2,1)$ is set equal to desired y deflection. Now, if all three deflections at station $i$ are specified, all terms of $B$ and $C$ matrices become zero. 
5. BUCKLING AND INSTABILITY OF THE BEAM COLUMNS.

A major concern of this study was the determination of the elastic buckling of a beam column. The analysis of a beam column, using the recursive technique, for load values up to and beyond the buckling load indicates a point of discontinuity at the buckling load value. If a load-deflection curve is plotted based on calculated values, using the derived recursive solution, one obtains a curve similar to Figure 6. At instability a sudden change in the sign of the deflection occurs. This is one possible indication of the buckling. However, it is necessary to have a more fundamental definition. To achieve this, the equations used in the beam column analysis are repeated and examined.

The two basic recursive equations are:

$$
\mathrm{AA}_{i} \mathrm{~W}_{\mathrm{i}-2}+\mathrm{BB}_{\mathrm{i}} \mathrm{W}_{\mathrm{i}-1}+\mathrm{CC}_{\mathrm{i}} \mathrm{W}_{\mathrm{i}}+\mathrm{DD}_{\mathrm{i}} \mathrm{W}_{\mathrm{i}+1}+\mathrm{EE}_{\mathrm{i}} \mathrm{W}_{\mathrm{i}+2}=\mathrm{GG}_{\mathrm{i}}
$$

and

$$
w_{i}=A_{i}+B_{i} W_{i+1}+C_{i} w_{i+2}
$$

or

$$
w_{i}-B_{i} w_{i+1}-C_{i} W_{i+2}=A_{i}
$$

where

$$
\begin{aligned}
& A_{i}=-\frac{1}{D_{i}}\left(E_{i} A_{i-1}+A_{i} A_{i-2}-G_{i}\right) \\
& B_{i}=-\frac{1}{D_{i}}\left(E_{i} C_{i-1}+D_{i}\right) \\
& C_{i}=-\frac{1}{D_{i}}\left(E_{i}\right)
\end{aligned}
$$




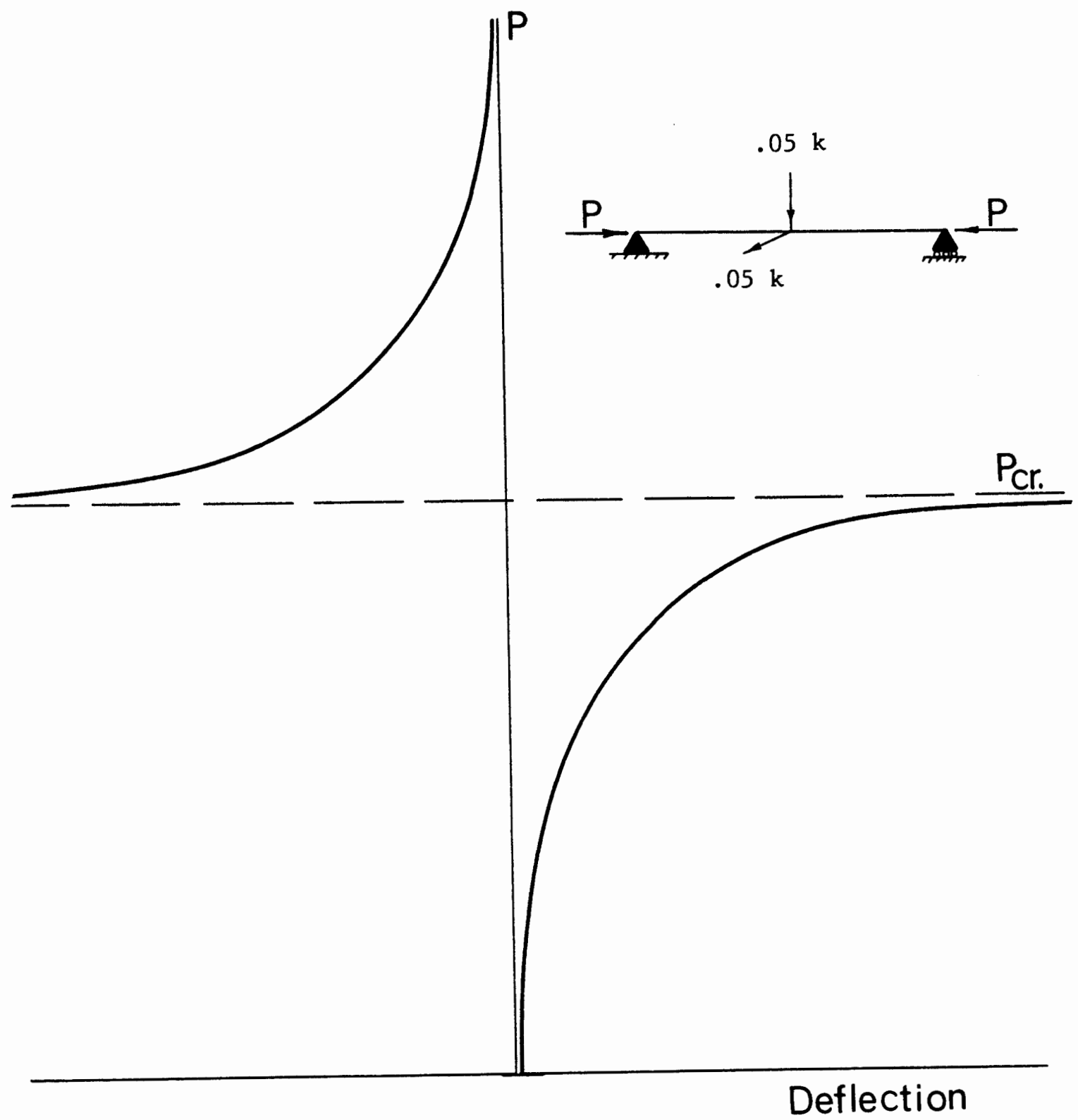

Figure 6 Load vs. lateral deflection 
in which

$$
\begin{aligned}
& D_{i}=C C_{i}+E_{i} B_{i-1}+A A_{i} C_{i-2} \\
& E_{i}=A A_{i} B_{i-2}+B B_{i}
\end{aligned}
$$

If equation ( 3.51$)$ is repeated for each station $i$ along the beam column and written in matrix form, the coefficients $A A, B B, C C$, DD and EE will make up a stiffness matrix with a band width of five.

In the preceding sections, it was demonstrated that the recursive method is a special case of the Guassian elimination method. Therefore, the check for stability used in classical matrix method may be applied.

In classical matrix analysis, it is required that the stiffness matrix be positive definite in order to have stability (9). Mathematically, this condition exists if all terms on the diagonal of the stiffness matrix are positive after elimination (9). Therefore, if a zero or negative term appears as a diagonal element of the stiffness matrix after the elimination process, the structural system is unstable or buckling has occured. It should be noted that $-1 / D_{i}$ is the negative reciprocal of the diagonal element for each row of the stiffness matrix after elimination. Therefore, as a diagonal term approaches zero, $-1 / D_{i}$ goes to infinity and if a diagonal term is negative the corresponding $-1 / D_{i}$ is positive.

$-1 / D_{i}$ is a $3 \times 3$ matrix in Eq. (3.54A) and it is the negative reciprocal of an algebraic expression, i.e.,

$$
D_{i}=C_{i}+\left(A_{i} B_{i-2}+B B_{i}\right) B_{i-1}+A_{i} C_{i-2}
$$

in which $E_{i}$ is replaced by its equivalent as in Eq. (3.54B) 
The problem of instability in this case can be investigated by examining the diagonal of the $D_{i}$ matrix (a $3 \times 3$ matrix). If zero or a negative number appears on the diagonal of $D_{i}$, it shows that the beam column has become unstable. Depending on where the zero or negative term appears, one can determine the direction of instability. For example, if $D_{i}(1,1)$ is zero or negative, it means that the beam column buckles in the $x$ direction (or about the $y$ axis), either in pure flexural buckling or in flexural torsional buckling. If $y_{0}$ is equal to zero, there is no coupling effect between torsional buckling and flexural buckling about the $y$ axis, therefore the buckling is pure flexural. However, if $x_{0}$ is equal to zero and $y_{0}$ is not equal to zero, there is a coupling effect between torsional buckling and flexural buckling about the $y$ axis which causes flexural torsional buckling. $D_{i}(1,1)$ being zero or negative in this case, indicates that the beam column is weaker about the $y$ axis than in torsion. Similar discussions are valid for $D_{i}(2,2)$, and $D_{i}(3,3)$. Now, if $x_{0}$ and $y_{0}$ are both non-zero, the beam column will buckle in flexural torsional buckling and this buckling is a combination of all three modes of buckling, $x, y$ and 0 . Depending on which one of the diagonal terms of $D_{i}$ appears zero or negative term, the beam column is the weakest about that axis. For example, $D_{i}(2,2)$ pertains to bending about the $x$ axis.

It needs to be emphasized that axial load is the only applied load that appears on the stiffness matrix and can cause elastic instability in an otherwise stable structure. 
CONCLUSION

This method can treat any beam column with general load and support configuration. It can calculate the deflections in the $x$ and $y$ direction and rotation about the $z$ axis. It can also predict the elastic buckling load.

The advantage of this technique is that it is self starting and the boundary conditions of the differential equations are automatically input into the solution through the description of the beam column. The computation of the constants starts from the left end and proceed to the right and then deflections are calculated at the right end and moving to the left end. Figure 7 summarizes this solution technique. 

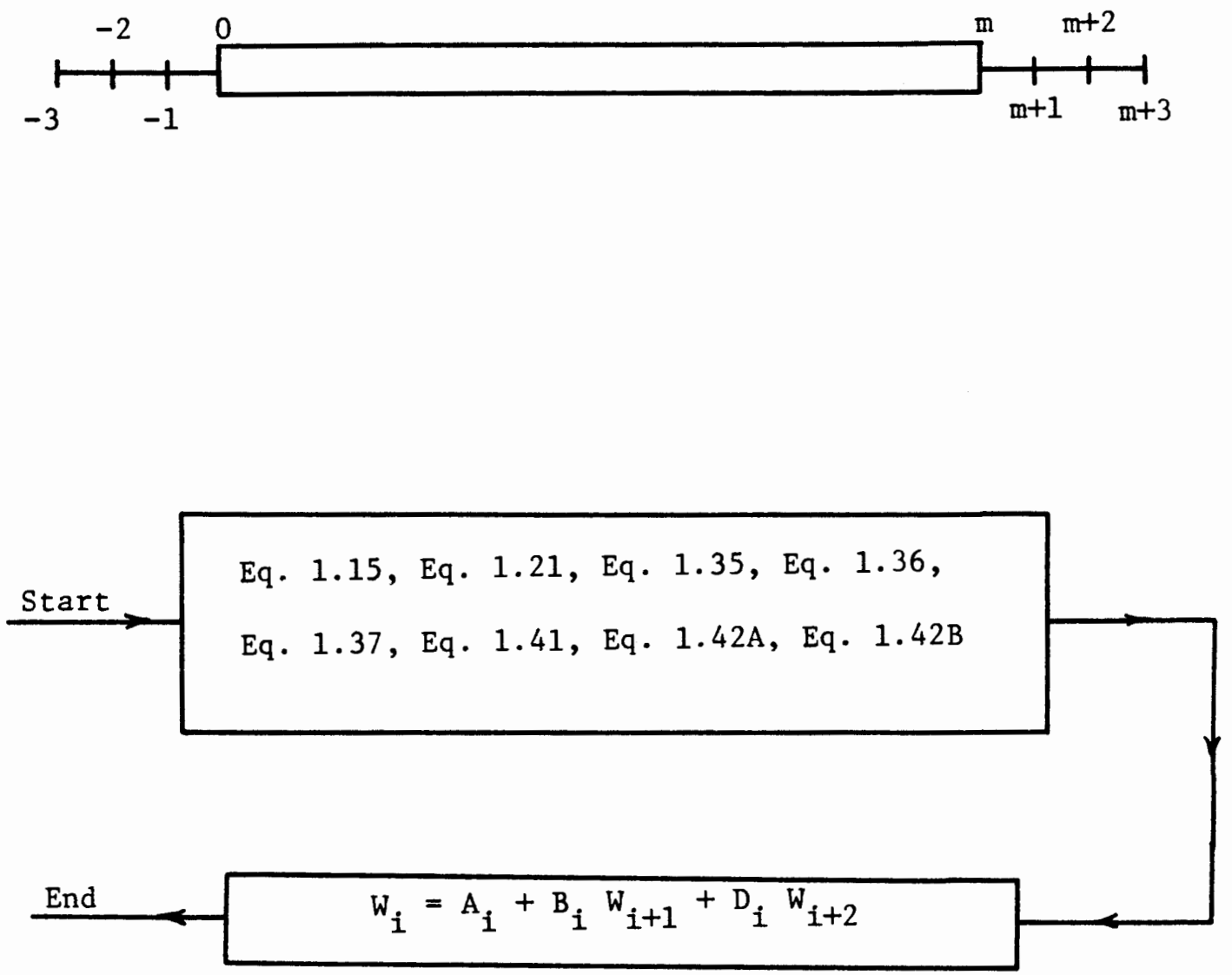

Figure 7 Two pass recursive method in three dimensional beam column 
CHAPTER IV

COMPARING WITH OTHER ANALYTICAL TECHNIQUES

The computer model is checked by comparing the results obtained from the program with data obtained by other investigators and classical analytical techniques.

Basic examples which demonstrate various components of the program's capability are presented below. The detailed output for the examples are in Appendix (C). It should be noted that increased accuracy results from using a higher number of stations.

\section{CONCENTRATED MOMENTS}

Figure 8 shows a beam in which two moments are applied at the left end of the beam about the $x$ and $y$ axes. The moments of intertia are constant throughout the beam about both axes and the beam is divided into eight increments.

Deflections at station 2 and 4 are computed by the Conjugate Beam Method and compared with the ones obtained from the computer program, i.e.,

Computer Program

$$
x_{2}=.0140 \text { in. }
$$$$
\mathrm{Y}_{4}=.0160 \mathrm{in} \text {. }
$$

Conjugate Method

$x_{2}=.0140$ in.

$\mathrm{Y}_{4}=.0160 \mathrm{in}$.

The results are exactly the same in this example. 
2. THREE CONCENTRATED LOADS

A beam, 160 inches long, is loaded with three concentrated loads in the $y$ direction as in Figure 9. The moment of inertia about the $x$ axis is constant throughout the member and $E I_{x}$ is equal to $.3 \times 10^{8}$ in. ${ }^{2} k$. Deflections obtained from the computer program for station 2 and 4 are compared with the ones obtained from Conjugate Beam Method, i.e.,

Computer Program

$\mathrm{Y}_{2}=.098667 \mathrm{in}$.

$\mathrm{Y}_{4}=.138667 \mathrm{in}$.
Conjugate Method

$\mathrm{Y}_{2}=.096000 \mathrm{in}$.

$Y_{4}=.135111 \mathrm{in}$.

The computer results are approximately $2.7 \%$ higher than the exact values. By increasing the number of stations the computer results become closer to the exact values.

\section{APPLIED TORQUES}

Two torques, $20 \mathrm{ft.k}$ and $5 \mathrm{ft.k}$, are applied to a member $14 \mathrm{ft}$. long with circular cross sections (Figure 10). The rotations obtained from the program are compared with the ones determined by torsion equation $(\varnothing=(\mathrm{TL}) /(\mathrm{GJ}))$. The results are identical.

The computer program does not have the option to input the external torques about the $z$ axis directly. Therefore, two new statements are added to the subroutine MAIN1 in the computer program to account for the two external torques. Coefficients GG at station 9 and 14 need to be redefined. It should be emphasized that the real stations 9 and 14 become computer stations 13 and 18 . The two terms GG $(3,13)$ and GG $(3,18)$ are redefined as follows: 

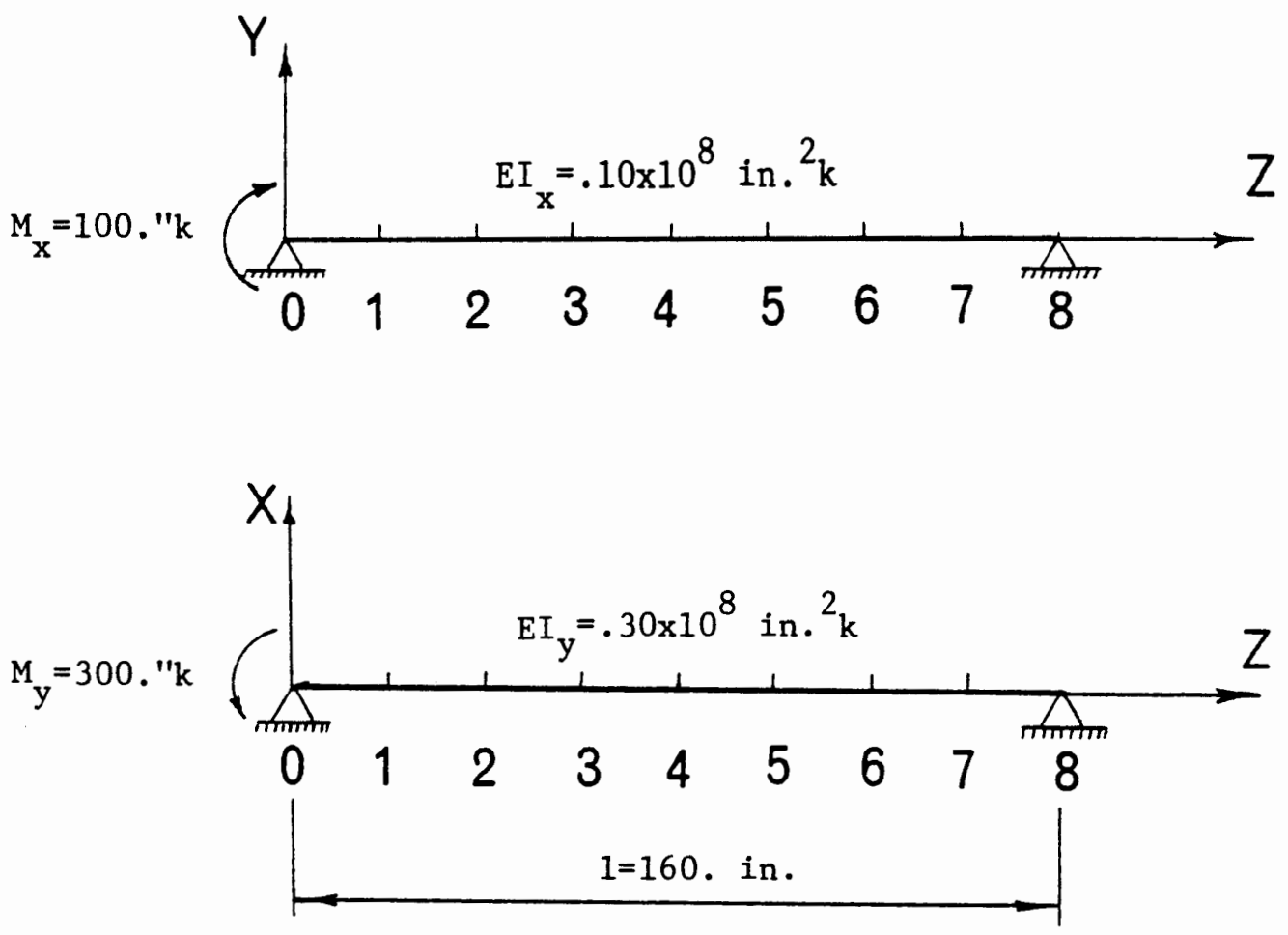

Figure 8 Simple beam with concentrated moments

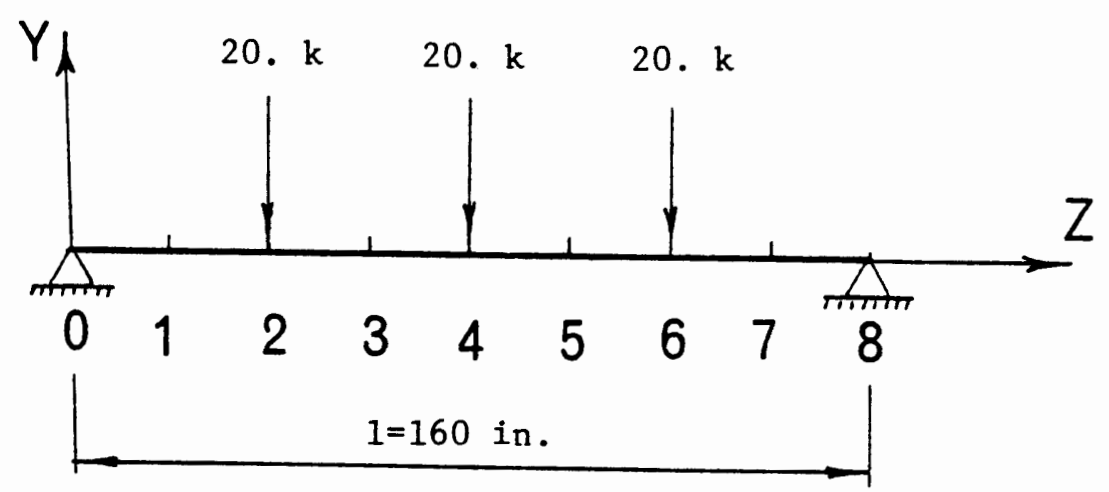

Figure 9 Simple beam with three point loads 


$$
\begin{aligned}
& \text { GG }(3,13)=G G(3,13)+h^{3} T_{z} \\
& G G(3,13)=G G(3,13)+(12 \text {. in. })^{3} \cdot(20 . \times 12 \text {. in.k }) \\
& \text { GG }(3,13)=G G(3,13)+414,720 \text {. in. }{ }^{4} k
\end{aligned}
$$

and

$$
\begin{aligned}
& \text { GG }(3,18)=G G(3,18)+h^{3} T_{z} \\
& \text { GG }(3,18)=G G(3,18)+(12 \cdot \text { in })^{3} \cdot(-5 \cdot \times 12 \text {. in.k }) \\
& \text { GG }(3,18)=G G(3,18)-103,680 . \text { in. }^{4} k
\end{aligned}
$$

See appendix C for the proper location of GG $(3,13)$ and $G G(3,18)$ in subroutine MAIN1.

Rotations about the $z$ axis obtained from the computer program and torsion equations for station 9 and 14 are:

$$
\begin{aligned}
& \text { Computer Output } \\
& \phi_{9}=0.06437087 \mathrm{Rad} . \quad \phi_{9}=.06437086 \mathrm{Rad} \text {. } \\
& \phi_{14}=0.05245034 \mathrm{Rad} . \quad \phi_{14}=.05245033 \mathrm{Rad} \text {. }
\end{aligned}
$$

The example problems presented below illustrate the technique for finding the flexural, torsional and flexural torsional buckling loads. The critical loads interpreted from the computer outputs are compared with the ones calculated by Euler's equation and equations given by Chajes, Fang and Winter (2).

\section{FLEXURAL BUCKLING ABOUT X AXIS}

A column, 160 inches long, is divided into eighty increments and loaded axially. The buckling load obtained from the program is checked against the one calculated from Euler's equation. 


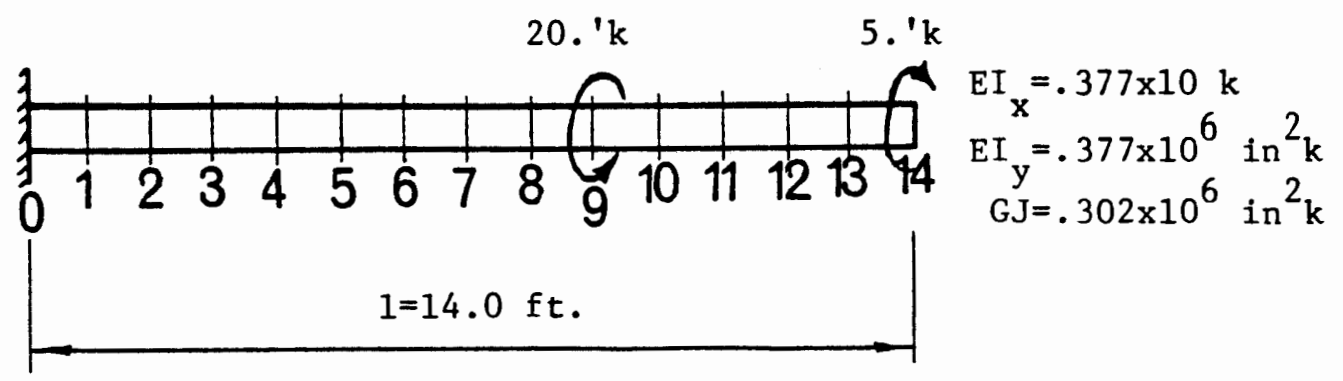

Figure 10 Applied Torques

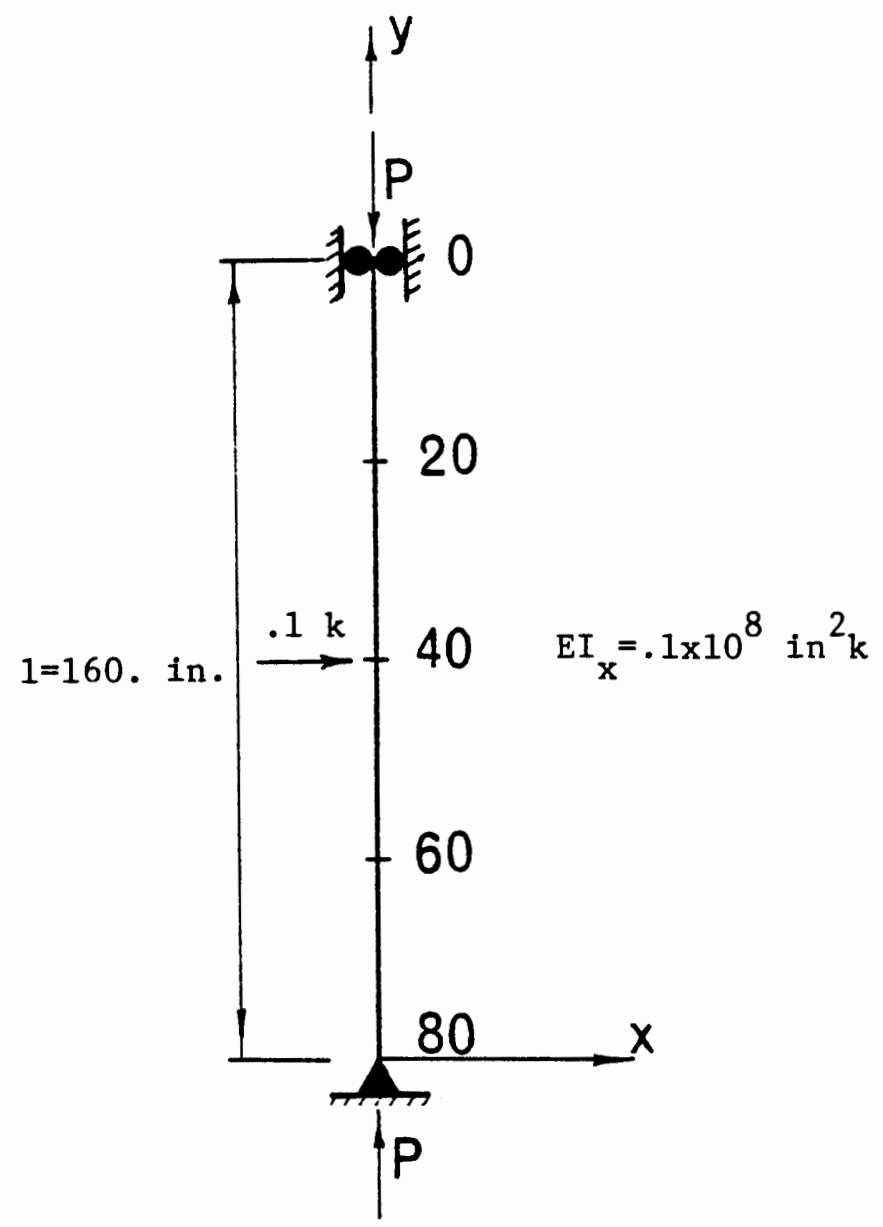

Figure 11 Flexural Buckling about the $\mathrm{x}$ axis 
A small lateral load is applied in the $y$ direction at the midheight of the column, (station 40) as in Figure 11. This load is needed to input into the solution a non-zero $P$. The axial load is increased until the instability is observed in the deflections. The critical load interpreted from the computer runs is 3751.6 kips. The critical load from Euler's equation is:

$$
\begin{aligned}
& P_{x}=\frac{n^{2} E I x}{L^{2}}=\frac{3.14^{2}\left(.1 \times 10^{8}\right) \text { in. }{ }^{2} k}{(160 . \text { in. })^{2}} \\
& P_{x}=3855 . k
\end{aligned}
$$

The computer result is about $97.4 \%$ of Euler's buckling load.

\section{FLEXURAL BUCKLING ABOUT THE Y AXIS}

The member of example 4 is investigated for the critical load about the $y$ axis. A small lateral load is applied in the $y$ direction at the mid height of the column (Figure 12). Axial load is increased until instability is observed.

The critical load interpreted from the computer model is approximately $1126.5 \mathrm{kips}$, and the Euler buckling load is

$$
\begin{aligned}
& P_{y}=\frac{\pi^{2} E I y}{L^{2}}=\frac{3.14^{2}\left(.3 \times 10^{8}\right) \text { in. }{ }^{2} k}{(160 . \text { in. })^{2}} \\
& P_{y}=11566 . k
\end{aligned}
$$

The result from the computer program is approximately $97.4 \%$ of the exact answer. 
6. TORSIONAL BUCKLING

The member of example 4 is tested for torsional buckling (Figure 13). The column is free to warp and the shear center coincides with the center of gravity $\left(x_{0}=0\right.$. and $\left.y_{0}=0.\right)$. The torsional buckling is independent of the flexural buckling because the centroid and the shear center are at the same point.

The column is divided into eight increments and a small torque (.0008 in.k) is applied at station 4 to cause the torsion. Then axial load is increased until the rotational instability is observed.

The following statement is added to the subroutine MAIN1 to account for the applied external torque, i.e.,

$$
\begin{aligned}
& \text { GG }(3,8)=G G(3,8)+h^{3} T_{z} \\
& \text { GG }(3,8)=G G(3,8)+(20 . \text { in. })^{3} \cdot(.0008 \text { in. } k) \\
& \text { GG }(3,8)=G G(3,8)+6.4 \text { in. } 4 k
\end{aligned}
$$

The torsional buckling load obtained from the computer program is $60 . k$ and the one computed from the torsional buckling equation presented by Chajes (1) is:

$$
\begin{aligned}
& P_{\phi}=\frac{1}{r_{0}^{2}}\left(G J+\frac{r^{2} E T}{L^{2}}\right) \\
& r_{0}^{2}=\left(\frac{I_{x}+I_{y}}{A}\right)+x_{0}^{2}+y_{0}^{2} \\
& r_{0}^{2}=\left[\left(\frac{.1 \times 10^{8}+.3 \times 10^{8}}{.3 \times 10^{5}}\right) \cdot \frac{1}{20}\right]=66.67 \mathrm{in} . \\
& P_{\phi}=\frac{.4 \times 10^{4} i n_{0}^{2} k}{66.7 \mathrm{in}^{2}}=60 . k
\end{aligned}
$$




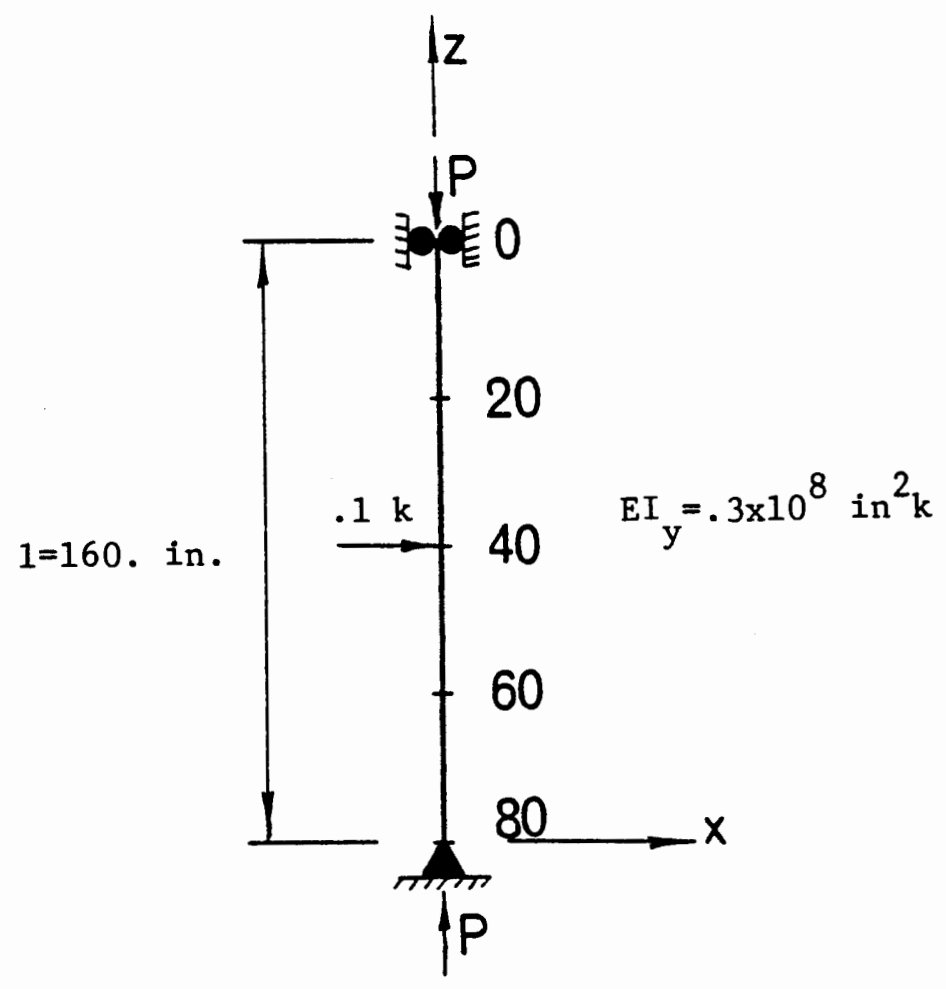

Figure 12 Flexural Buckling about $y$ axis

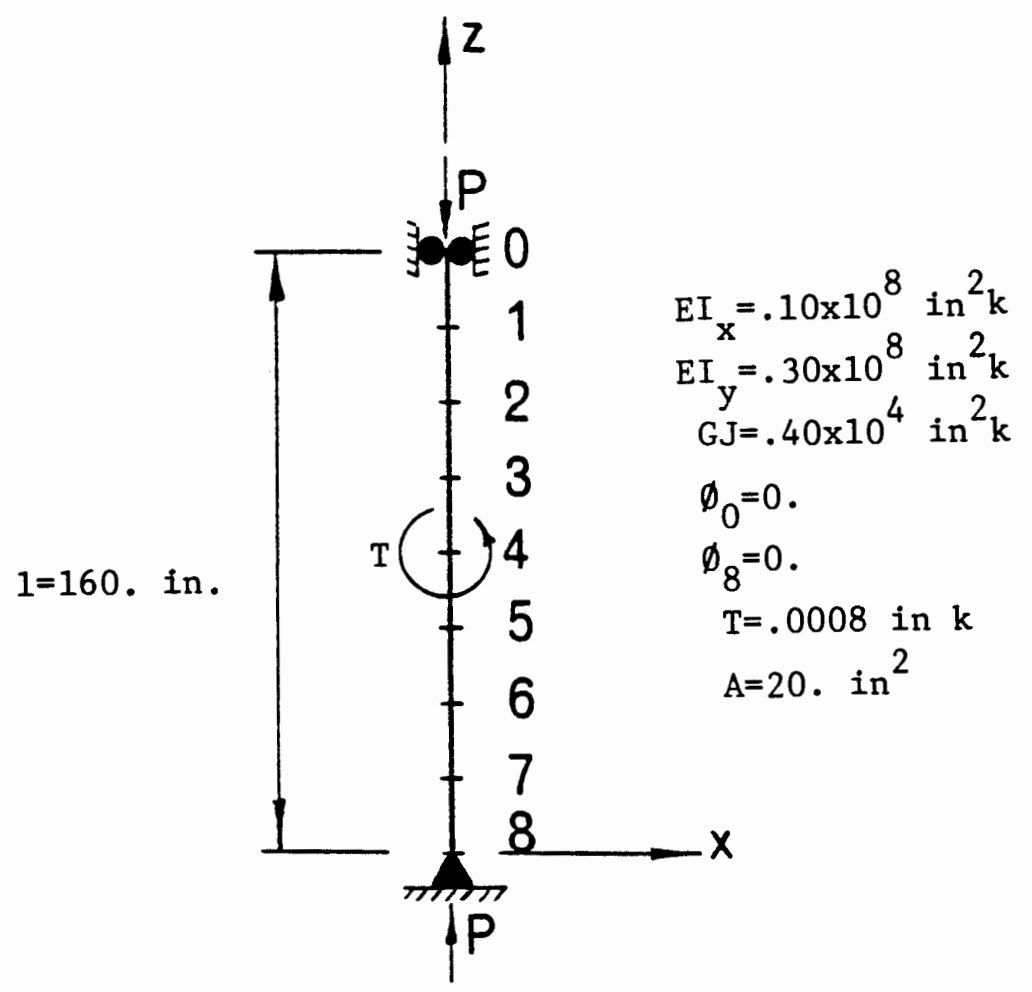

Figure 13 Torsional Buckling about $z$ axis 
The two results from the program and the equation are identical.

\section{FLEXURAL TORSIONAL BUCKLING}

Flexural torsional buckling is illustrated in this example by investigating the buckling load of a 32 inch long, 3" 3 "x1/4" angle. The resistance to warping for the angle sections is practically zero and $y_{0}$, the distance from the shear center to center of gravity in the $y$ direction, is zero for equal leg angles (Figure 14). There are two types of buckling for this member; bending about the $y$ axis (flexural buckling) and a combination of bending about the $x$ axis and torsion about the $z$ axis (flexural torsional buckling).

The member is divided into eight increments and a small disturbing torque $(.0008$ in.k $)$ is applied at station 4 to initiate the flexural torsional buckling. The following statement is added to subroutine MAIN1 for the applied external torque,

$$
\text { GG }(3,8)=\text { GG }(3,8)+6.4 \text { in. }{ }^{4} k
$$

The axial load is increased until the deflections in the $y$ direction and rotations about the $z$ axis change signs. The critical load predicted by the computer program is approximatly $104.1 \mathrm{k}$. This result is compared with the flexural buckling load calculated by the equation presented by Chajes, Fang and Winter (2), i.e.,

$$
P_{c r}=\frac{1}{2 K}\left[\left(P_{\phi}+P_{x}\right)-\sqrt{\left(P_{\phi}+P_{x}\right)^{2}-4 K P_{\phi} P_{x}}\right]
$$

where

$$
P_{\phi}=\frac{G J}{r_{0}^{2}}=\text { Torsional buckling load }
$$



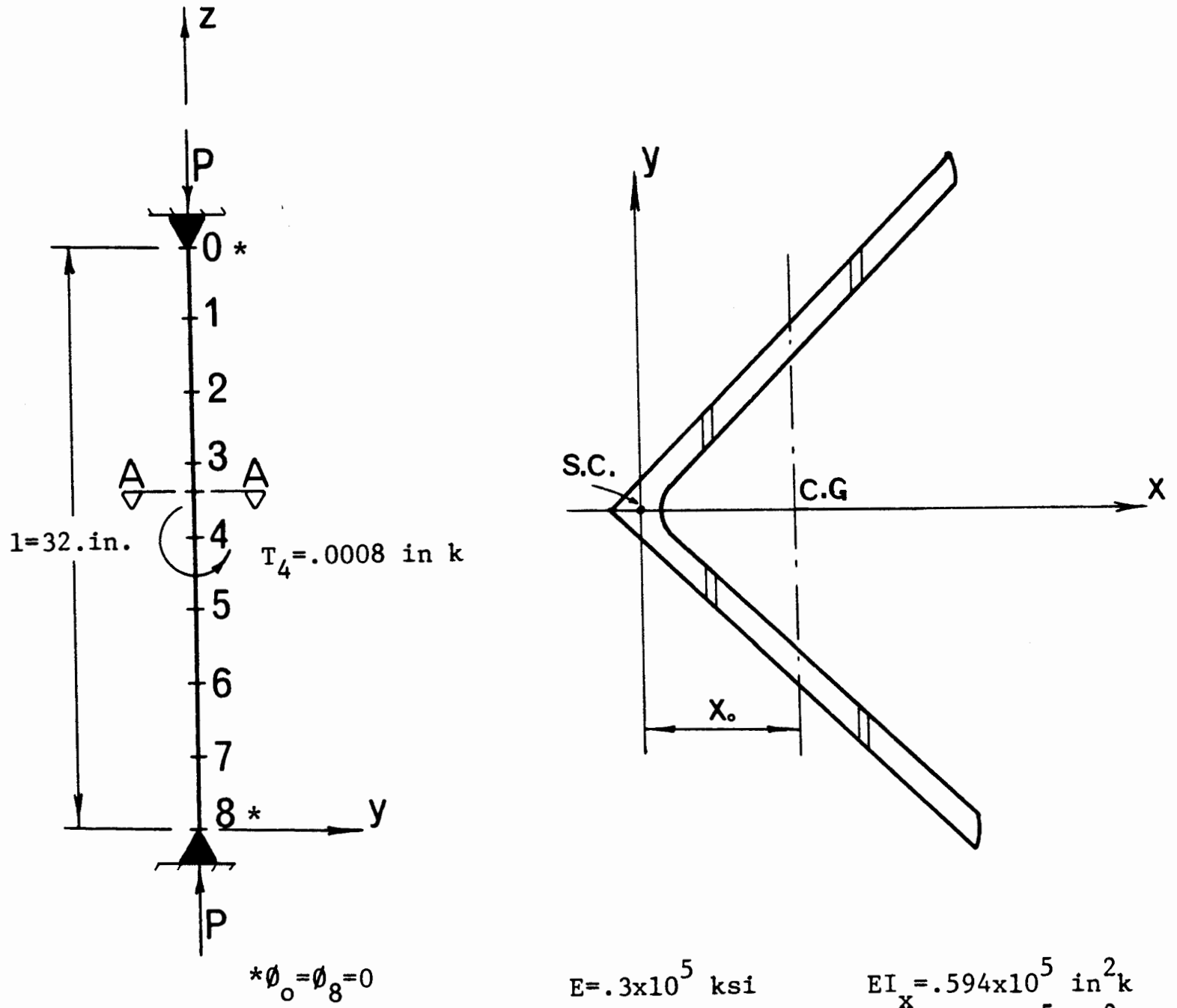

$$
\begin{aligned}
E & =.3 \times 10^{5} \mathrm{ksi} \\
\mathrm{A} & =.144 \mathrm{in} . \\
\mathrm{x}_{0} & =1.19 \mathrm{in} .
\end{aligned}
$$$$
\begin{aligned}
& E I_{x}=.594 \times 10^{5} \text { in }^{2} k \\
& E I_{y}=.150 \times 10^{5} \text { in }^{2} k \\
& G J=.360 \times 10^{3} \text { in }^{2} k
\end{aligned}
$$

Figure 14 Flexural Torsional Buckling of 3 " $\times 3$ " $\times 1 / 4$ " angle 


$$
\begin{aligned}
& P_{x}=\frac{r^{2} E I_{x}}{L^{2}}=\text { Flexural buckling load about } x \text { axis } \\
& K=1-\frac{x_{0}^{2}}{r_{0}^{2}} \\
& x_{0}=\text { Distance from shear center to center of gravity } \\
& r_{0}^{2}=\frac{I_{0}}{A}=\text { Polar radius of gyration } \\
& \left.I_{0}=\text { (I } x \text { I } I_{y}\right)+x_{0}^{2} A=\text { Polar moment of intertia } \\
& A=\text { Cross sectional area }
\end{aligned}
$$

The critical load calculated by this equation is $104.23 \mathrm{k}$ which is very close to the one predicted by the computer program.

The flexural buckling load about the $y$ axis $\left(P_{y}=\pi^{2} E I_{y} / L^{2}\right)$ is approximately $144.57 \mathrm{k}$ which is larger than the flexural torsional buckling load and does not govern.

It should be noted that a small lateral load in the $y$ direction can be applied instead of the applied external torque in order to cause the member to buckle in the flexural torsional buckling.

The above examples show that the results predicted by the computer program are the same as those obtained by other techniques. 


\section{CHAPTER V}

\section{EXPANSION POSSIBILITIES}

The elastic beam column solution that is presented may be extended to take into account some other conditions as follows:

\section{SPECIFIED SLOPES AND FIXED END CONDITIONS}

Slopes can be specified by proper adjustments of the coefficients A, B and C in Eq. (3.41). The fixed conditions can be treated by specifying zero slopes. Matlock (10) presents a solution for this in one dimensional beam columns.

\section{SPECIFIED EXTERNAL TORQUES}

A beam column may be subjected to an external torque about the $z$ axis. This external torque appears in Eq. (3.24), i.e.,

$$
d M_{z}+m_{z}(d z)+t_{z}(d z)+\left(q_{y} d z\right) x_{0}-\left(q_{x} d z\right) y_{0}=0
$$

Where $t_{z}$ is external torque about the $z$ axis (in F.L/L) and it appears in the GG Matrix, i.e.,

$$
\mathrm{GG}(1,3)=\mathrm{QY}_{\mathbf{i}}-\mathrm{QX}_{\mathbf{i}}+\mathrm{T}_{\mathbf{z}_{\mathbf{i}}}
$$

in which

$$
\mathrm{T}_{\mathrm{z}_{\mathbf{i}}}=\mathrm{h}^{4} \mathrm{t}_{\mathrm{z}_{\mathbf{i}}}
$$


This is arrived at in a similar manner as used in Eq. (3.24) through Eq. (3.35).

The torque is specified at station $i\left(h t_{2}\right)$ in the computer input. Therefore, the specified torque is only needed to be multiplied by $h^{3}$, i.e.,

$$
T_{z_{i}}=h^{3}\left(t_{s_{i}}\right)
$$

where $t_{s_{i}}$ is the specified torque at station $i$ (in F.L).

\section{SPRING SUPPORTS}

Springs may be attached to the beam column along its length. There can be five types of springs, three spiral springs with rotational restraints $\left(R_{x}, R_{y}\right.$, and $\left.R_{z}\right)$ about the three axes $x, y$ and $z$ and two coil springs with translational restraints $\left(K_{x}\right.$ and $\left.K_{y}\right)$ in the $\mathrm{x}$ and $\mathrm{y}$ direction (Figures 15, 16 and 17).

An infintesimal increment of beam column, $\mathrm{dz}$, is considered and the three major differential equations are derived with springs included. Consider the element $\mathrm{dz}$ in Figure 15, and take moment about Point A. The following equation results :

$$
\begin{gathered}
M_{x}-\left(M_{x}+d M_{x}\right)+t_{x}(d z)+v_{y}(d z)+R_{x} d z\left(\frac{d y^{\prime}}{d z}\right)+P(d y)+ \\
q_{y}\left(\frac{d z^{2}}{2}\right)-k_{y}\left(y^{\prime}\right) \frac{d z^{2}}{2}=0
\end{gathered}
$$

Neglecting higher order differentials and dividing Eq. (5.1) by $\mathrm{dz}$ gives :

$$
\frac{d M}{d z}=v_{y}+t_{x}+R_{x} \frac{d y^{\prime}}{d z}+P \frac{d y}{d z}
$$




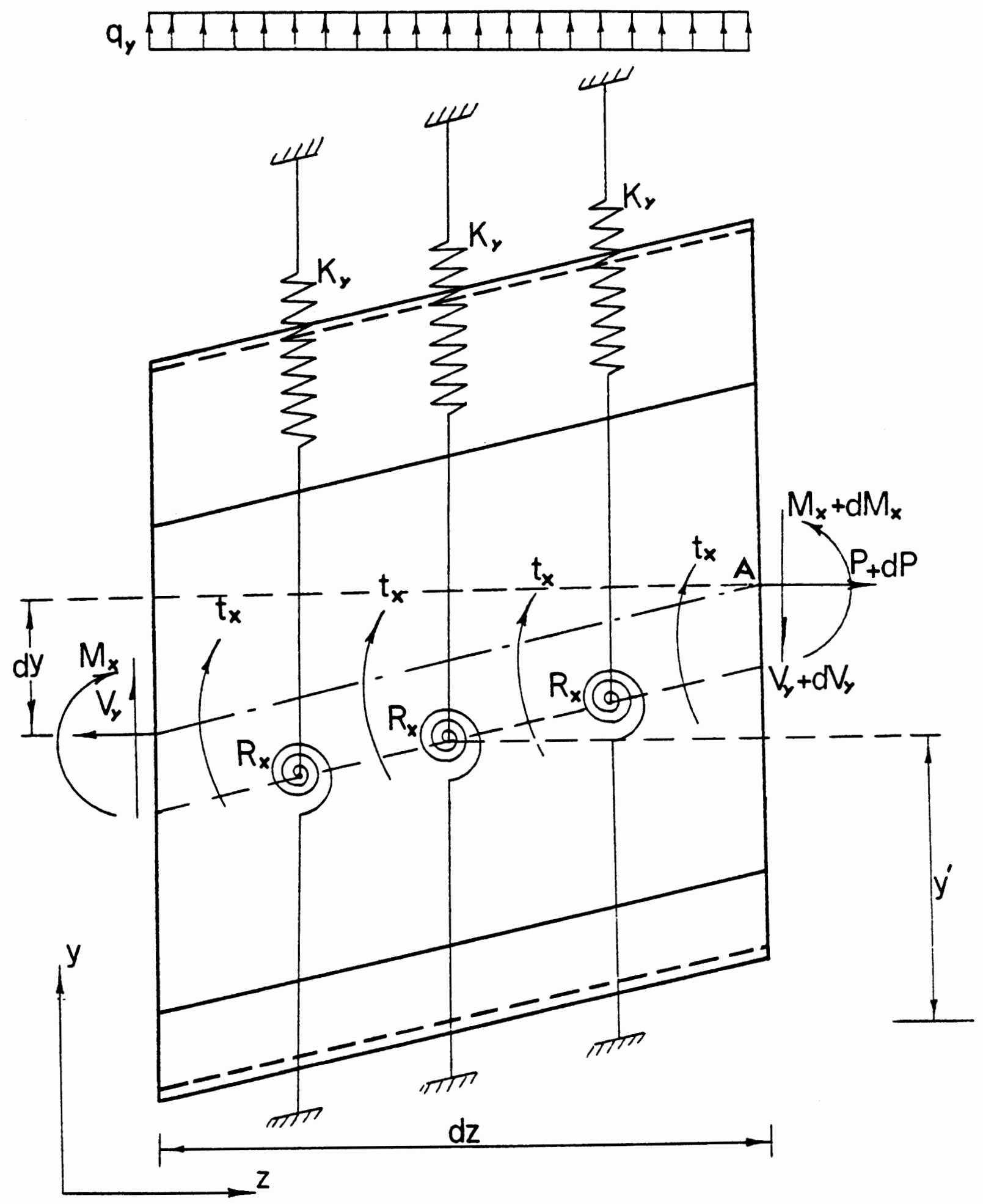

Figure 15 Infintesimal beam column increment in the yz plane with springs attached 
in which $y$ and $y^{\prime}$ are respectively the displacements of the center of gravity and point $N$ where springs are attached. $y$ and $y^{\prime}$ are equal to:

$$
\begin{aligned}
& y=v-x_{0} \varnothing \\
& y^{\prime}=v-\left(x_{0}-h_{x}\right) \varnothing
\end{aligned}
$$

See Appendix D. Taking the derivative of Eq. (5.2) with respect to $z$ and substituting $\mathrm{y}$ and $\mathrm{y}^{\prime}$ gives:

$\frac{d^{2} M}{d z^{2}}=\frac{d V}{d z}+\frac{d}{d z} T_{x}+R_{x}\left[\frac{d v}{d z}-\left(x_{0}-h_{x}\right) \frac{d \emptyset}{d z}\right]+P\left(\frac{d v}{d z}-x_{0} \frac{d \emptyset}{d z}\right)$

Now consider the equilibrium of the forces in the $y$ direction:

$$
v_{y}-\left(v_{y}+d v_{y}\right)+q_{y} d z-k_{y} y^{\prime} d z=0
$$

or

$$
\frac{d V}{d z}=q_{y}-k_{y}\left[v-\left(x_{o}-h_{x}\right) \phi\right]
$$

replacing $\frac{d V}{d z}$ in Eq. (5.4) gives:

$$
\begin{aligned}
\frac{d^{2} M}{d z^{2}}= & q_{y}-K_{y}\left[v-\left(x_{0}-h_{x}\right) \emptyset\right]+\frac{d}{d z} t_{x}+R_{x}\left[\frac{d v}{d z}-\left(x_{0}-h_{x}\right) \frac{d \emptyset}{d z}\right] \\
& +P\left(\frac{d v}{d z}-x_{0} \frac{d \emptyset}{d z}\right)
\end{aligned}
$$

Eq. (5.6) is the differential equation in the yz plane. In a similar manner, the differential equation for the $x z$ plane (Figure 16) is derived. The result is: 

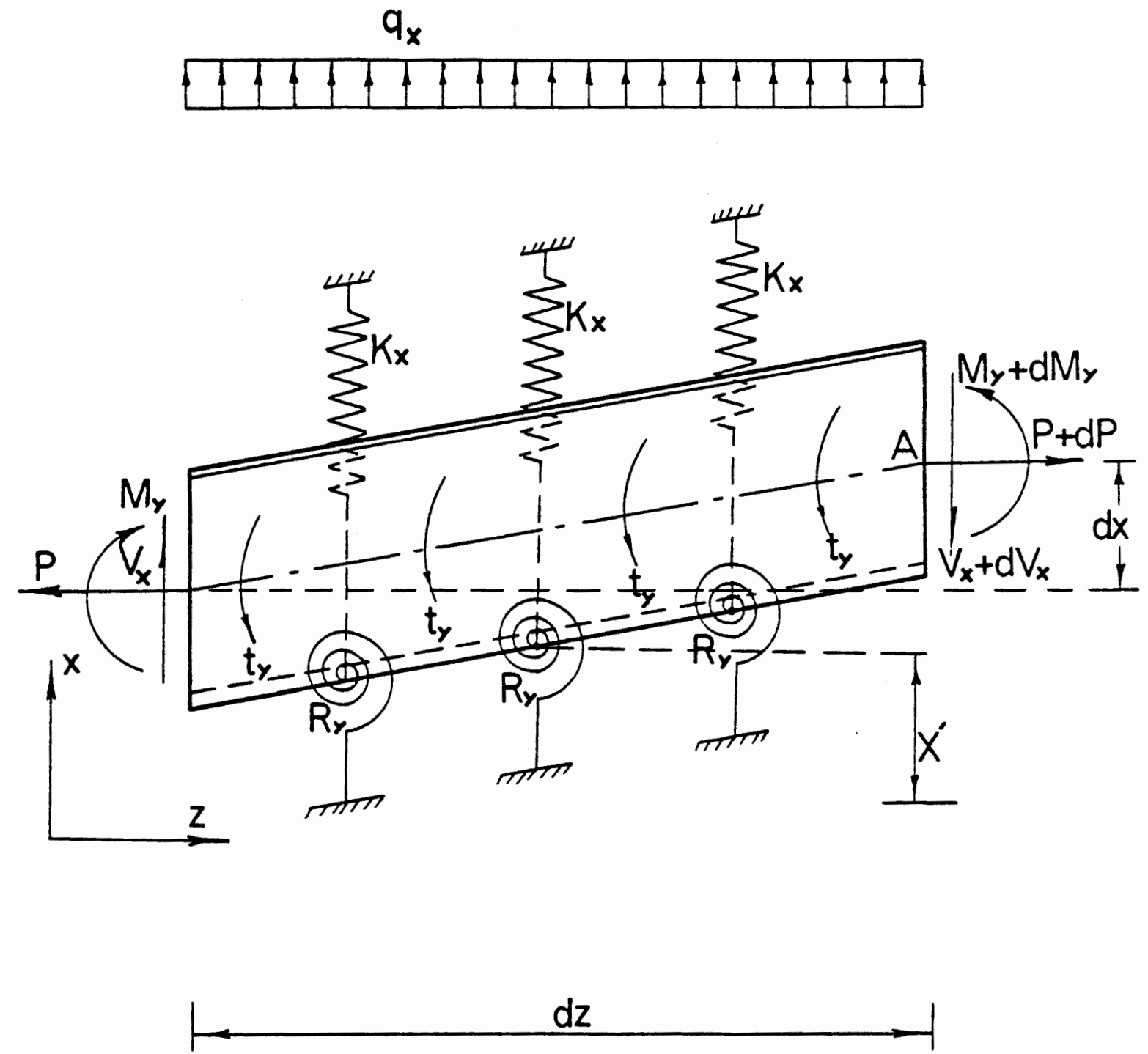

Figure 16 Infintesimal beam column increment in the $x z$ plane with springs attached 


$$
\begin{aligned}
\frac{d^{2} M}{d z^{2}}= & q_{x}-K_{x}\left[u+\left(y_{0}-h_{y}\right) \varnothing\right]+\frac{d}{d z} t_{y}+R_{y}\left[\frac{d u}{d z}+\left(y_{0}-h_{y}\right) \frac{d \phi}{d z}\right] \\
& +P\left(\frac{d u}{d z}+y_{0} \frac{d \varnothing}{d z}\right)
\end{aligned}
$$

It should be noted that the displacements of the center of gravity and point $\mathrm{N}$ in the $\mathrm{x}$ direction respectively are:

$$
\begin{aligned}
& x=u+y_{\alpha} \phi \\
& x^{\prime}=u+\left(y_{0}-h_{y}\right) \varnothing
\end{aligned}
$$

(See Appendix D)

The third equation is derived by taking the moment about the $z$ axis, Figure 17. The two coil springs and the spiral spring in the $x y$ plane, $R_{z}$, produce additional moments to the ones shown in Equation (3.25A). Therefore, the following equation gives:

$$
\begin{gathered}
\frac{d M_{z}}{d z}+m_{z}+q_{y} x_{0}-q_{x} y_{0}-R_{z} \varnothing-k_{y}\left[v-\left(x_{0}-h_{x}\right) \varnothing\right] \cdot\left(x_{0}-h_{x}\right)+ \\
k_{x}\left[u+\left(y_{0}-h_{y}\right) \varnothing\right] \cdot\left(y_{0}-h_{y}\right)=0
\end{gathered}
$$

in which $k_{y}\left[v-\left(x_{0}-h_{x}\right) \phi\right]$ and $k_{x}\left[u+\left(y_{0}-h_{y}\right) \phi\right]$ are the forces in the coil springs, and $\left(x_{0}-h_{x}\right)$ and $\left(y_{0}-h_{y}\right)$ are the lever arms. $M_{z}$ and $m_{z}$ are the same as in Chapter III, Computer Model.

It should be emphasized that the unit of the spring constants $K_{x}$ and $K_{y}$ are in force per length per unit length of the beam column increment and the unit of spring constants $R_{x}, R_{y}$ and $R_{z}$ are in force per radian per unit length of the increment dz.

The three equations $(5.6),(5.7)$ and (5.9) are the differential equations of the beam column with springs attached. 


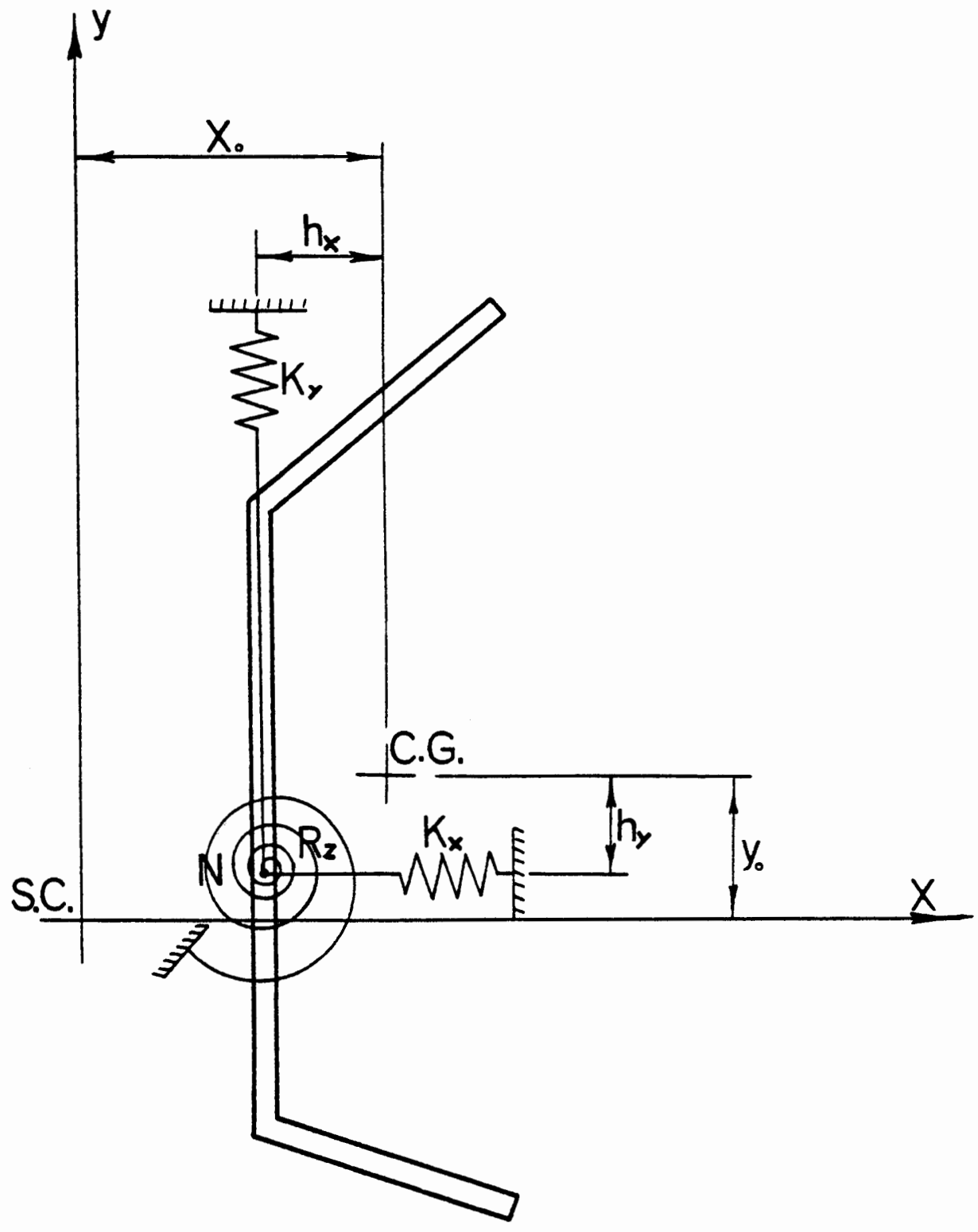

Figure 17 Cross section of the beam column with springs attached ( $x y$ plane) 


$$
\text { Q - DELTA EFFECT }
$$

A member that is loaded transversely and bent about its major axis may buckle laterally if the compression flange is not laterally supported. The compression flange, which acts like a column on an elastic foundation, becomes unstable and tends to bend sideways at the critical $Q$ load. As a result of this a torque is produced about the $z$ axis due to $Q\left(-u_{1}+u\right.$ ) (Figure 18a). The quantity $u_{1}$ is the deflection of the centroid at the free end of the beam as shown in Figure $18 \mathrm{~b}$ and $\mathrm{u}$ is the deflection at any cross section $\mathrm{mn}$ as in Figure $18 \mathrm{c}$. Modifying the presented analysis technique to include $Q-\Delta$ effect would allow the calculation of the lateral torsional buckling component of deflection. 


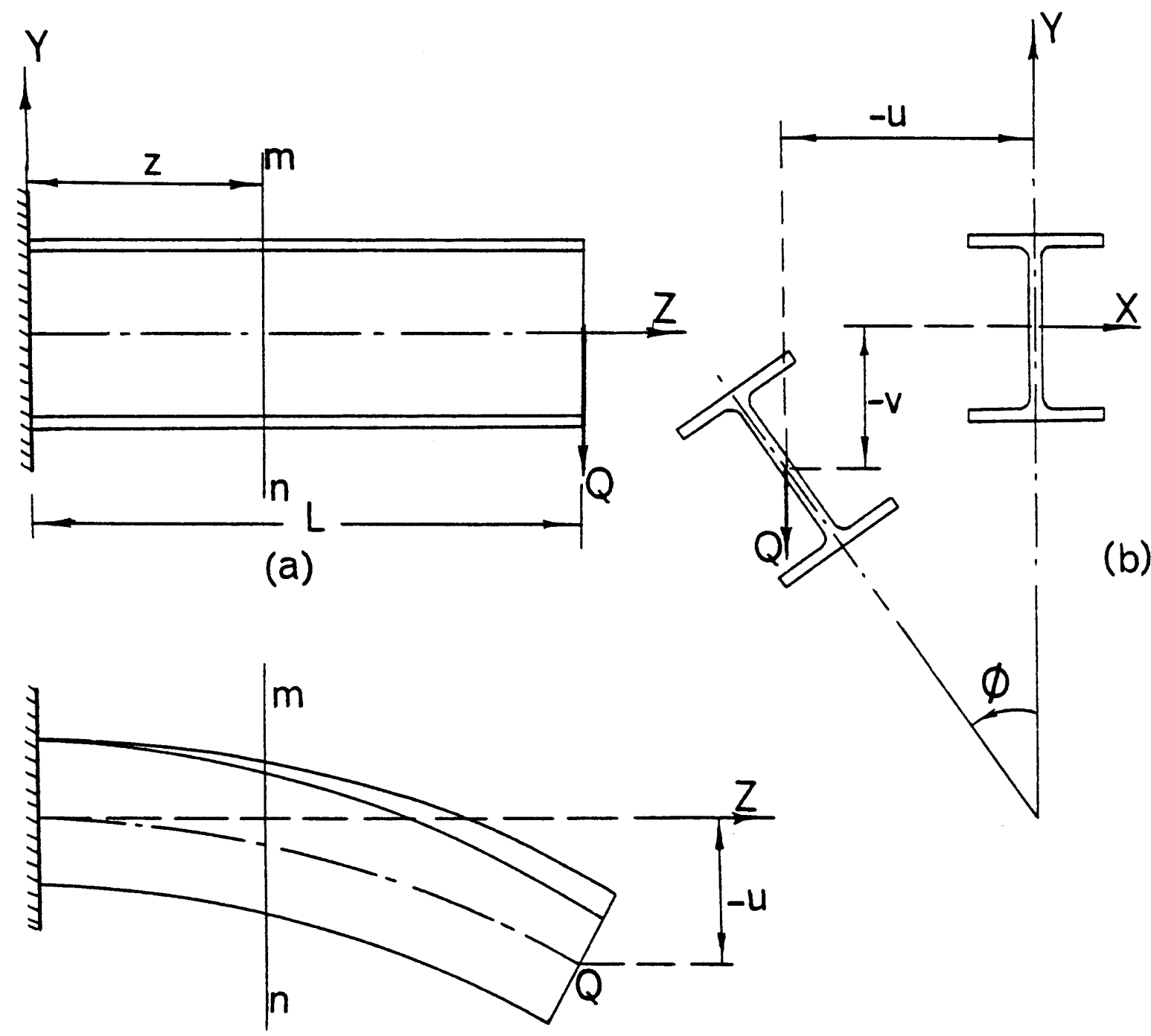

(c)

Figure 18 a) Q- $\Delta$ effect in a cantilever beam with concentrated load at the free end. b) Displacement of the cross section. c) Top view of the deflected beam. 


\section{REFERENCES}

1. Chajes, A., "Principles of Structural Stability Theory," PrenticeHall Inc., Englewood Cliffs, N.J., 1974.

2. Chajes, A., Fang, P., and Winter, G., "Torsional Flexural Buckling, Elastic and Inelastic, of Cold Formed Thin Walled Columns," Cornell Engineering Research Bulletin, Department of Structural Engineering, School of Civil Engineering, Cornell University, Ithaca, New York, August 1966.

3. Dwyer and Galambos, "Plastic Behavior of Tubular Beam-Columns," Journal of the Structural Division, ASCE, Volume 91, ST4, August 1965 .

4. Ellis, J. S., "Plastic Behaviour of Compression Members," Transactions of the Engineering Institute of Canada, Volume 2, P. 49-60, May 1958.

5. Galambos, T. V., and Ketter, R. L., "Columns Under Combined Bending and Thrust," Journal of the Eng. Mech. Division, ASCE, Volume 85, EM2, P. 1-30, Apri1 1959.

6. Haliburton, T. A., "Soil Structure Interaction - Numerical Analysis of Beam and Beam Columns," Technical Publication No. 14. School of Civil Engineering, Oklahoma State University, Stillwater, Oklahoma, February 1971.

7. Hudson, W. R., Stelzer, C. F., Jr., "A Direct Computer Solution for Slabs on Foundation," ACI Journal, Title No. 65-15, March 1968.

8. Ketter, R. L., Kaminsky, E.L., and Beedle, L. S., "Plastic Deformation of Wide Flange Beam-Columns," Transactions, ASCE, Volume 120 , P. 1028-1061, 1955.

9. Livesley, R. K., "Matrix Methods of Structural Analysis," Pergamon Press Ltd., 1964.

10. Matlock, H, Haliburton, T. A., "A Finite Element Method of Solution for Linearly Elastic Beam Column," Research Report No. 56-1 Center of Highway Research, The University of Texas, Austin, September 1966.

11. McGuire, W., "Steel Structures," Prentice-Hall Inc., Englewood Cliffs, N.J., 1968.

12. Mueller, W.H., "A Numerical Solution for Beam-Columns on Non-Linear Foundations," Masters Thesis, University of Missouri, Rolla, 1966. 
13. Timoshenko, S., Gere, J. M., "Theory of Elastic Stability," Second Edition, McGraw-Hill Inc., New York 1961.

14. Wagner, A. L., "A Numerical Solution for the Ultimate Strength of Tubular Beam-Columns," Masters Thesis, Portland State University, 1976. 
APPENDIX A

FLOW DIAGRAM - SUBROUTINE MAIN1

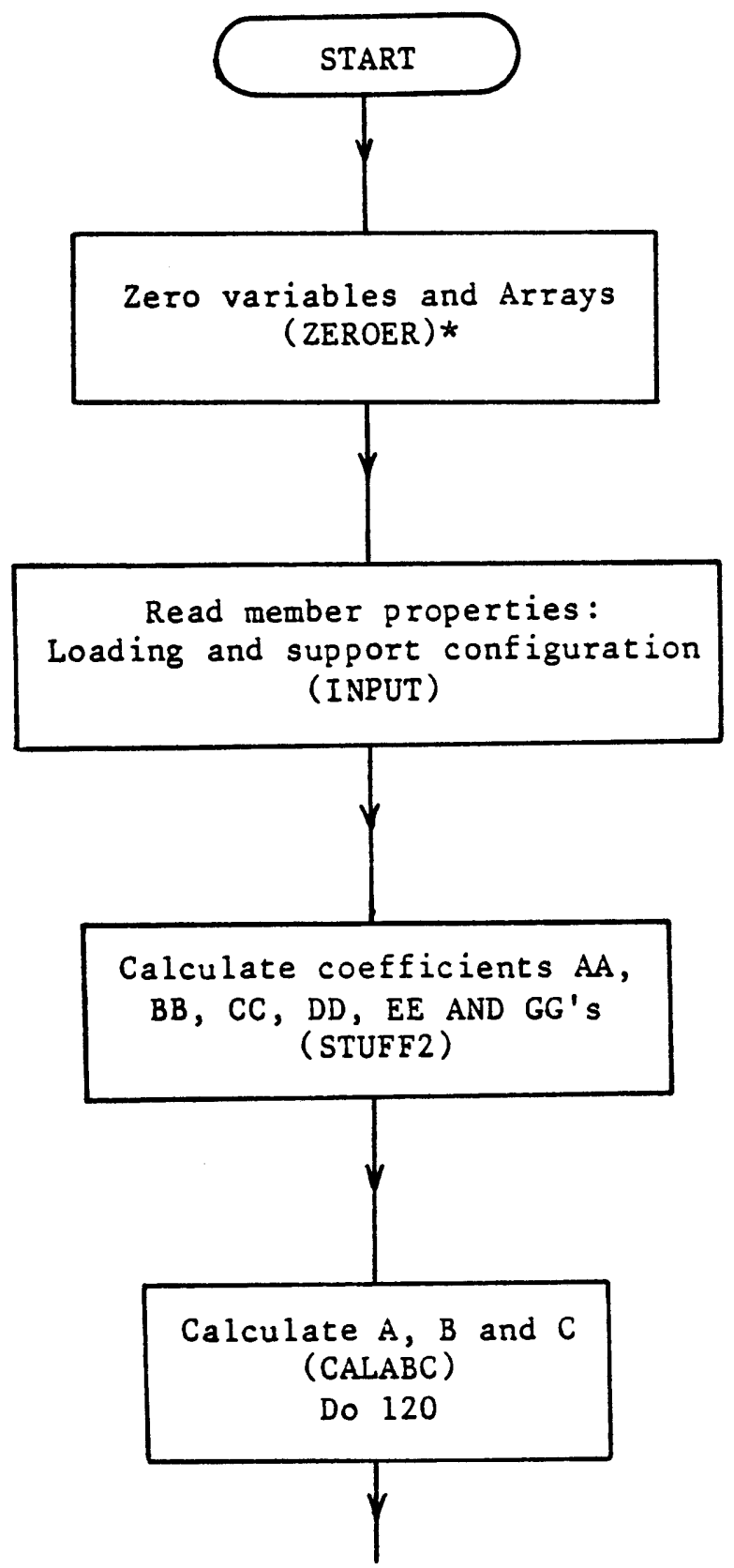

*Names of FORTRAN SUBROUTINES are indicated by ( ). 


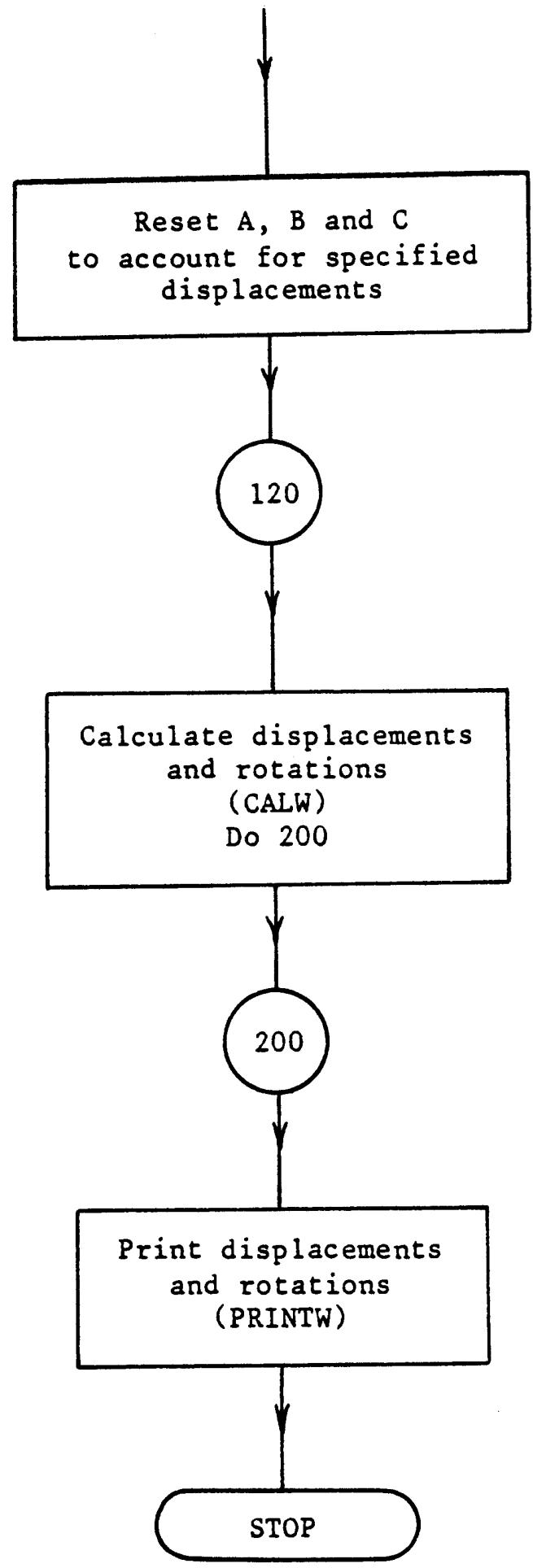


FLOW DIAGRAM - SUBROUTINE ZEROER

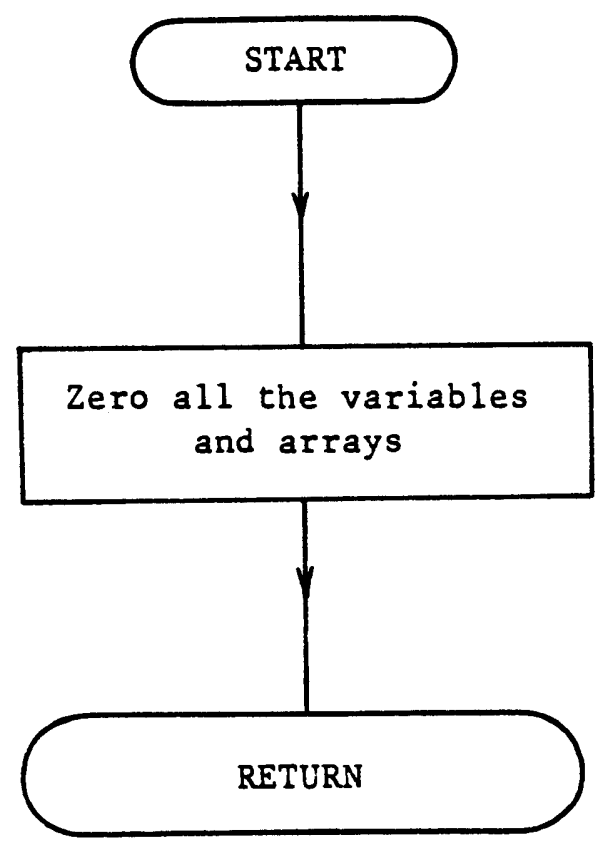


FLOW DIAGRAM - SUBROUTINE INPUT

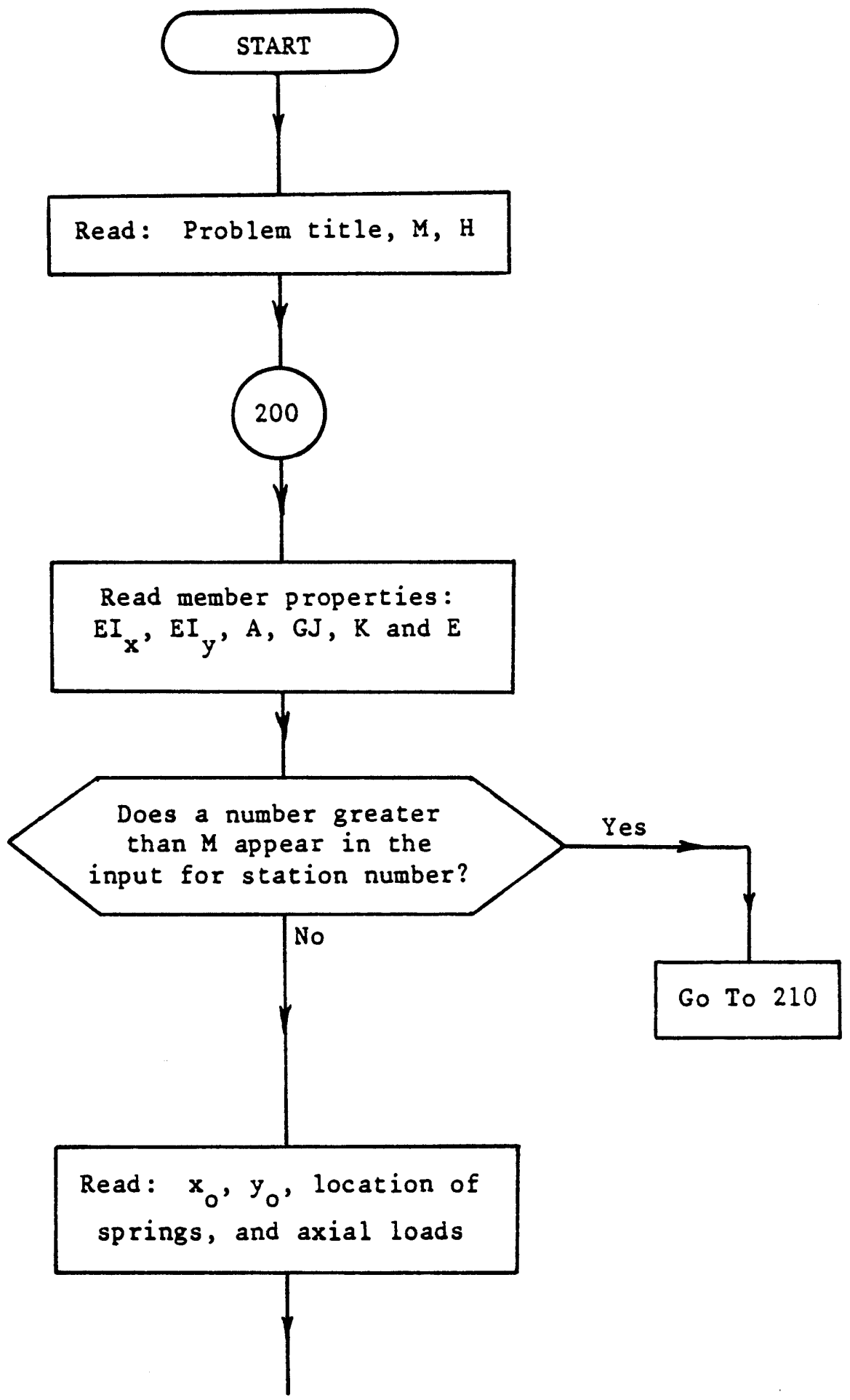




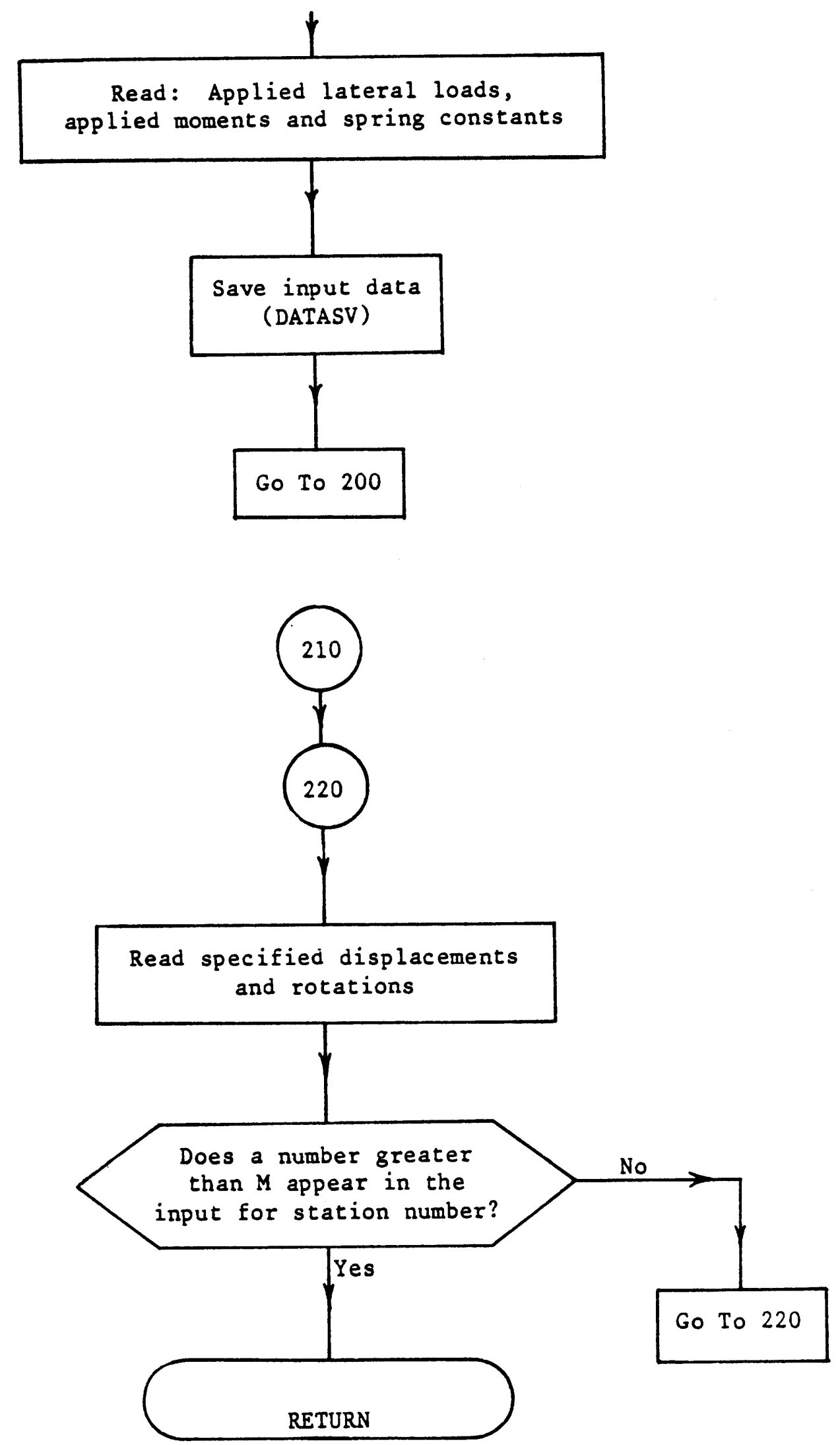


FLOW DIAGRAM - SUBROUTINE DATASV

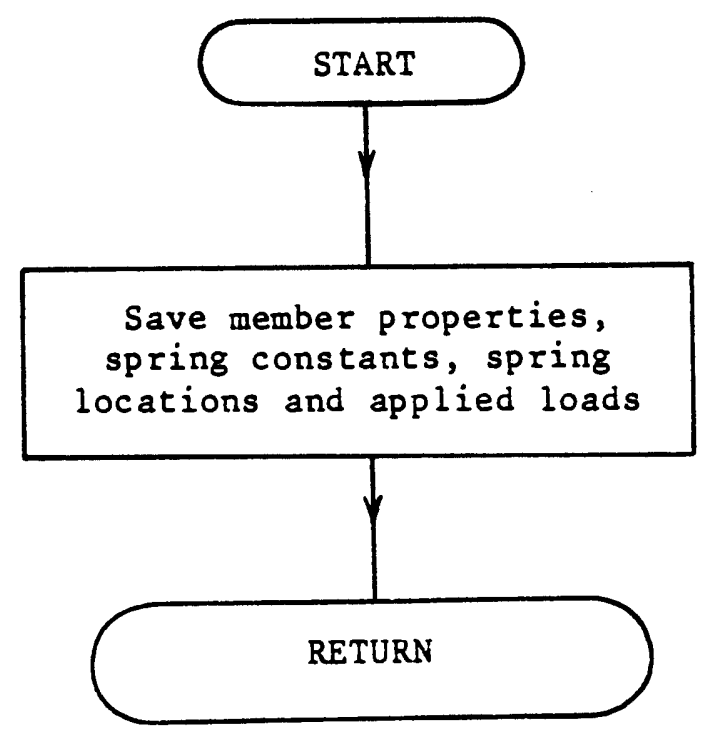


FLOW DIAGRAM - SUBROUTINE STUFF2

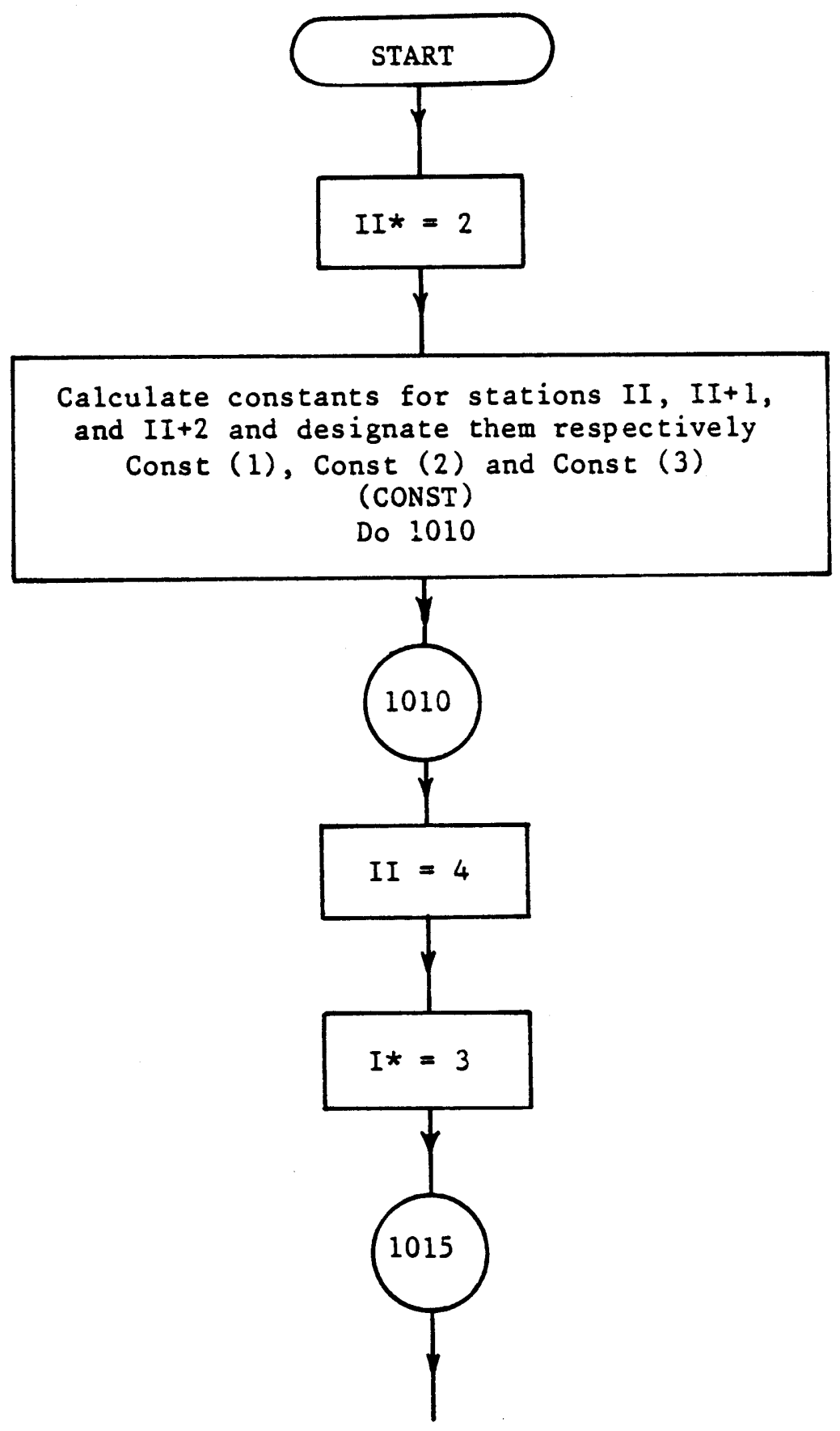

$\overline{\text { *II and I are computer stations }}$ 


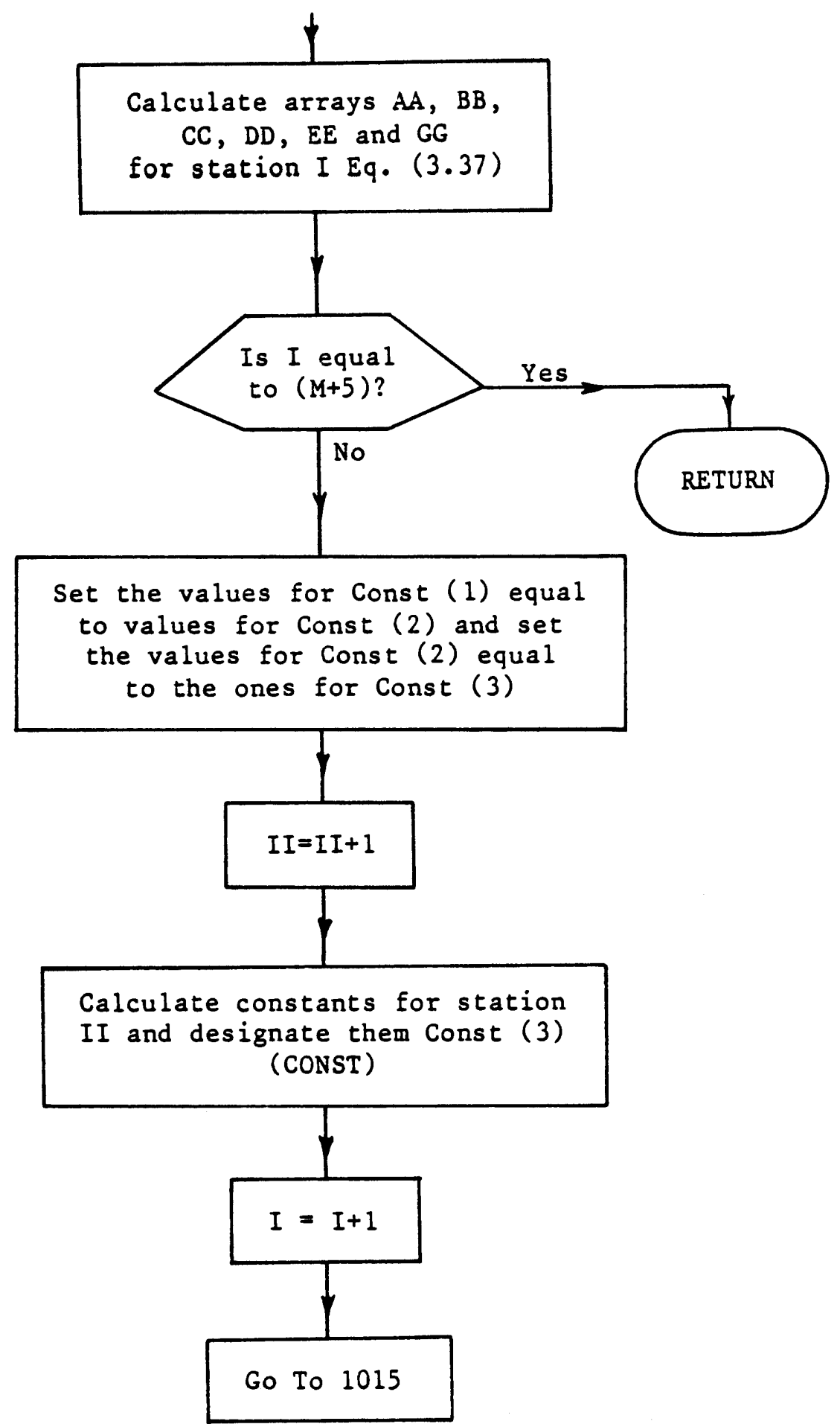


FLOW DIAGRAM - SUBROUTINE CONST

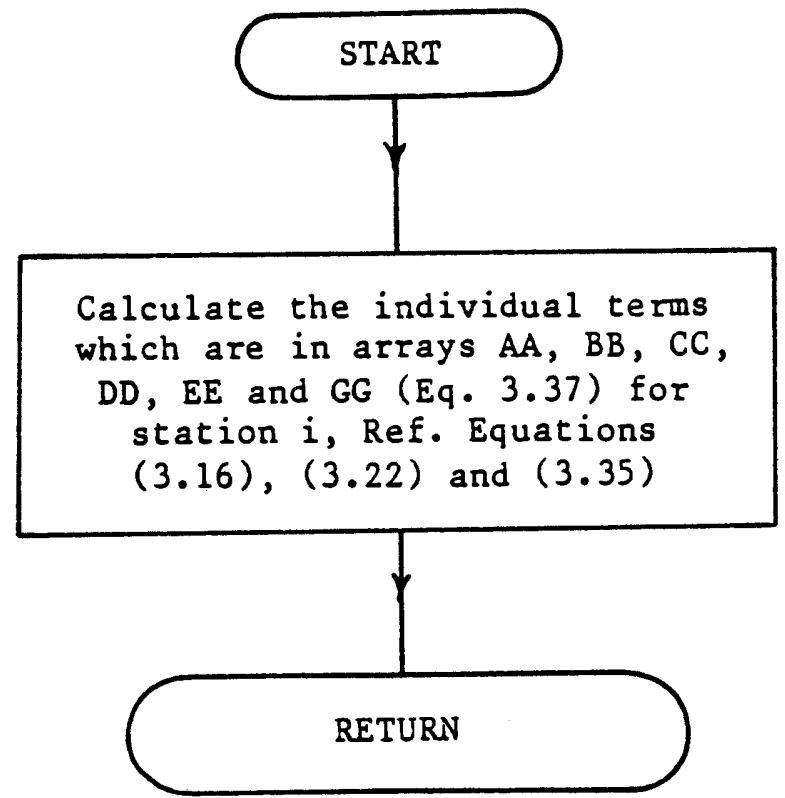

FLOW DIAGRAM - SUBROUTINE CALABC

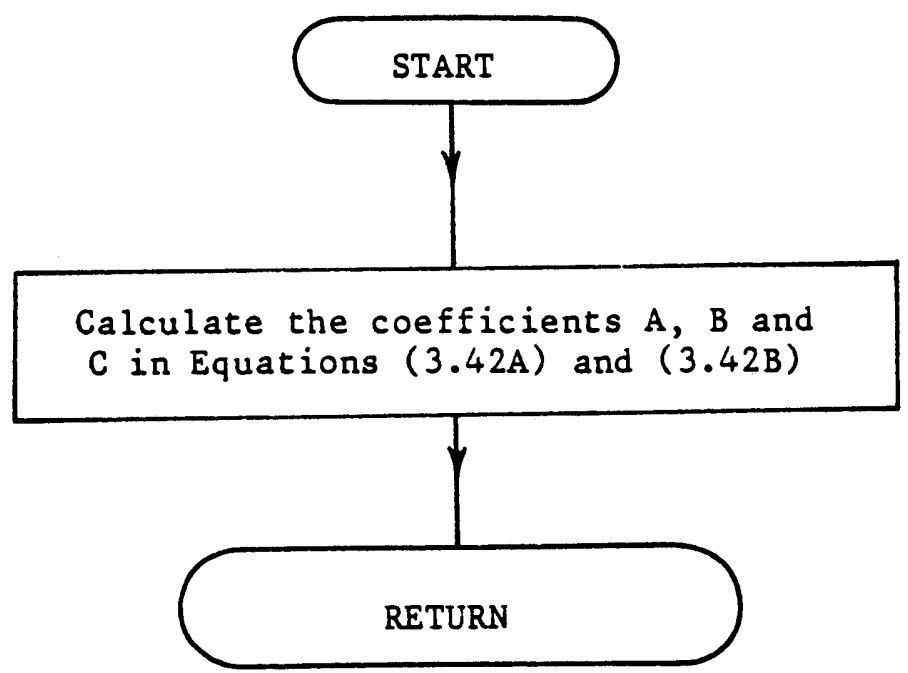


FLOW DIAGRAM - SUBROUTINE CALW

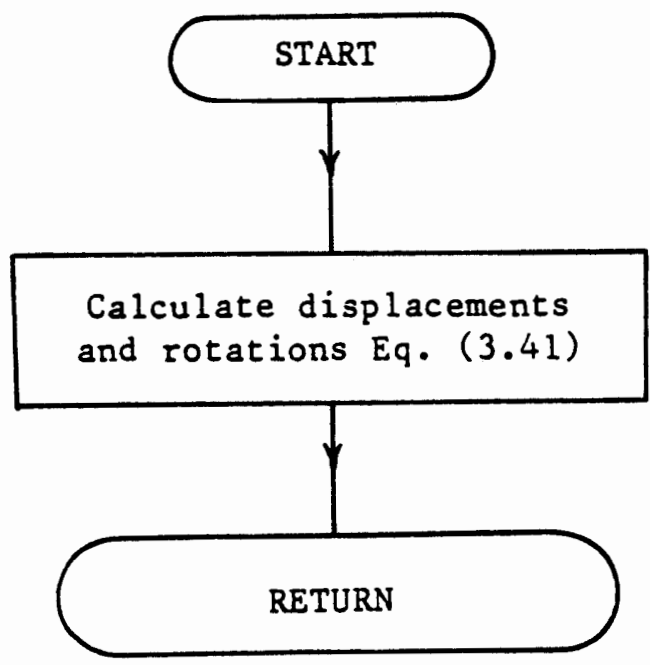

FLOW DIAGRAM - PRINTW

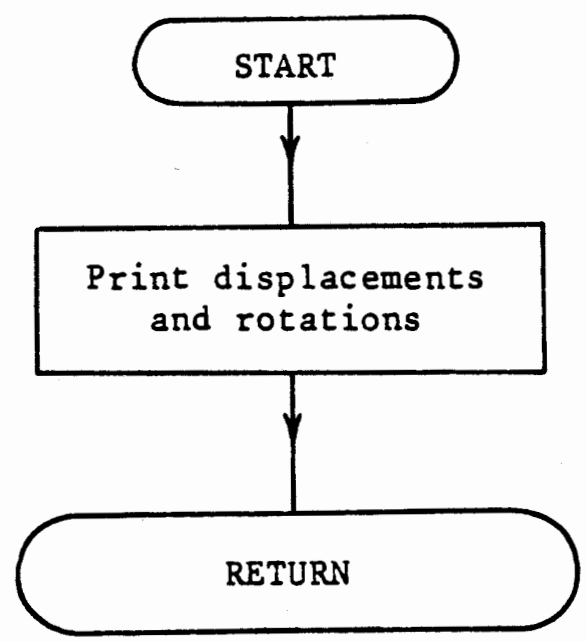




\section{MATRIX MANIPULATING SUBROUTINES}

SUBROUTINE FUNCTION

PLUCK1............. Isolates a $1 \times 3$ matrix from a $3 x n$ array PLUCK3............. Isolates a $3 \times 3$ matrix from a $3 \times n$ array MCHSG1................... MCHSG3.................... MADDI..............Adds two $1 \times 3$ matrices MADD3..............Adds two $3 \times 3$ matrices MULT1................ MMULT3...........Multiplies two $3 \times 3$ matrices MPUT1................. a a $1 \times 3$ matrix in a $3 \times n$ array MPUT3..............Puts a $3 \times 3$ matrix in a $3 \times n$ array MINV3............... Inverts a $3 \times 3$ matrix 
APPENDIX B

BEAM COLUMN PROGRAM

The beam column is divided into m equal size increments. The number of a particular increment is referred to as the station number of the increment.

The beam column program can handle transverse loads in the $x$ and $y$ direction, applied moments about the $x$ and $y$ axes and applied axial loads as shown in Figure 19. The loads and moments shown in Figure 19 are positive. The axial load will be positive if it is tension force.

In the program, loads and external moments are treated as concentrated loads and moments. Therefore, the contribution of the loads and moments of each increment to its adjacent stations are input into the program. The data input is presented in the following pages. 


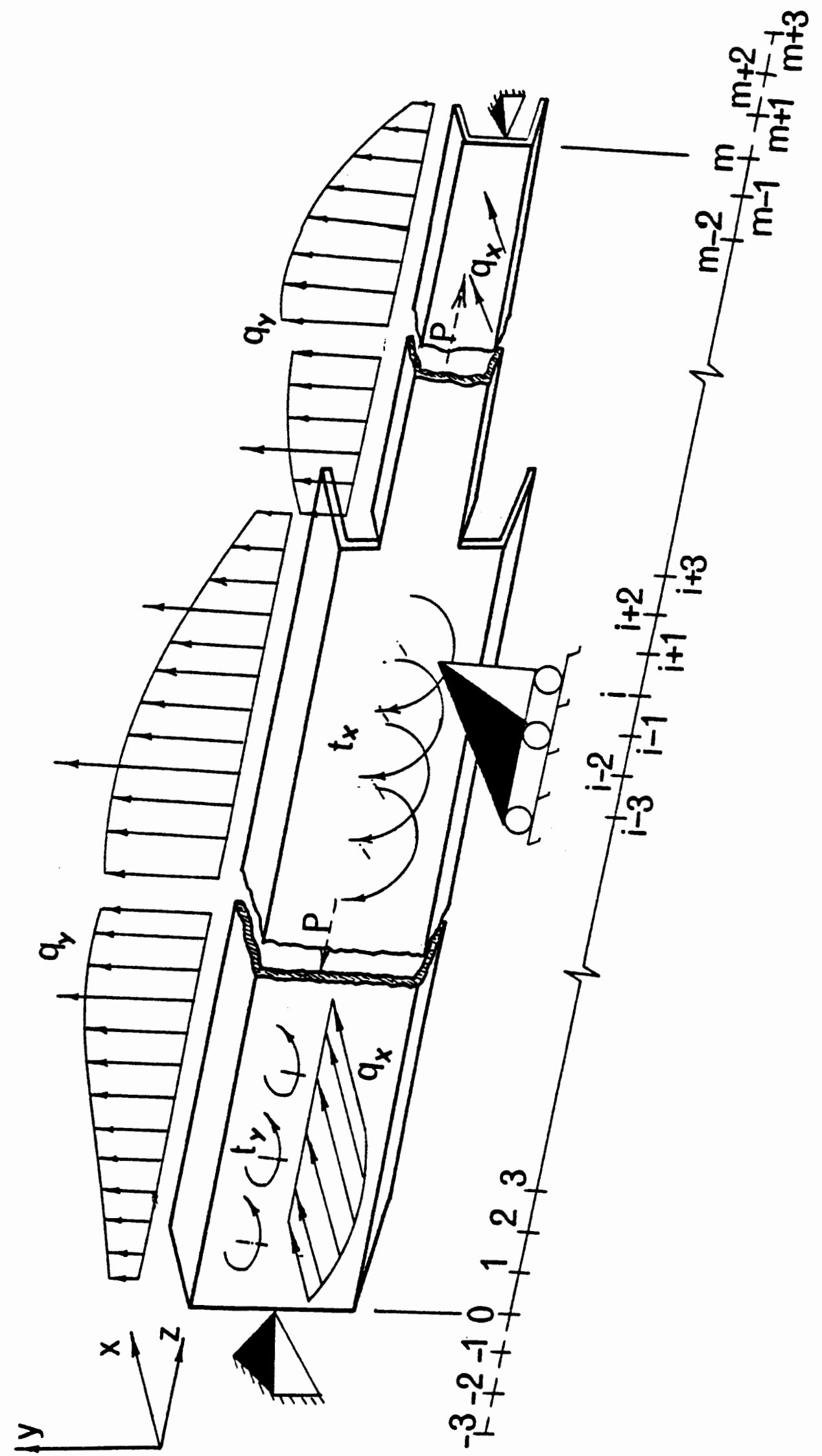

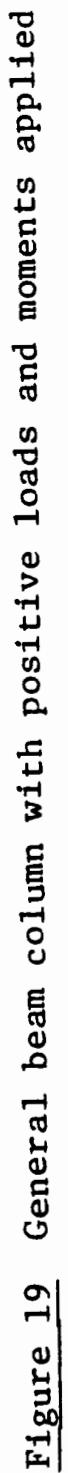


DATA INPUT

Note: Numbers at left indicate card columns.

A. Title of Problem

FORMAT $(80 \mathrm{H})$

1-80 Problem Title

B. Control Data

FORMAT $(2 \mathrm{I} 5,7 \mathrm{E} 10.3)$

1-5 Number of beam column increments (M).

11-20 Increment length (H).

C. Data Added through Specified Intervals

I. FORMAT $(2 \mathrm{I} 5,7 \mathrm{E} 10.3)$

1-5 Station

5-10 Through

11-20 Flexura1 stiffness about $x$ axis $\left(E I_{X}\right)$

21-30 Flexural stiffness about $y$ axis ( $\left.E I_{y}\right)$

31-40 Area of the cross section (A)

41-50 Torsional stiffness (GJ)

51-60 Warping stiffness $\left(K=E C_{W}\right)$

61-70 Modulus of Elasticity (E)

II. FORMAT $(2 \mathrm{I}, 7 \mathrm{E} 10.3)$

11-20 Distance from shear center to center of gravity in the $x$ direction $\left(x_{0}\right)$

21-30 Distance from shear center to center of gravity in the $\mathrm{y}$ direction $\left(\mathrm{y}_{0}\right)$

31-40* Distance from center of gravity to Point $N$ in the $x$ direction $\left(\mathrm{H}_{\mathrm{x}}\right.$, See Figure 17$)$ 
41-50* Distance from center of gravity to Point $N$ in the $y$ direction $\left(\mathrm{H}_{\mathrm{y}}\right.$, See Figure 17 )

51-60 Axial load through the center of gravity (P).

III. FORMAT (2I5, 7E 10.3)

11-20 Transverse load in the $x$ direction through center of gravity $\left(Q_{X}\right)$

21-30 Transverse load in the $y$ direction through center of gravity $\left(Q_{y}\right)$

31-40 Applied moment about $x$ axis $\left(M_{x}\right)$

41-50 Applied moment about y axis $\left(M_{y}\right)$

51-60* Stiffness of transverse spring in the $x$ direction $\left(\mathrm{K}_{\mathrm{x}}\right)$

61-70* Stiffness of transverse spring in the $y$ direction $\left(\mathrm{K}_{\mathrm{y}}\right)$

71-80* Stiffness of rotational spring about 2 axis

D. Control Card

FORMAT $(2 \mathrm{I} 5,7 \mathrm{E} 10.7)$

1-5 $N$, greater than $M$, indicates the end of the data for the sectional properties of the beam column.

E. Specified Deflections

FORMAT (I5 , 4X,A1,E 10.3$)$

1-5 Station

10 Direction of deflection ( $x, y$ or $R$ )

11-20 Specified deflection

F. Control Card

1-5 $N$, greater than $M$, indicates the end of the data for the specified deflections. 
APPENDIX C

COMPUTER PROGRAM DOCUMENTATION 


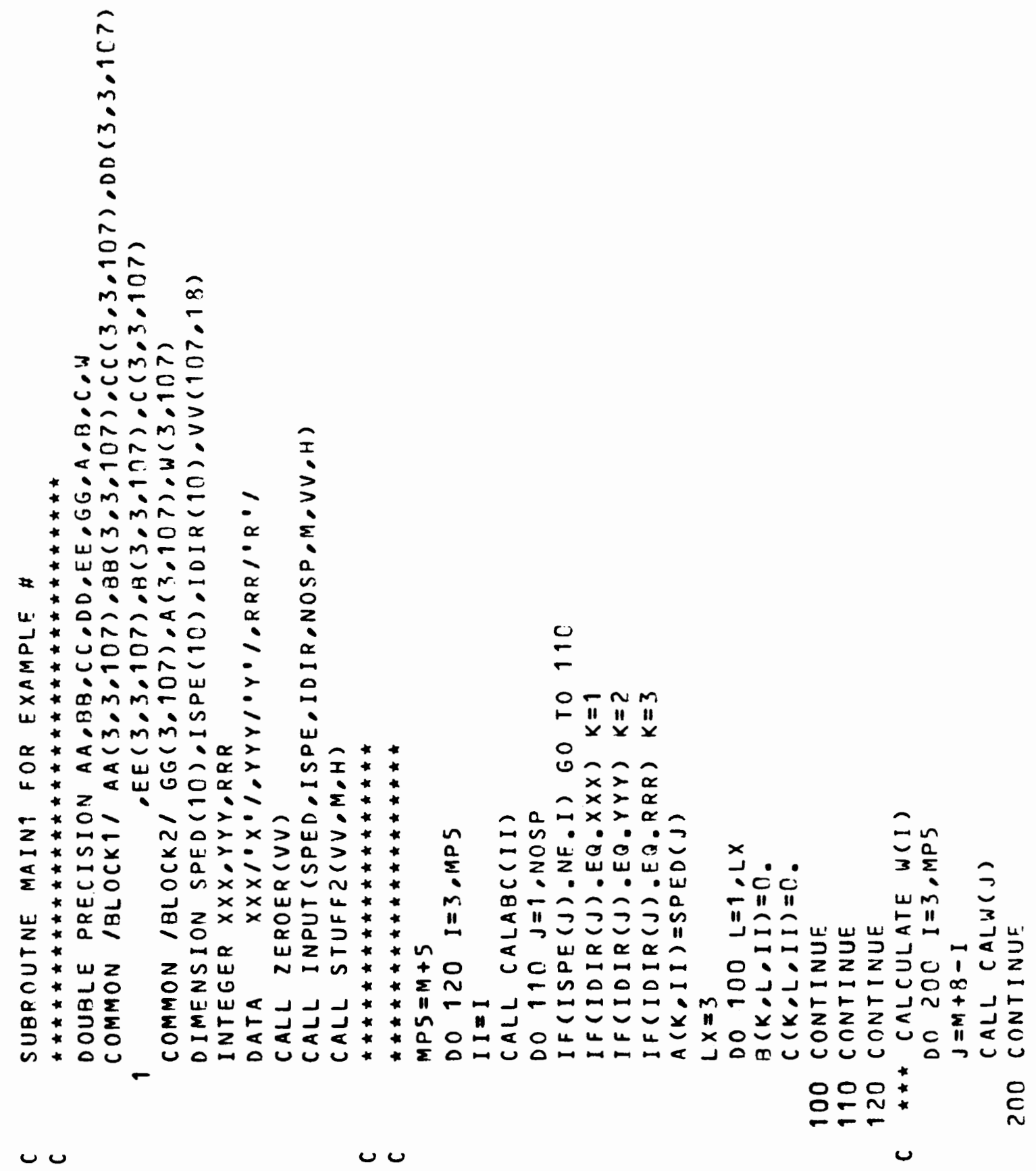

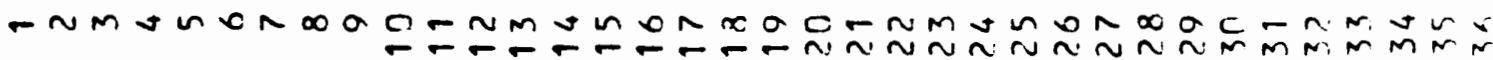



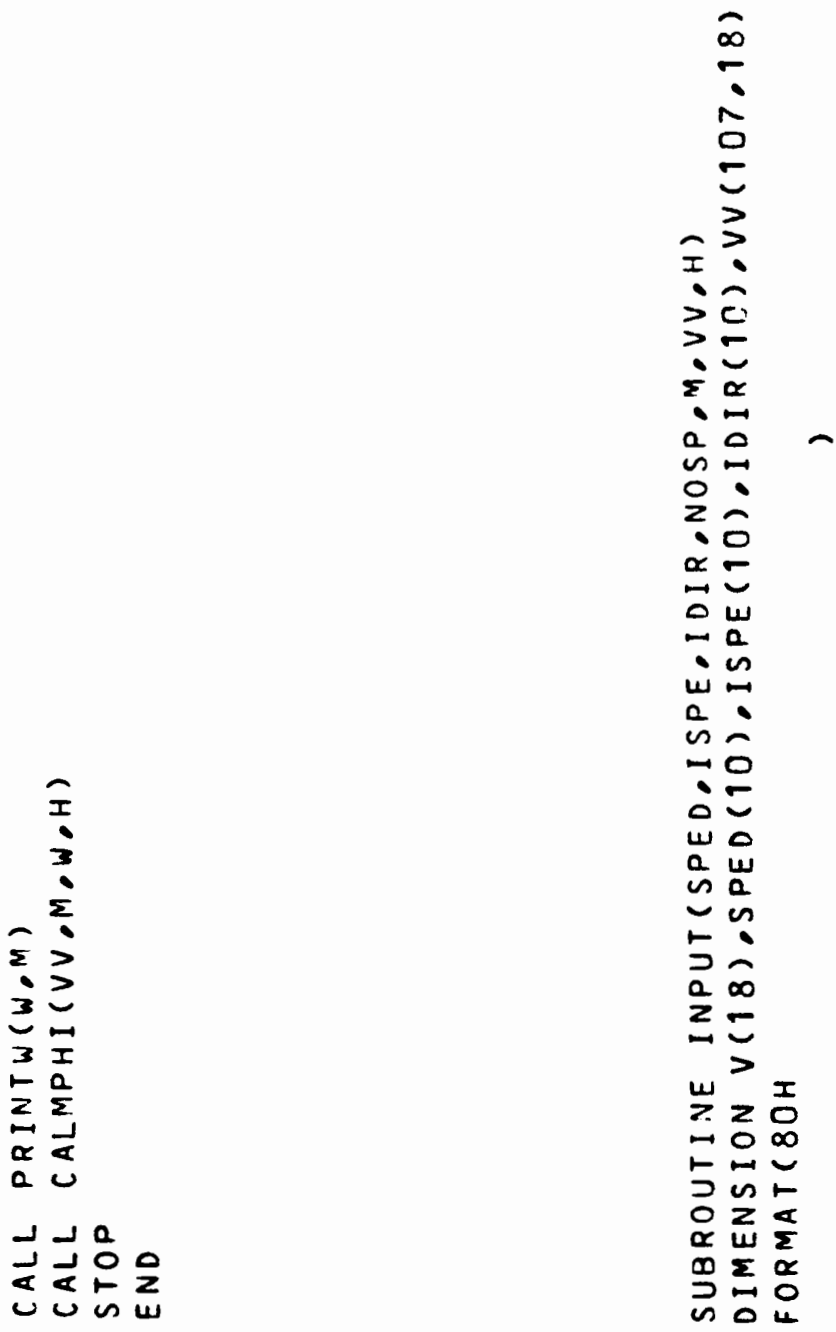

$x x$

$\infty \underset{\infty}{\infty}$

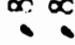

$\propto I$

Z

$\sim \perp x$

$=2$

$x \times$

$=$

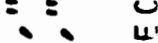

$u \vdash w \quad x \propto x$

$0 z_{w}=0$ u

$\alpha \sum x$

$=$

$>2$

w

$\boldsymbol{\alpha} \propto$.

$\sum \underline{0}=$

$=8$

$\because 1$

$\times \times \quad \sigma$

$\infty \propto ⿻$

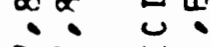

$=\approx \omega-$

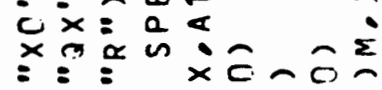

w

$N N$

$\leftarrow$

in : i $2 \div x+9$ ง cice

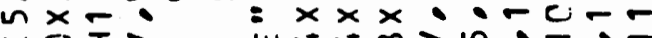
$\rightarrow 0 I V$ 山 $v \infty>n-1$

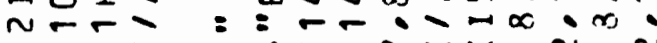

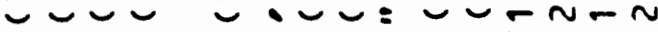

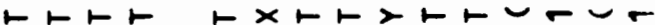

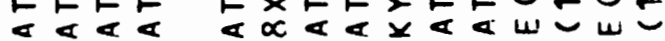

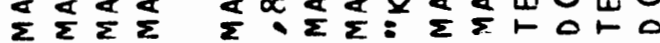
$\sum_{\alpha} \sum_{\alpha} \alpha=\alpha \alpha \sigma \alpha \alpha+\alpha$

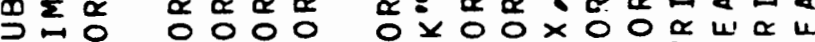

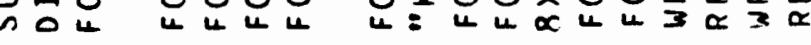

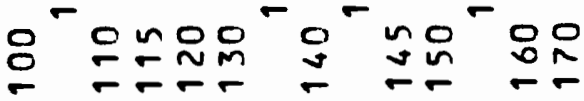




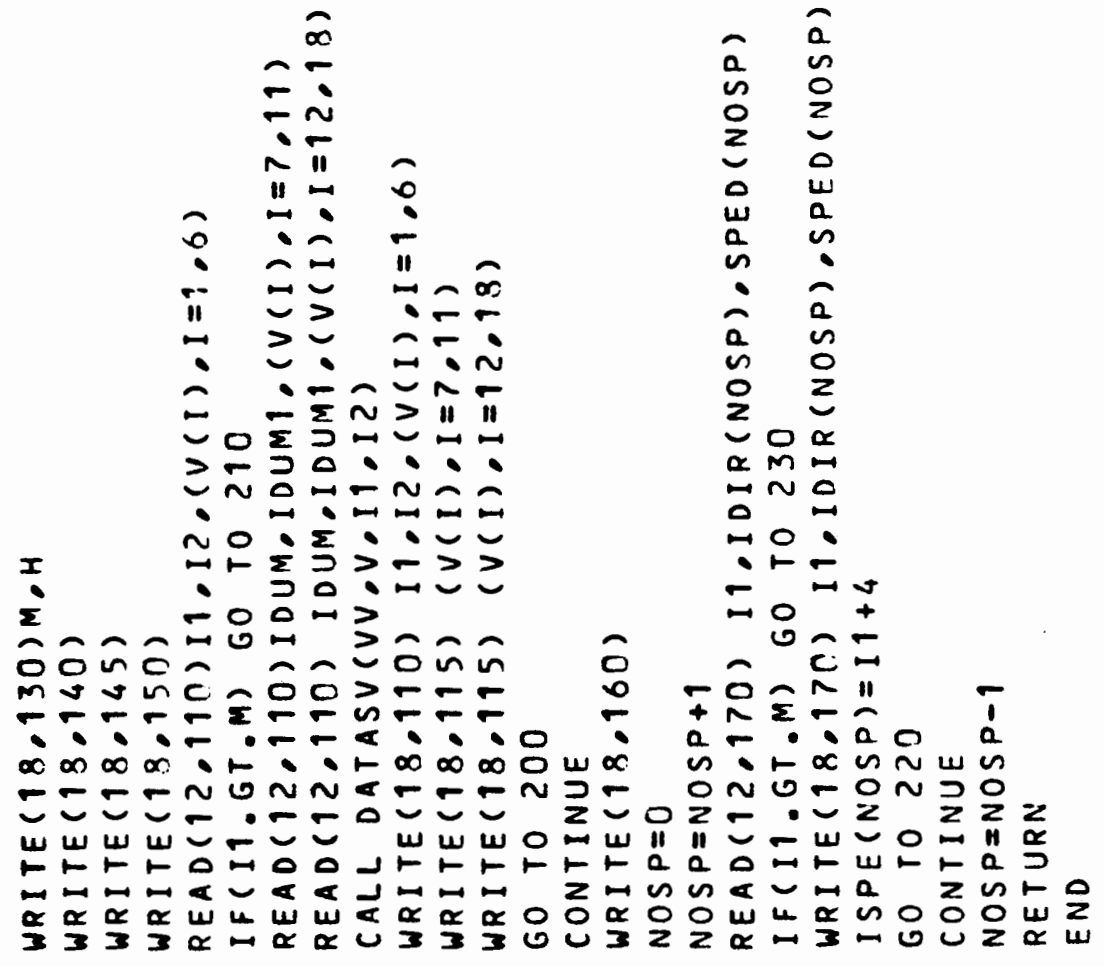




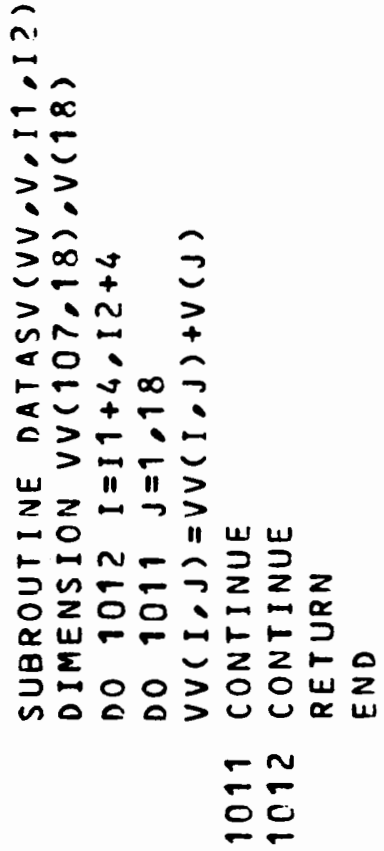

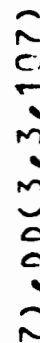

$\because$

$\sim \widetilde{R}$

$\because c$

$m \sigma$

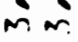

min

Sum

- U 0

ن

- 1

$\infty \sim \sim m$

- or

$a-03$

in.

ima

- $m \cdot E$

$\omega \smile m=$

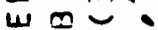

- $\infty \mathrm{m}$

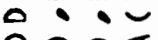

- $r$

Uc: $c=$

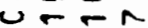

- -0

$n M M-$

$\sim \boldsymbol{D} \cup$

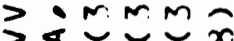

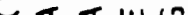

$\propto$ o $\sigma 0$.

แ?

$00->N$

$\alpha \sqcap-\pi=c \infty$

w山 $x$ x

N口U U

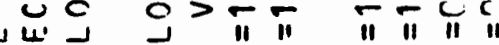

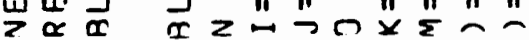

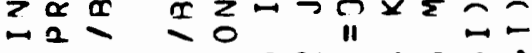

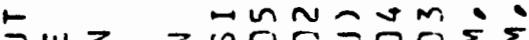

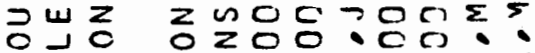

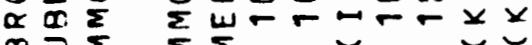

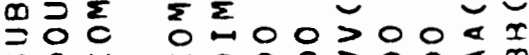

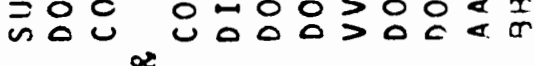

$\underset{0}{0}$ 
ก

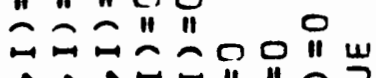

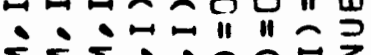

$\sum \Sigma \sum \sum 002$

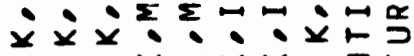

U

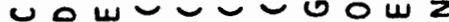

u 0 w

\begin{tabular}{ll}
$m$ & \multirow{2}{*}{$n$} \\
0 & 0 \\
0 & 0
\end{tabular}

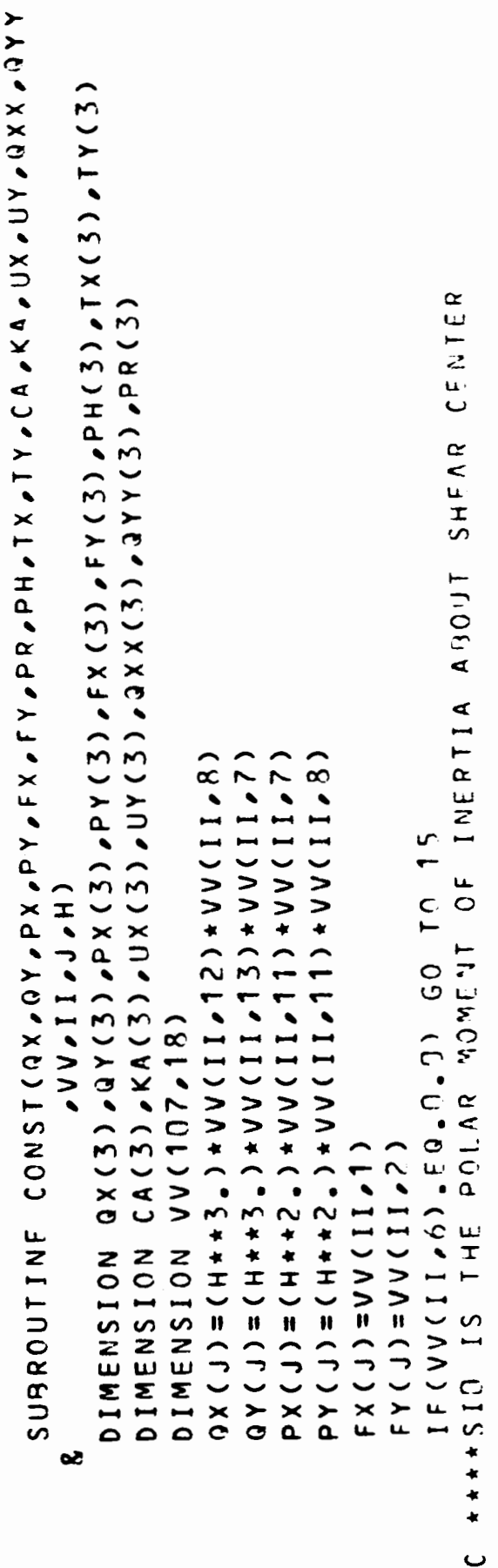

-nMs $n$ m 


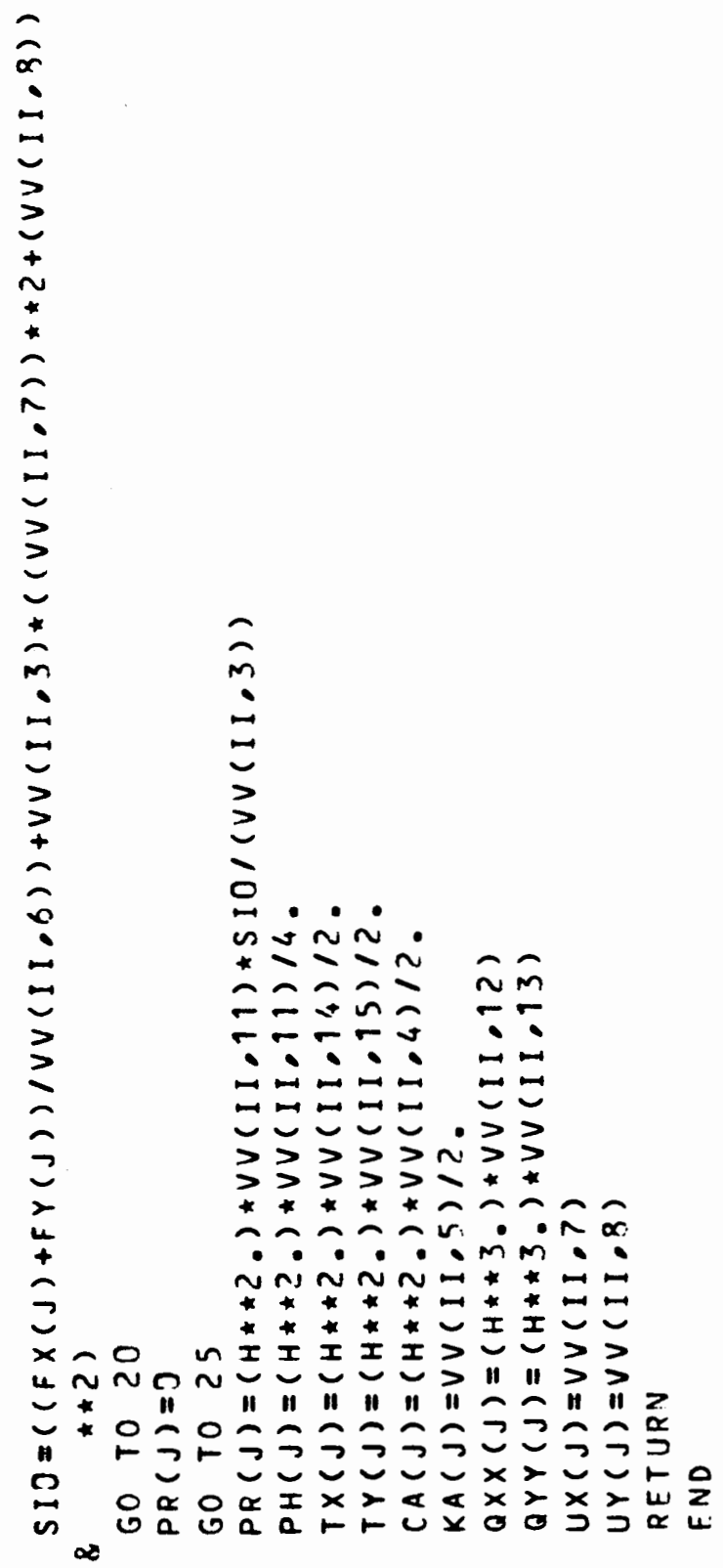

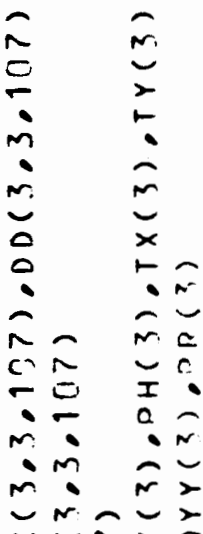
$3 \cup \smile r>$ - U ᄂ u $\because \therefore \therefore \div$ cramm - 0 c U $-5 \times x$ - 14 DMm-. G: r - MMCMN $\omega \smile \smile-\smile$ w $x \backsim>>$ - $x$ - ra a - 2 . $0 \sim \pi<\pi$ - $N O M M$ - U $0 \div-\sim \mathcal{r}$ IU $\sim \sim x \times$ - $m \subset a z$

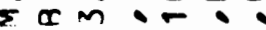
$\because \infty \because m \div 2$ $>M \smile M N M$ $>\varangle \smile w \smile \smile \smile$ 《 4 Uण $\tilde{u} z<v a y$ $40>0$ $D \sim \sim m M$ F⿻上丨 $x \cup$ n日u $40 \quad 00 u$ 出 $\vec{\alpha} \quad \vec{r} z z$ -a $>00$ गUz z $0+0 \quad 022$ $\propto \bar{\Sigma} \Sigma \omega \omega$ 召立

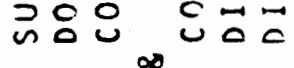
$\because \quad$ nก 

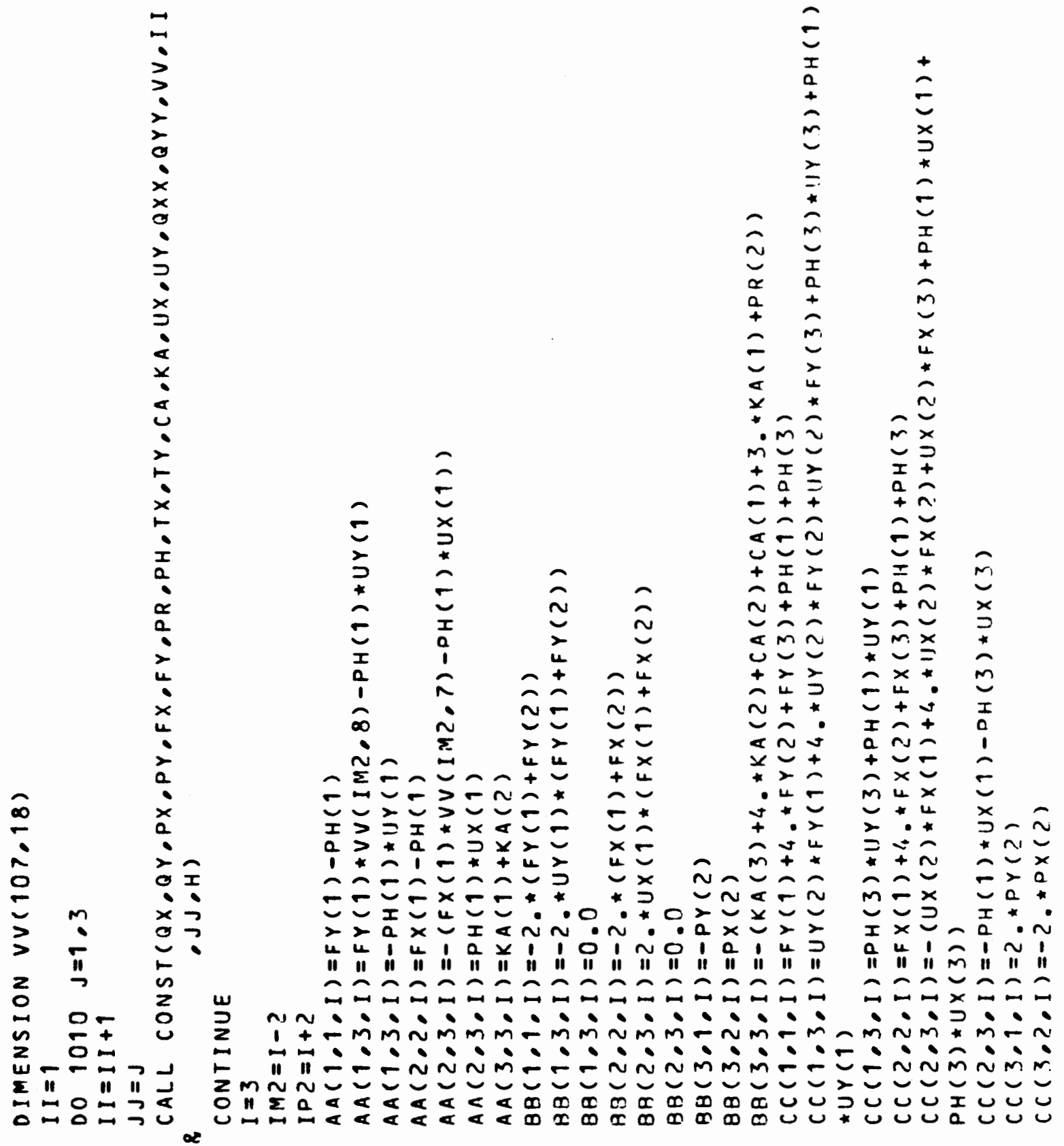

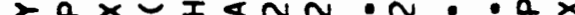

"II " i "I II

a I

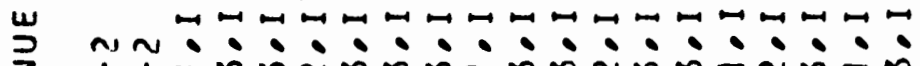

$1+-m m \sim m m m-m m \sim m m-N m-m \sim m \sim m * m-n$ $\rightarrow-1 . \cdots \cdots$

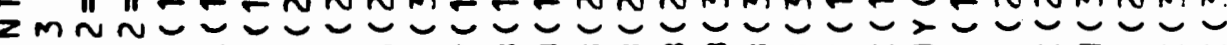

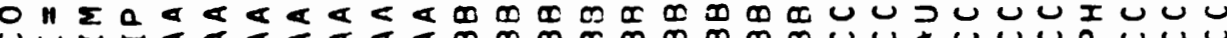

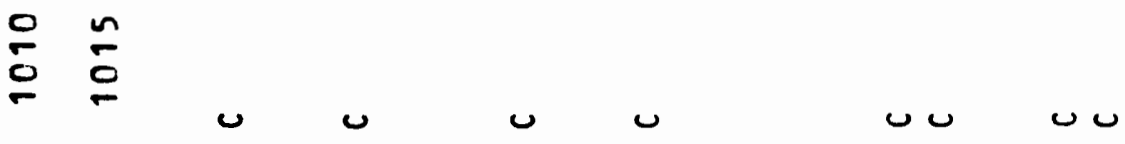

DaOrnmanon

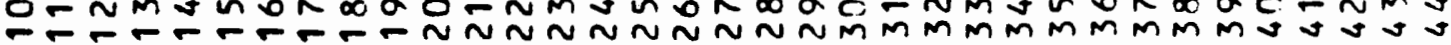



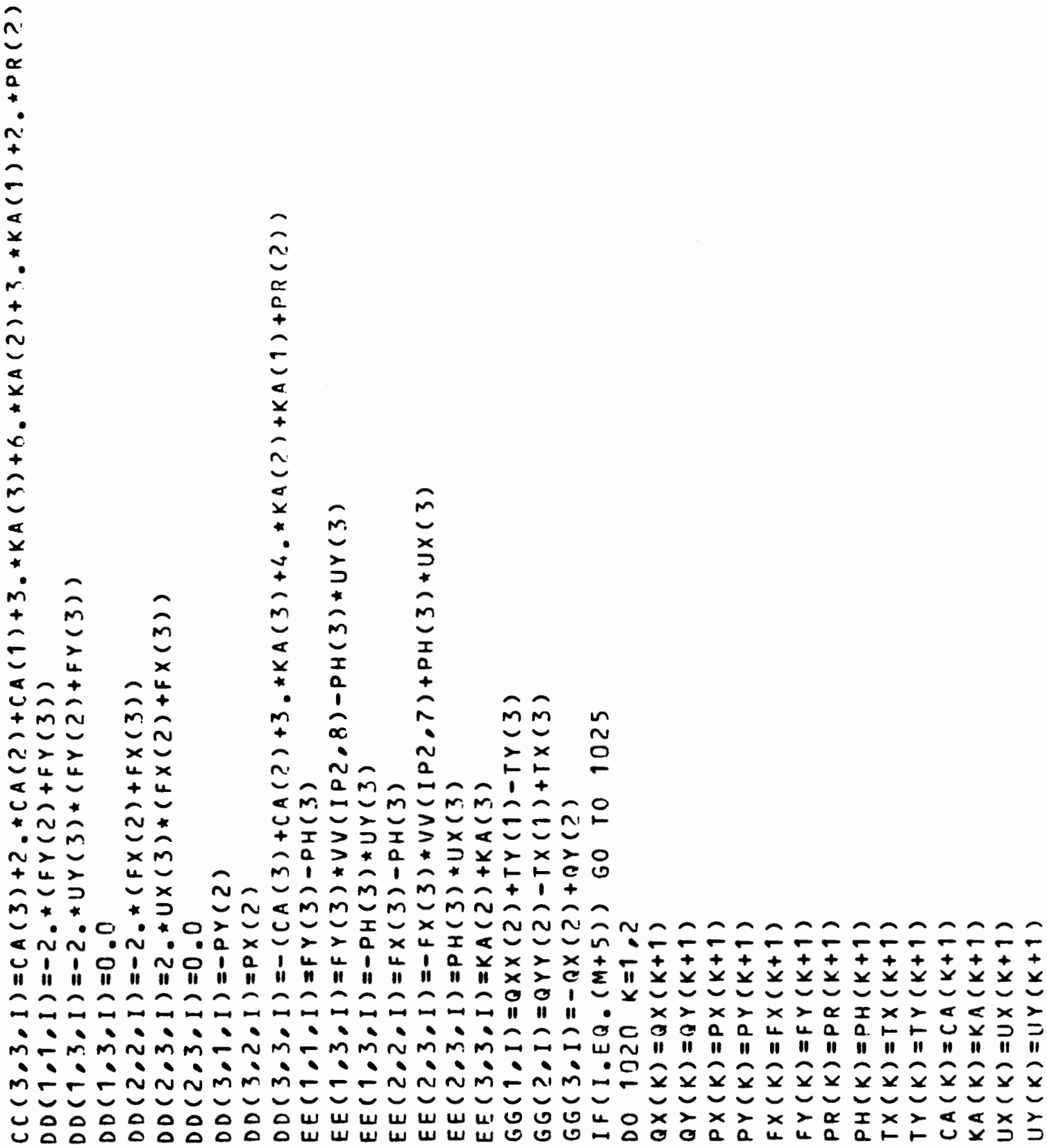

$\omega$

$\omega$

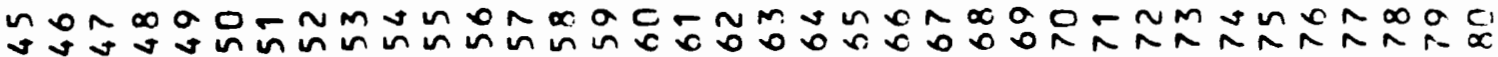



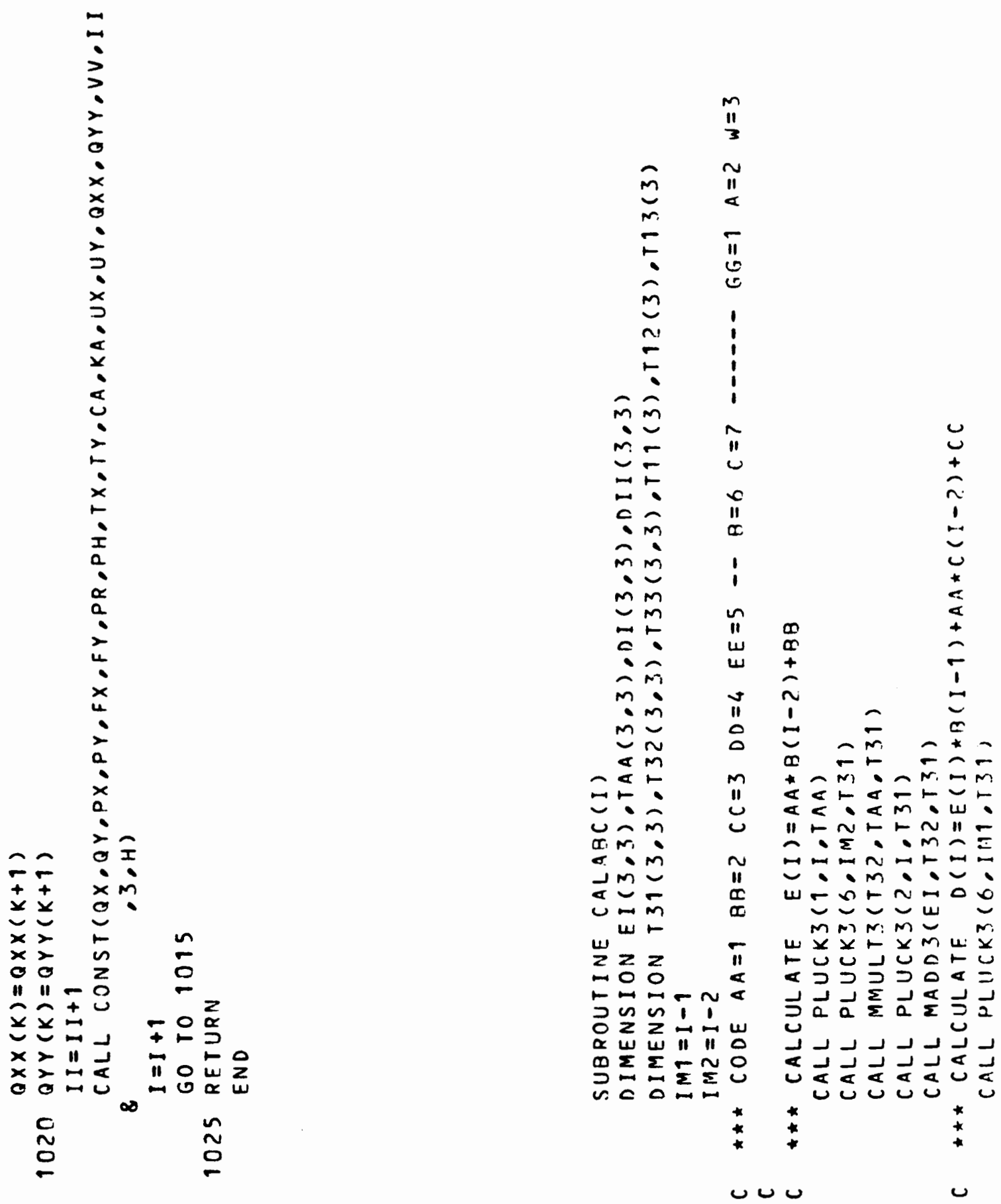


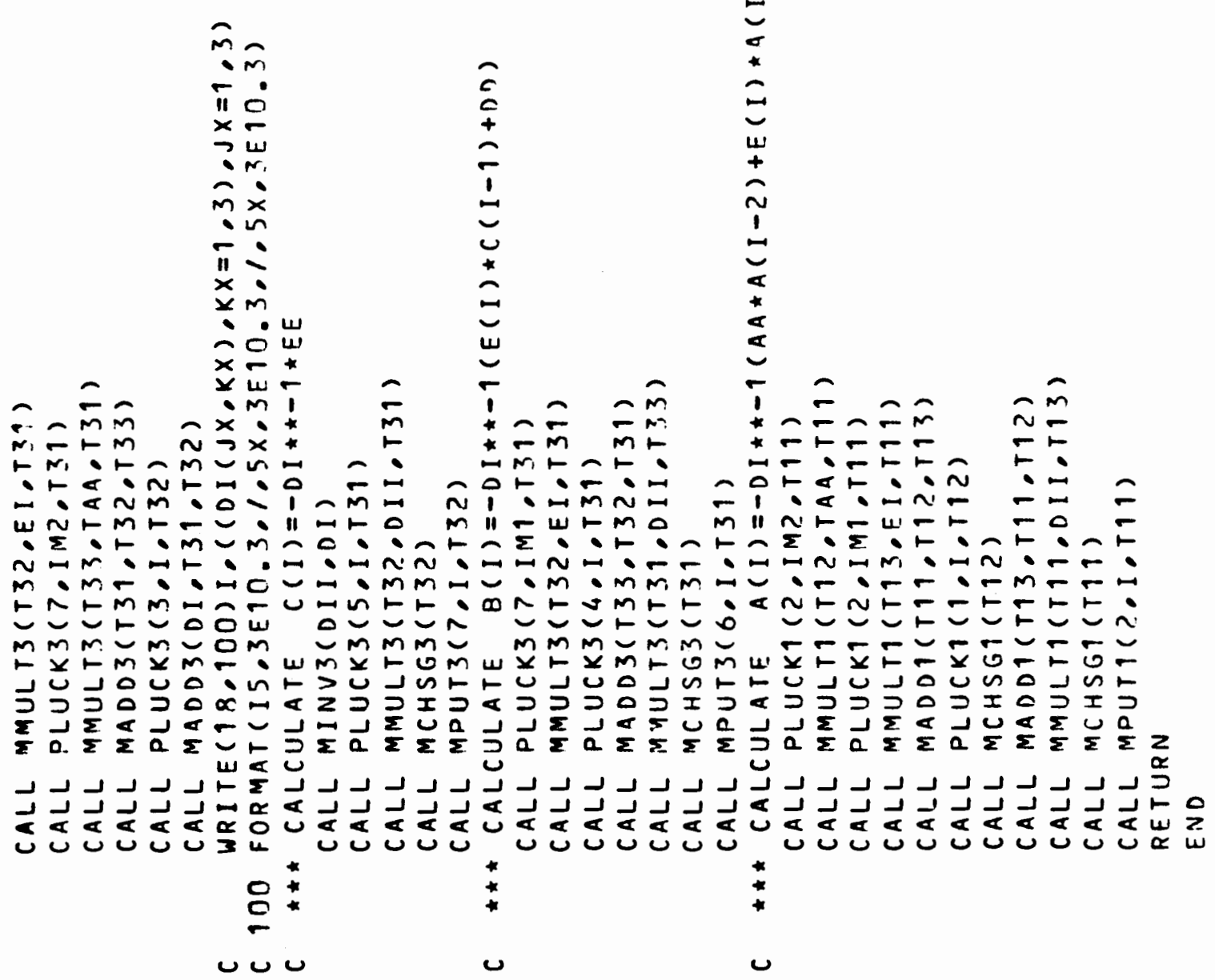

on

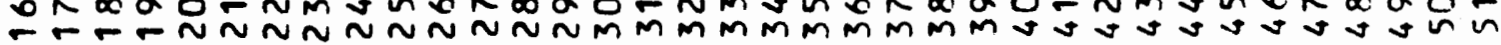




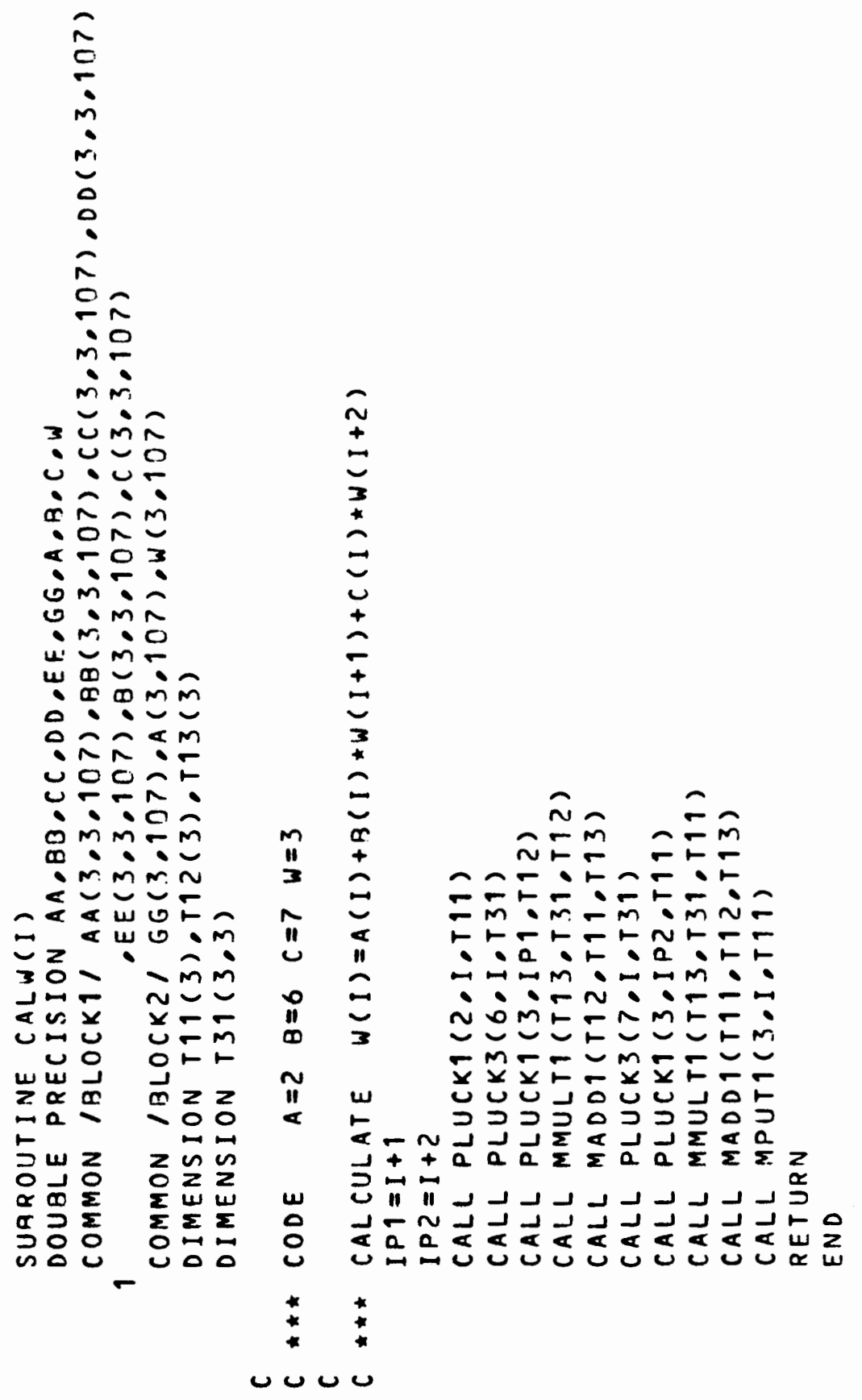




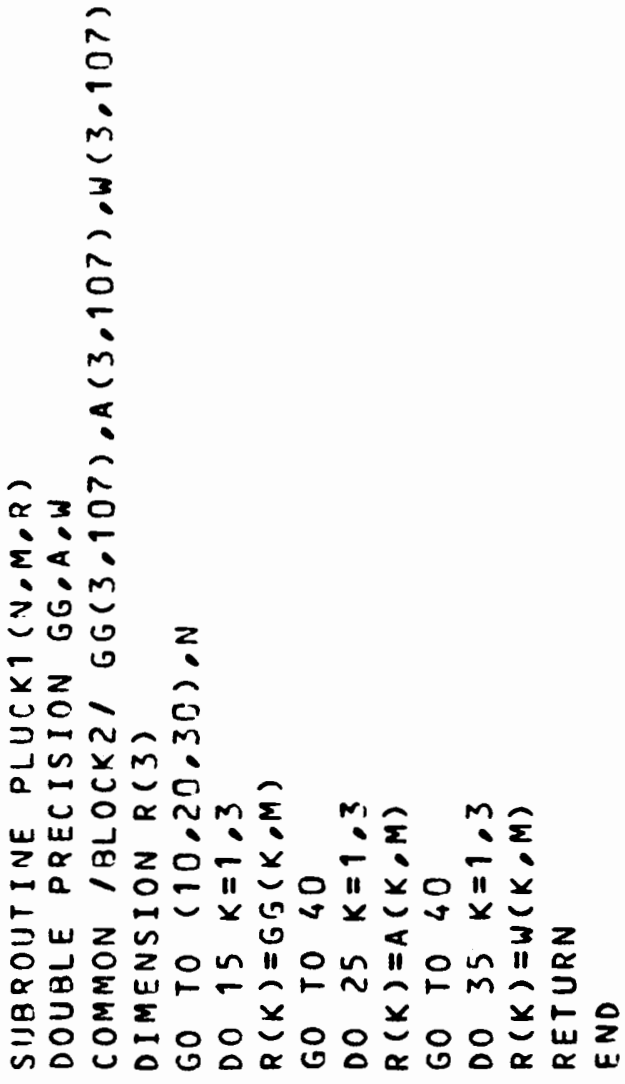

On $\ln _{n} \operatorname{con}_{\mathrm{m}}$

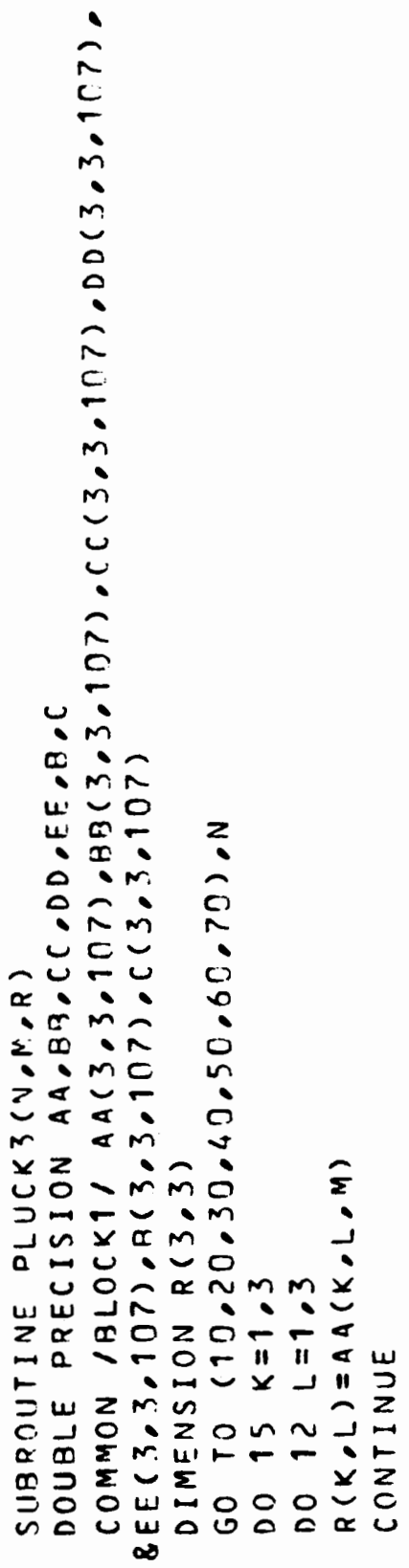

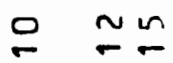

- NmS on 0 - 


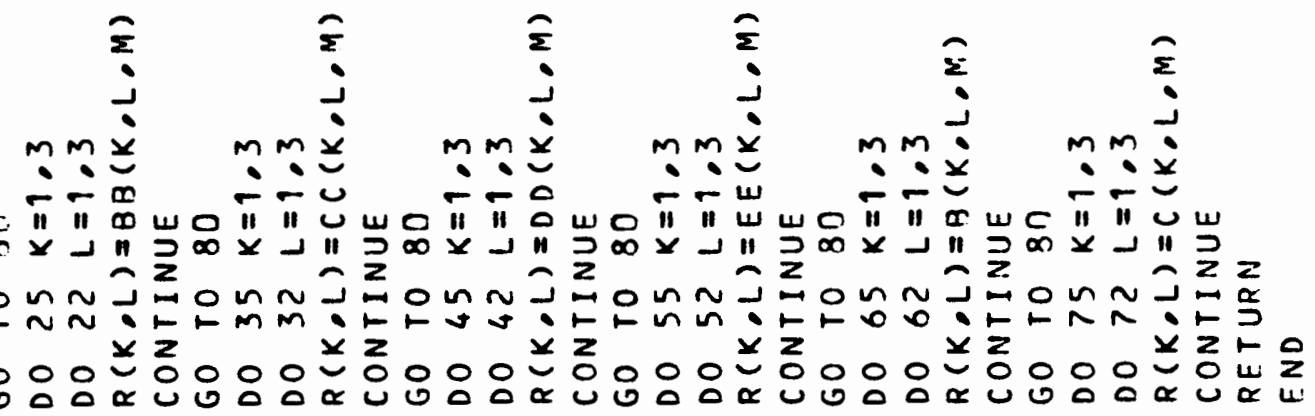

$\tilde{\sigma}$

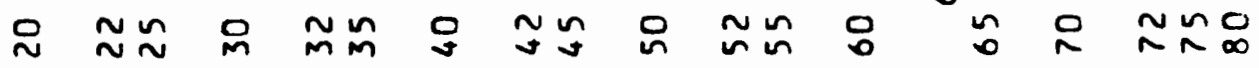




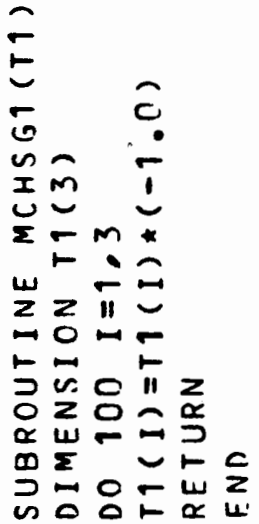

웅

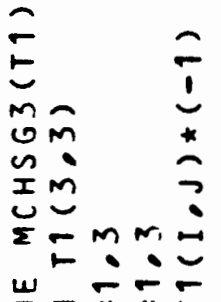

य $z=-5$

$m 0 \mapsto \rightarrow \|$ W

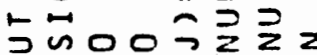

긍중으을중

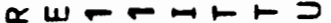

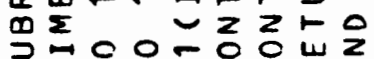

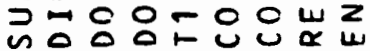

$\sigma_{-\infty} 0$ 


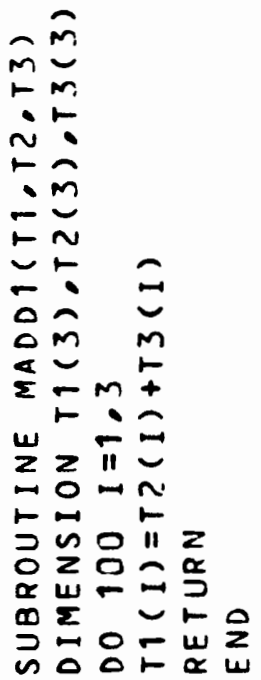

0

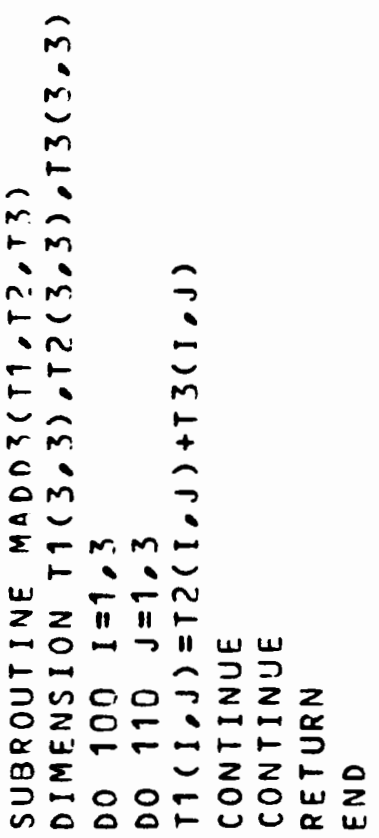

$\sigma E$
$-\sigma$ 

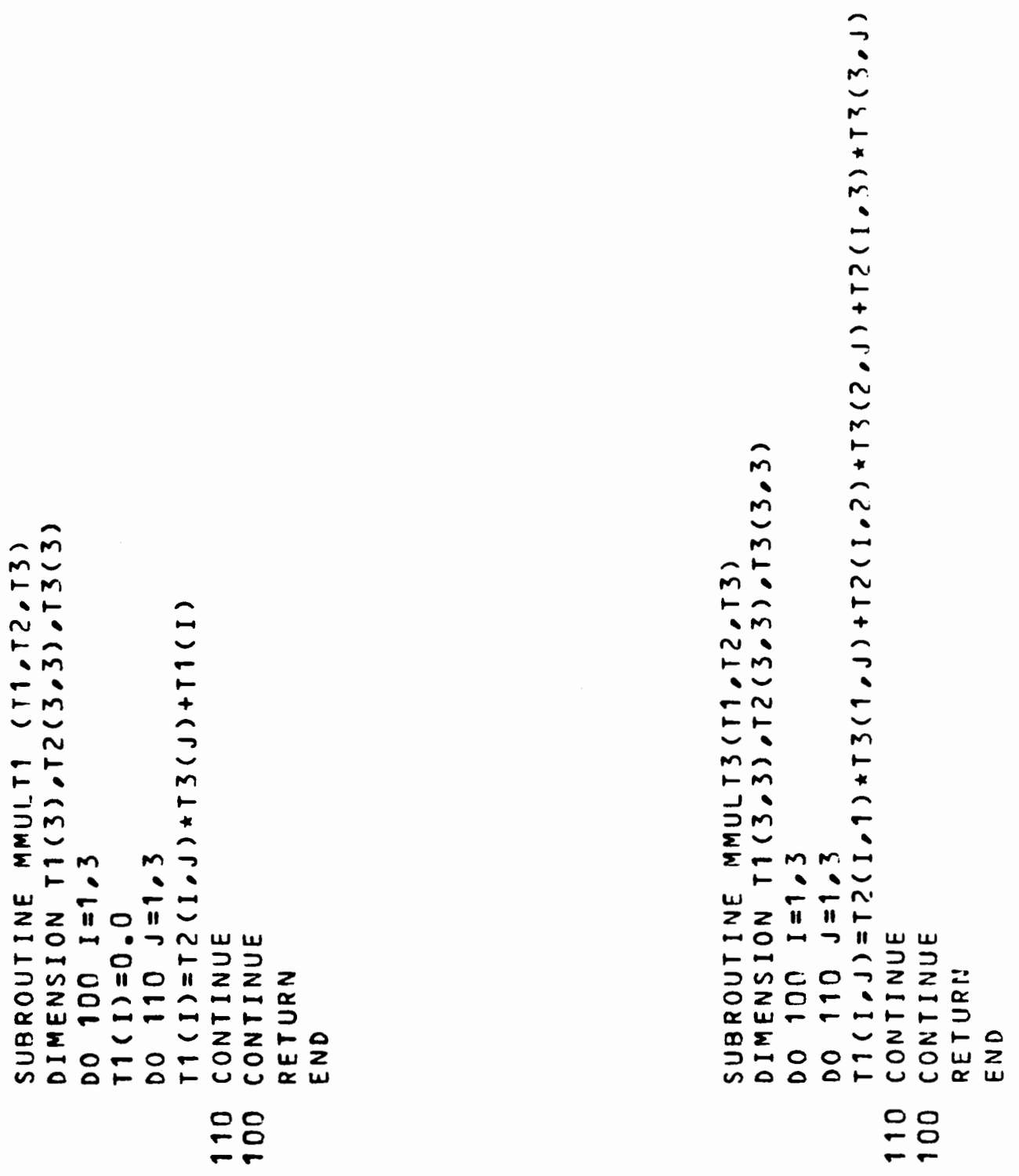


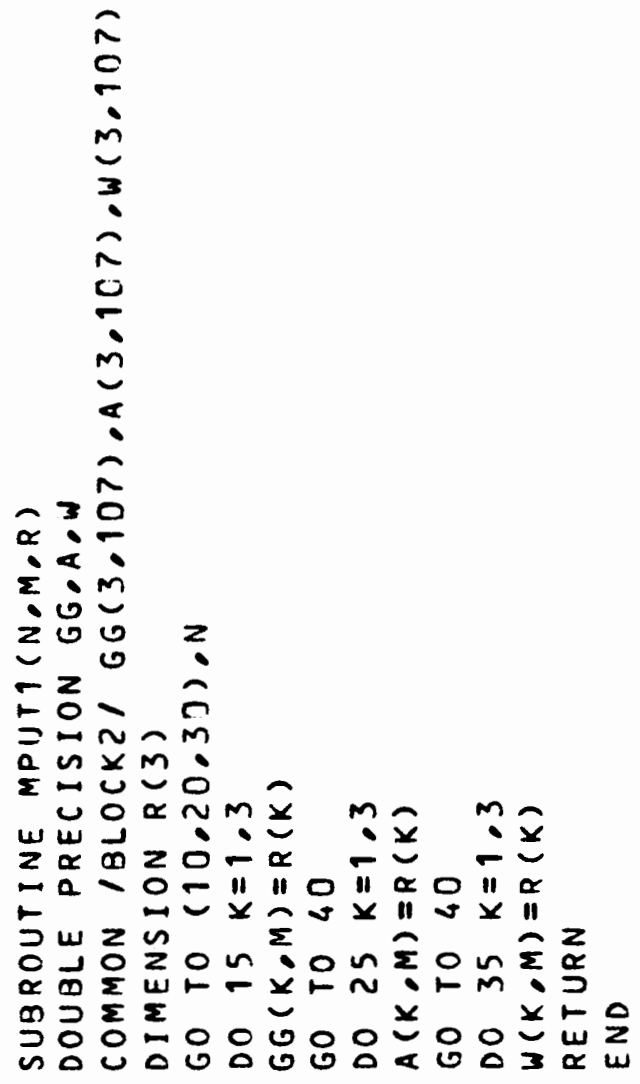

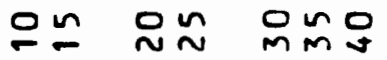




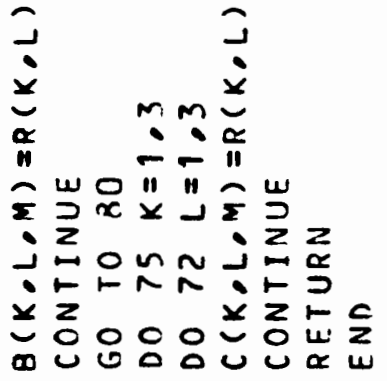

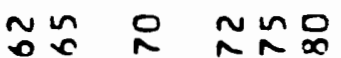

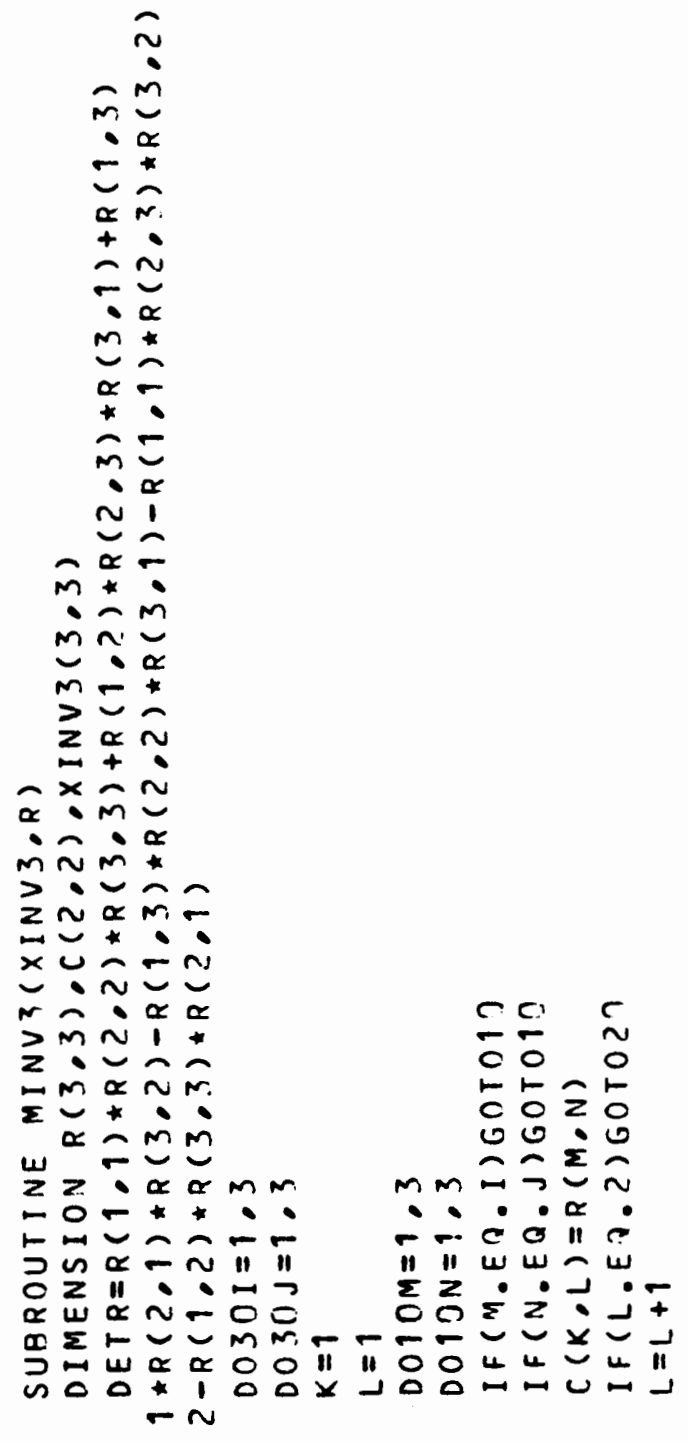


0
$\vdots$
$\vdots$
0
$\square$

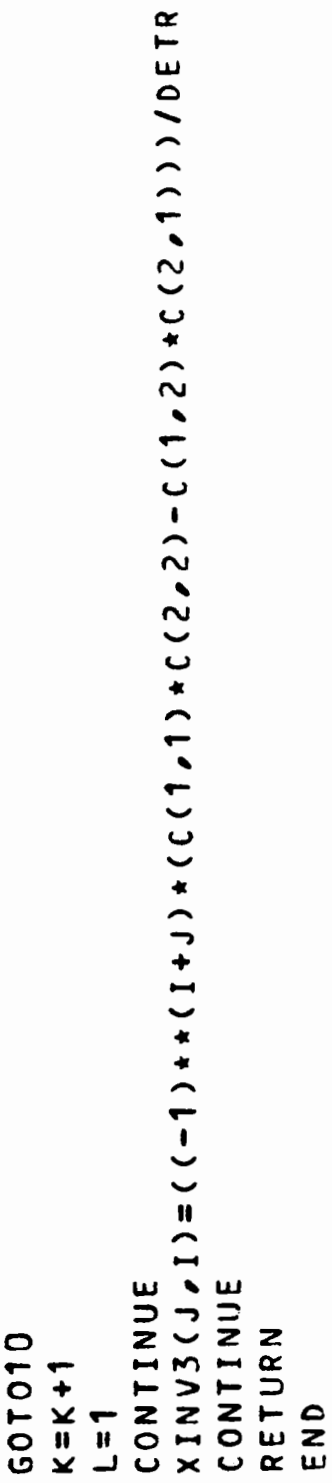

$\sum$

$=2$

$\exists=\hat{0}$

$20 \%$

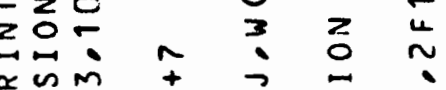

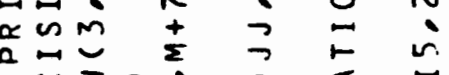

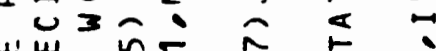

$\sum_{2}=\pi$ ก

जa 0 小

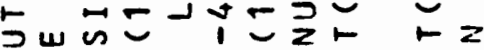

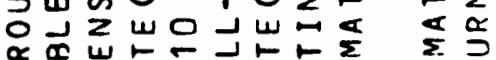

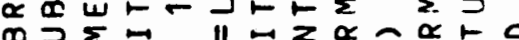

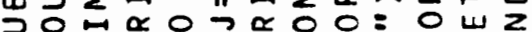

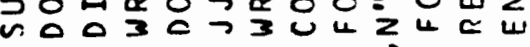

$\stackrel{ }{\sim}$ 은

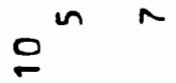


$\propto$

0

$\infty$

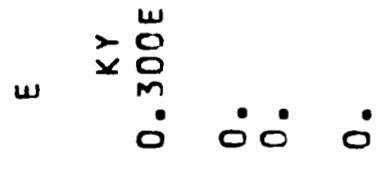

$\infty$

$\times a \times 0$

வீட்ட்

o

方芒岩

o

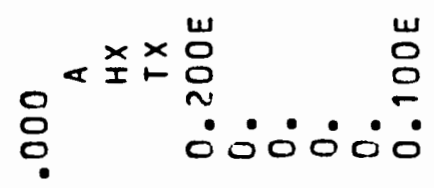

$\infty \stackrel{0}{\infty}$

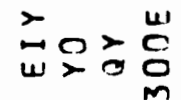

I" I "

$\propto I \quad 0$

$0 I$
$20 \times 1$
$\sim$

u

แ̌ z

$\alpha \sum$

w $\frac{1}{\alpha} \overrightarrow{0}$

$\stackrel{\infty}{\infty} \stackrel{x}{\underline{1}}$

$\infty \quad 0$

○ 0 z

ow

$\rightarrow$ 음

七こ

$\omega \rightleftarrows$

$\mathbb{4} \geq$

$w<\bullet \bullet \cdot \dot{0} \bullet$

$0 \sum 00000$

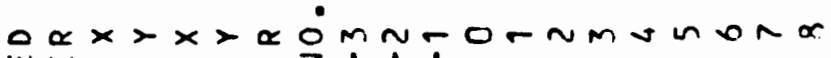
$\omega=$

$4 \quad 2$

U⿺辶一

$\frac{a}{n} n$ $\overrightarrow{0}$ $x$ 111
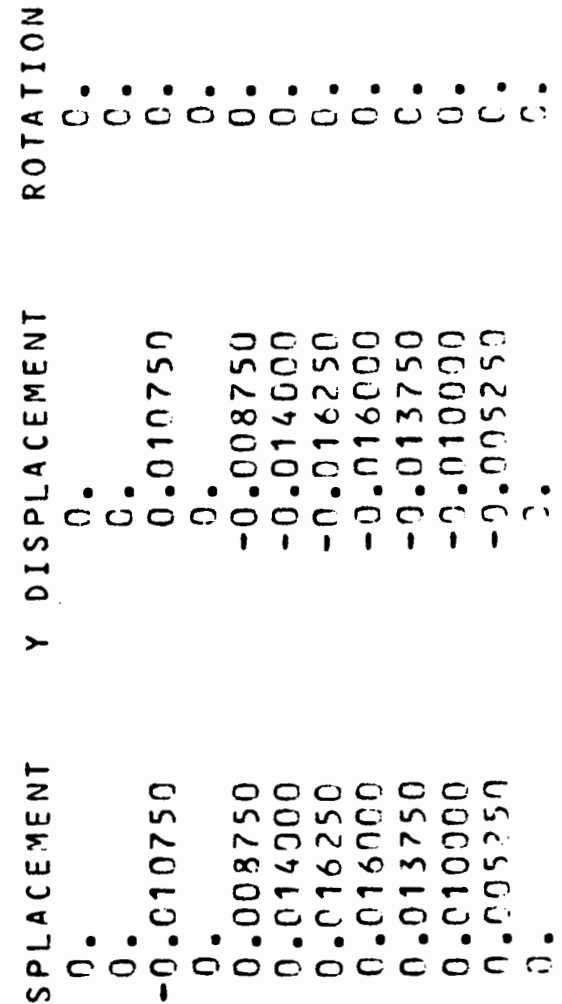
96

ச்

0
$n$
$n$
0
0
cं 00

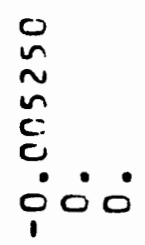

을 
$\propto$

i

气

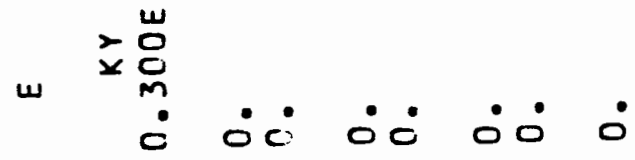

0
0
0

0
$w$
$\vdots$
0
$z$
$w$
$u$
$z$
0
$u$

$x a \stackrel{x}{x}$

:0்

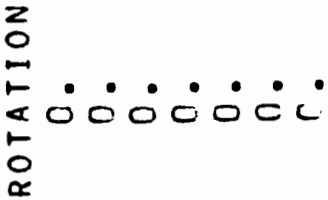

o

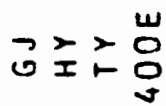

-

$\omega$

$\underset{I}{\square}$

$\tilde{0}$

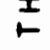

$\stackrel{I}{=}$

$0 \times \begin{array}{r}x \\ 0 \\ 0\end{array}$

ن்

$\sum_{w} m m \tilde{m}$

$\sum m M O C$

u $m$ in $\propto \alpha$

$\leq .0 .0 \%$

a is

$\vec{a}$

$>$

is

2

$\because 0$

$\cup \vdash$

w

$\stackrel{2}{2}$

บ

$\infty$

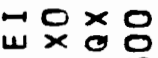

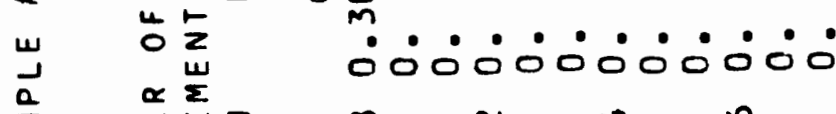

m

山区ن:

$\triangle \sum 0000$

$\underset{\omega}{\omega} \underset{\alpha}{\alpha}$

$\infty \sim \sim 0$

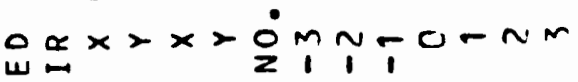

$$
\infty
$$

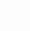

$\ddot{\infty}$

$\ddot{\omega} \propto 00 \infty \times \stackrel{i}{i}$

$$
\leftarrow \infty N+0
$$

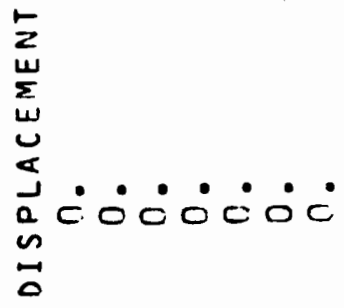

$x$

2 
¿ல்வல்ல்ல

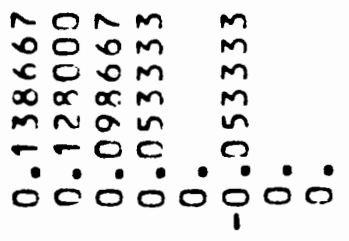

ல்0ல்00்

In on a o 
$\alpha$

$$
\begin{array}{rr}
m & 0 \\
0 \\
1 \\
\times & 0 \\
0 & 0 \\
0 & 0
\end{array}
$$

$$
x a \stackrel{x}{x}
$$

:0்

0

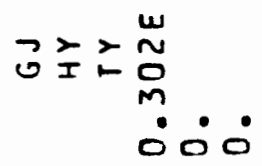

n

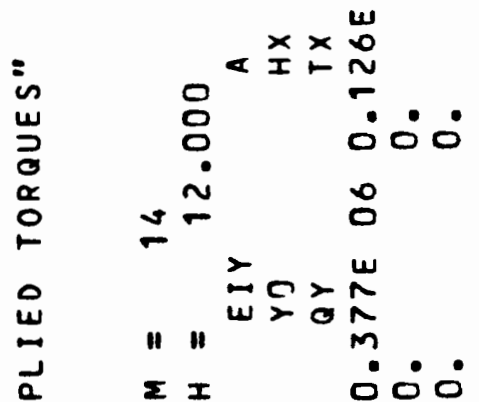

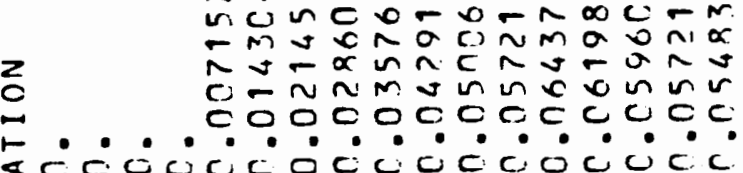

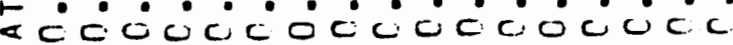
$\stackrel{1}{\circ}$

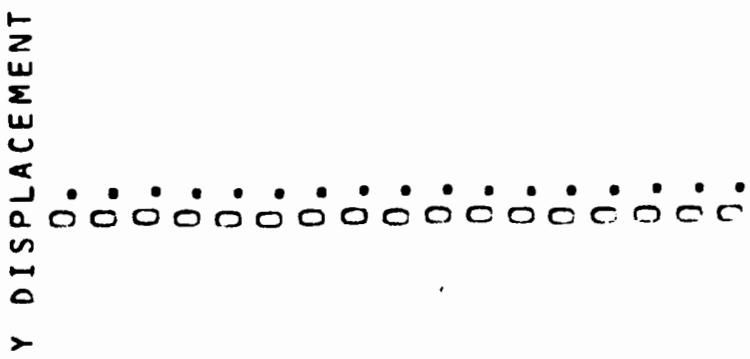

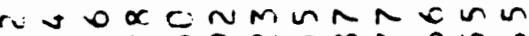
$m$ o a $\sim \sim a n$ in $x \sim 0$ n

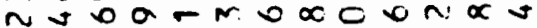
m $0-\infty-N \infty \omega-M$

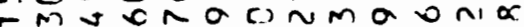

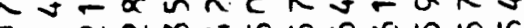
conmunun

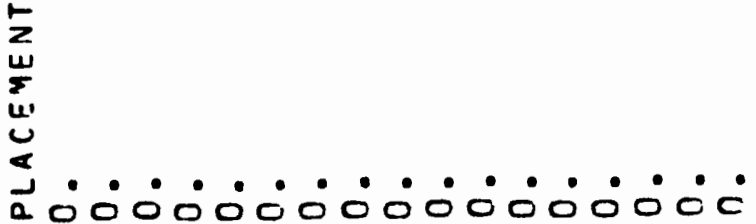

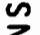

2

눙

픈

$U \Vdash$

$w \because$

는

$\omega \div$

w

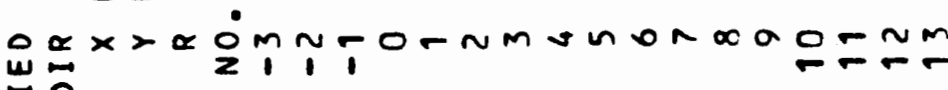

"药 000 :

a

$\infty$

ino000000000000000

$\stackrel{\circ}{\circ}$ 
$\vec{m}$

$m m$

c) 0

ป

$\sim \sim$

n

$c c$

c: 00

$\therefore \circ \dot{0}$

$\dot{0000}$

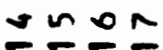




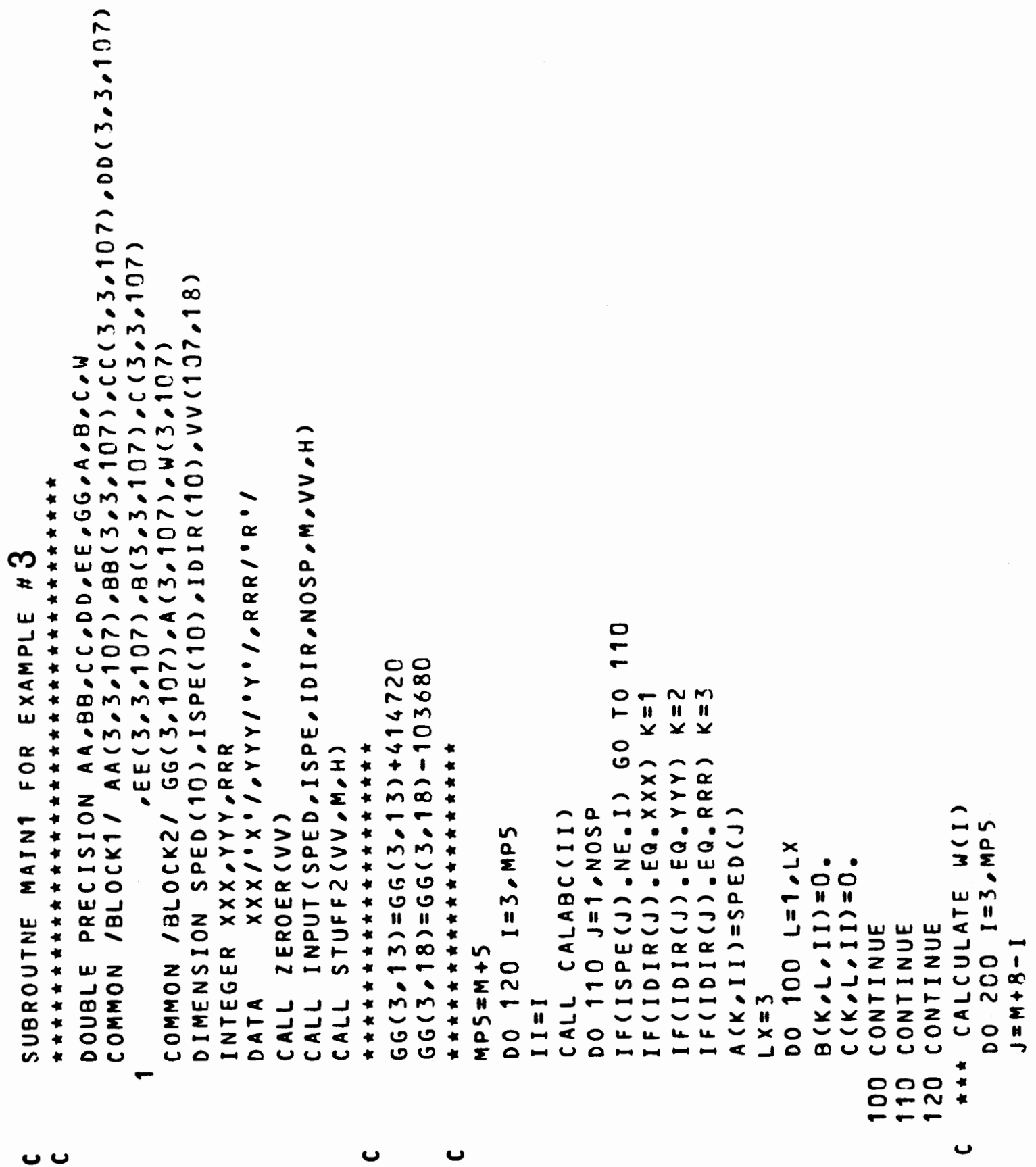




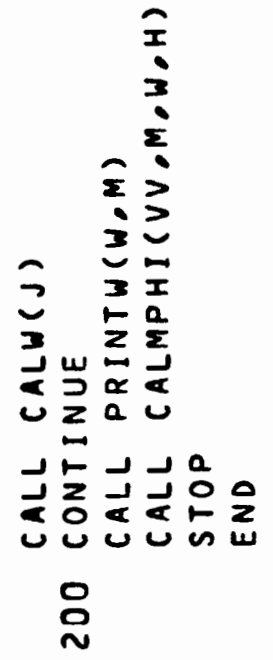


$\stackrel{-}{n}$

$=$
n
$x$
$\alpha$
$\times$
5
7
0
0
0

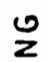

$\vec{z}$

$\varliminf_{\infty}^{0}$

$\frac{a}{a}$

w

!

$\because$

$\pm$

u

$a$
$a$
$a$
$x$
$x$

$\alpha$

i c

c

$>\stackrel{\omega}{\circ}$

$w$

i

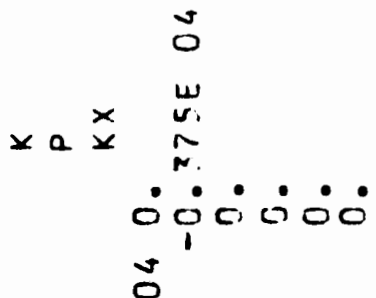

$\vec{G} \geq>0$

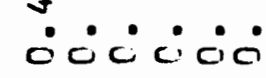

ก

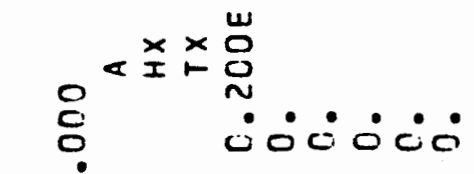

$\infty$

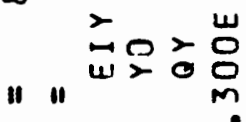

$\stackrel{\infty}{0}$

음

$\Sigma I$

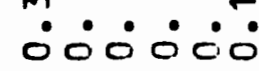

$\underset{0}{0} \quad \infty$

$25 \times$

$\sim-10 \times 0$

"ᄂ $2^{m \times 0}$

W

$\propto \sum$

$\omega \underset{\alpha}{\omega}$

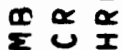

$\sum_{2} \sum^{1}$

$\stackrel{\square}{\infty}$

$$
\text { " }
$$$$
\text { வ000. }
$$

0

$0 \quad 0$ $\sum_{0}^{n}$

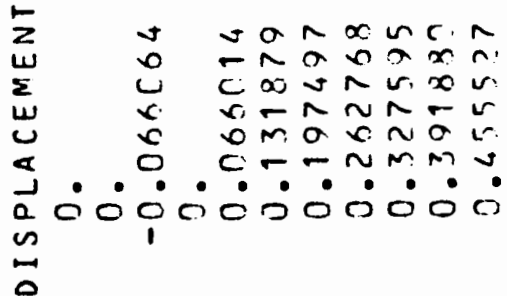

Ł

o

$\Xi \subseteq$

EE

$w=$

$+2$

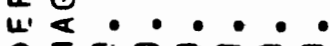

- Ico0000

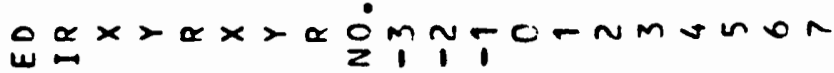
$w \underset{0}{\omega}$

$\stackrel{m}{U} \propto 000000 \stackrel{2}{1}$

岁占

n

$\boldsymbol{n}$
$>$

w

$\Sigma$

U

a $\dot{0} \dot{0} \dot{0} \dot{0} \dot{0} \dot{0} \dot{0} \dot{0}$ is
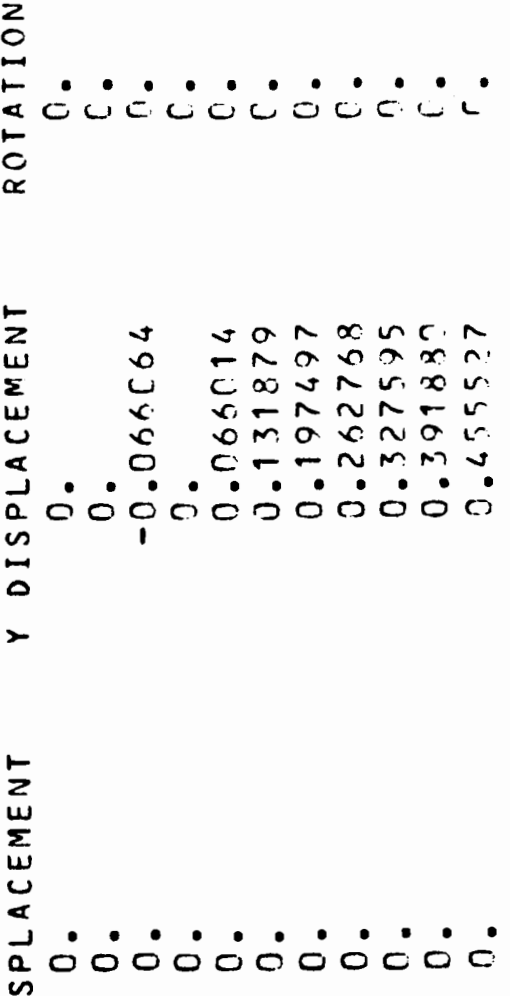


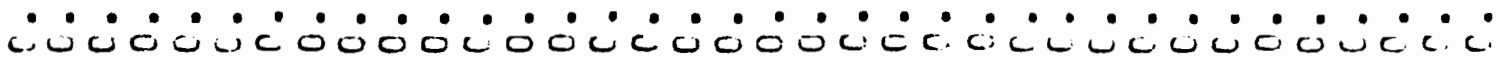

am $\mathrm{m}$ M m N V M O

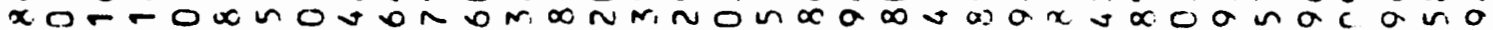

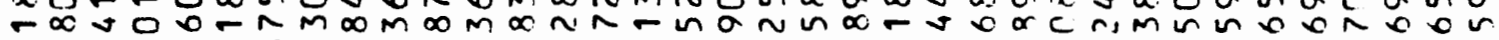

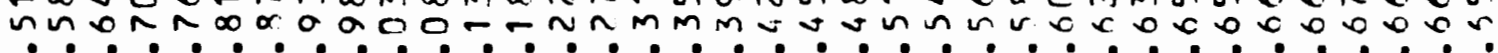

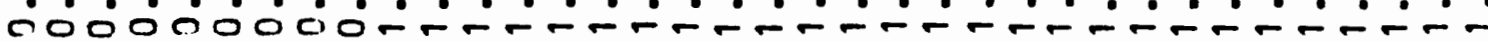

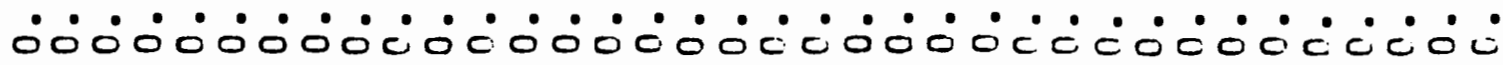

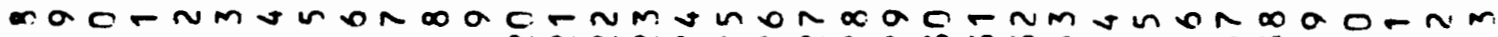

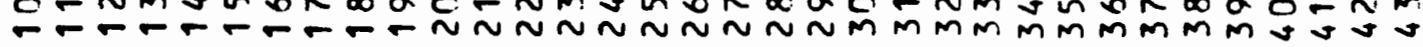




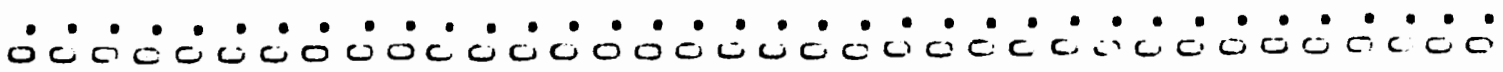

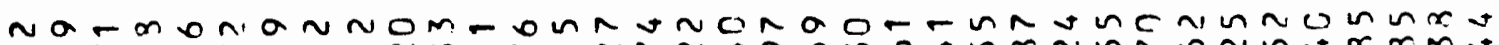

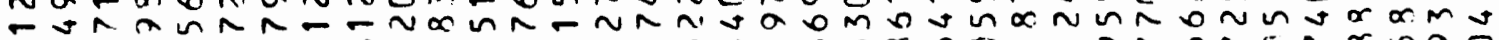

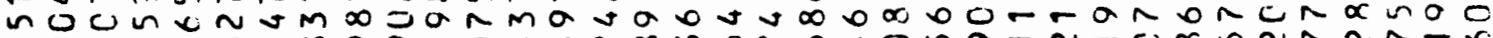

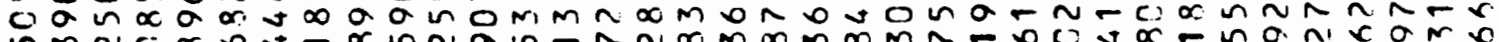

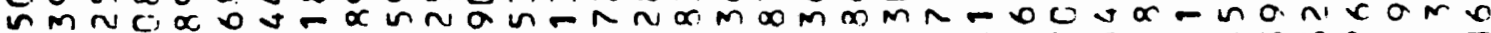
$\because 0$ ?

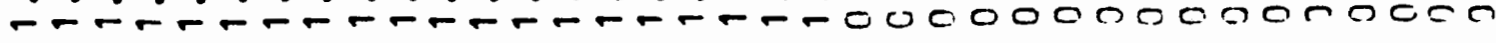

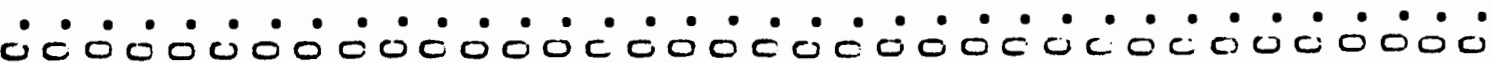

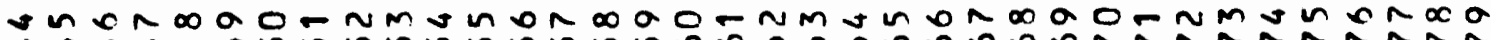

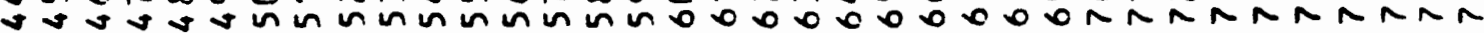


$\dot{0} \dot{0} \dot{0}$

$m$
$a$
0
0
0
0
000

$\dot{0} \dot{0} 0$

요 $\approx \sim \infty$ 


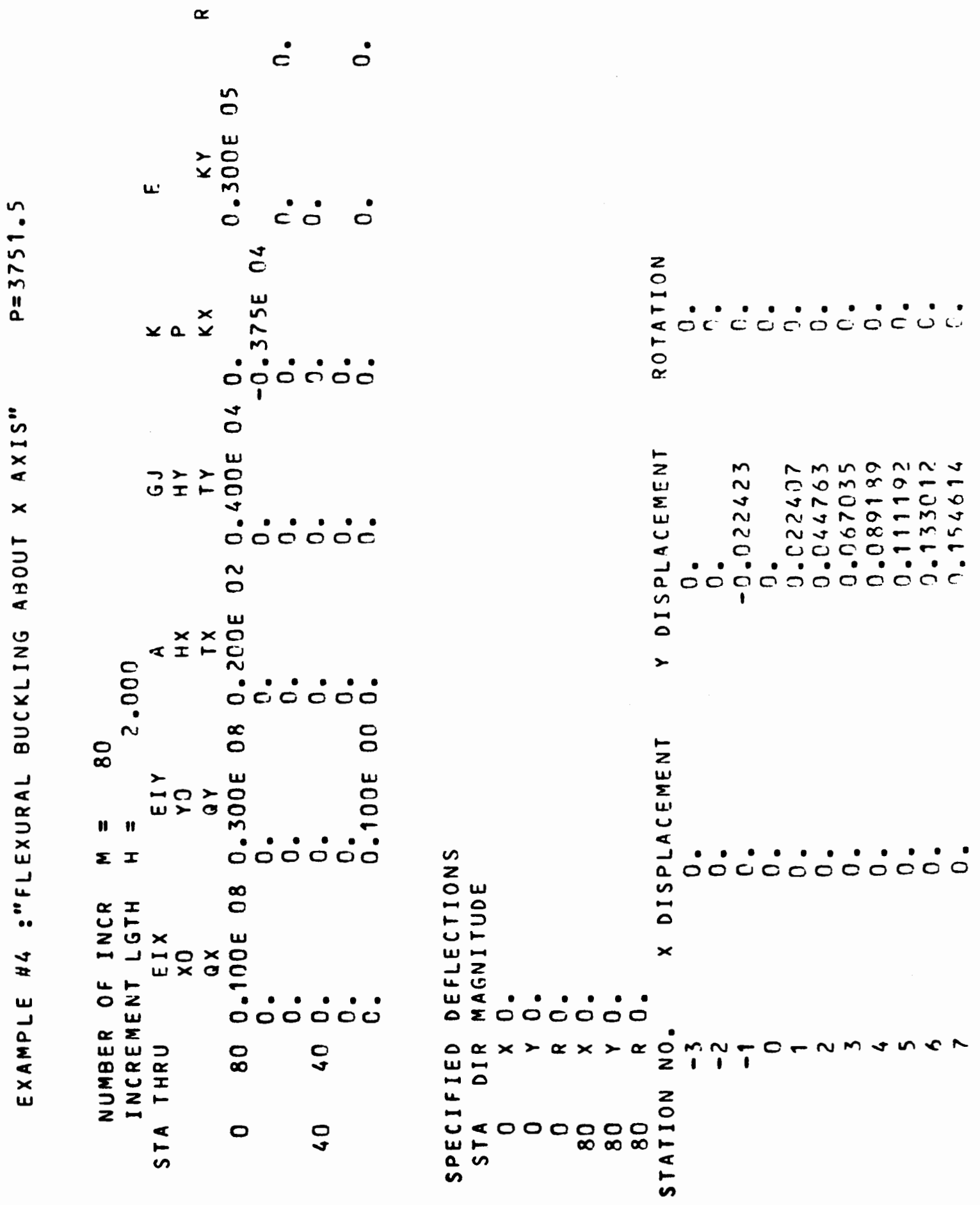


ن́ட்

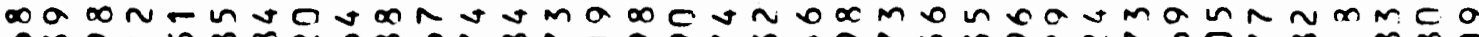

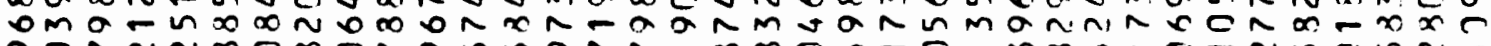

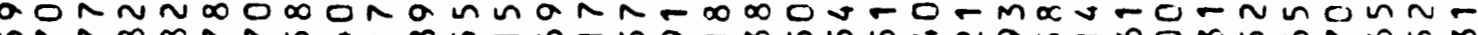

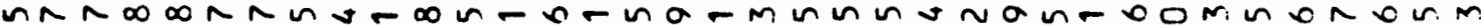

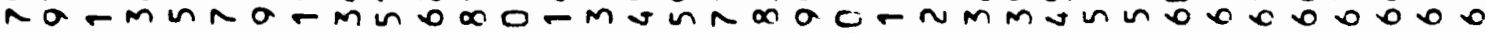

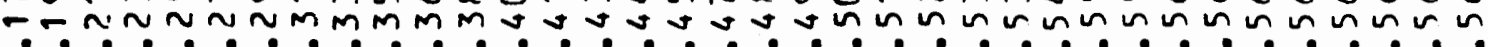

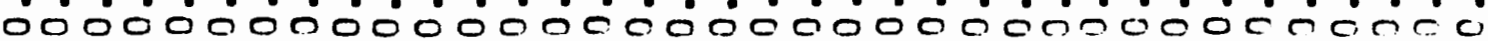

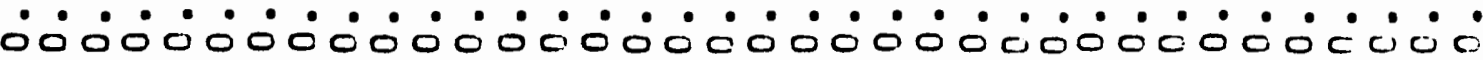

- a ornms n on

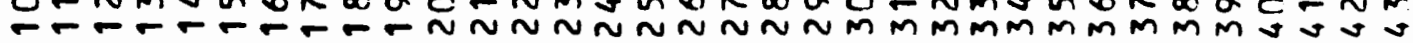




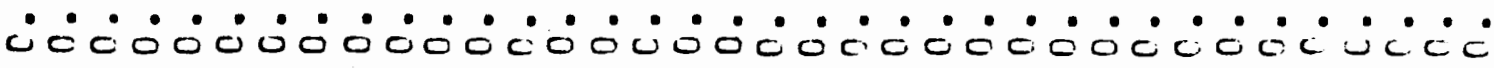

ma o m N NAmm O J D

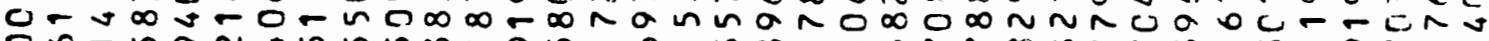

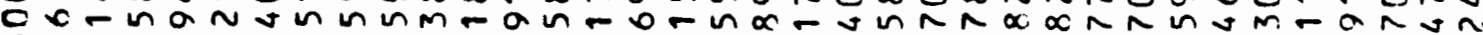

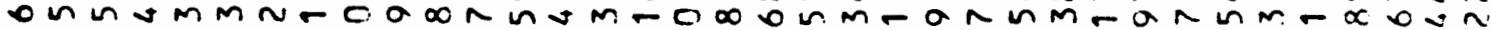

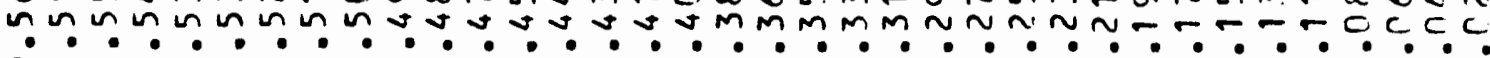

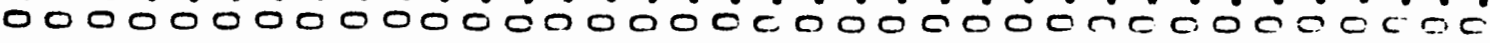

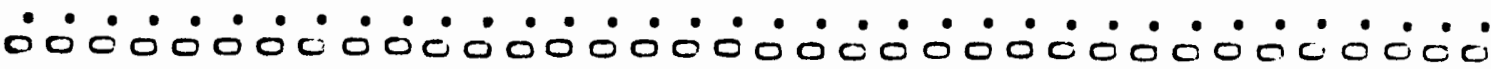

- n

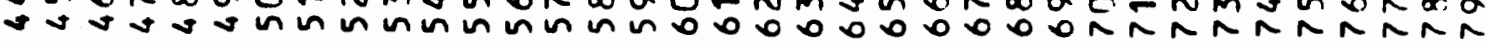


$\therefore \circ \dot{0}$

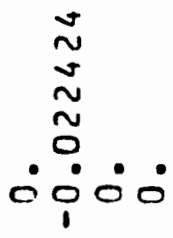

$\therefore \circ 0^{\circ}$

${ }_{0}=\tilde{\infty}$ 


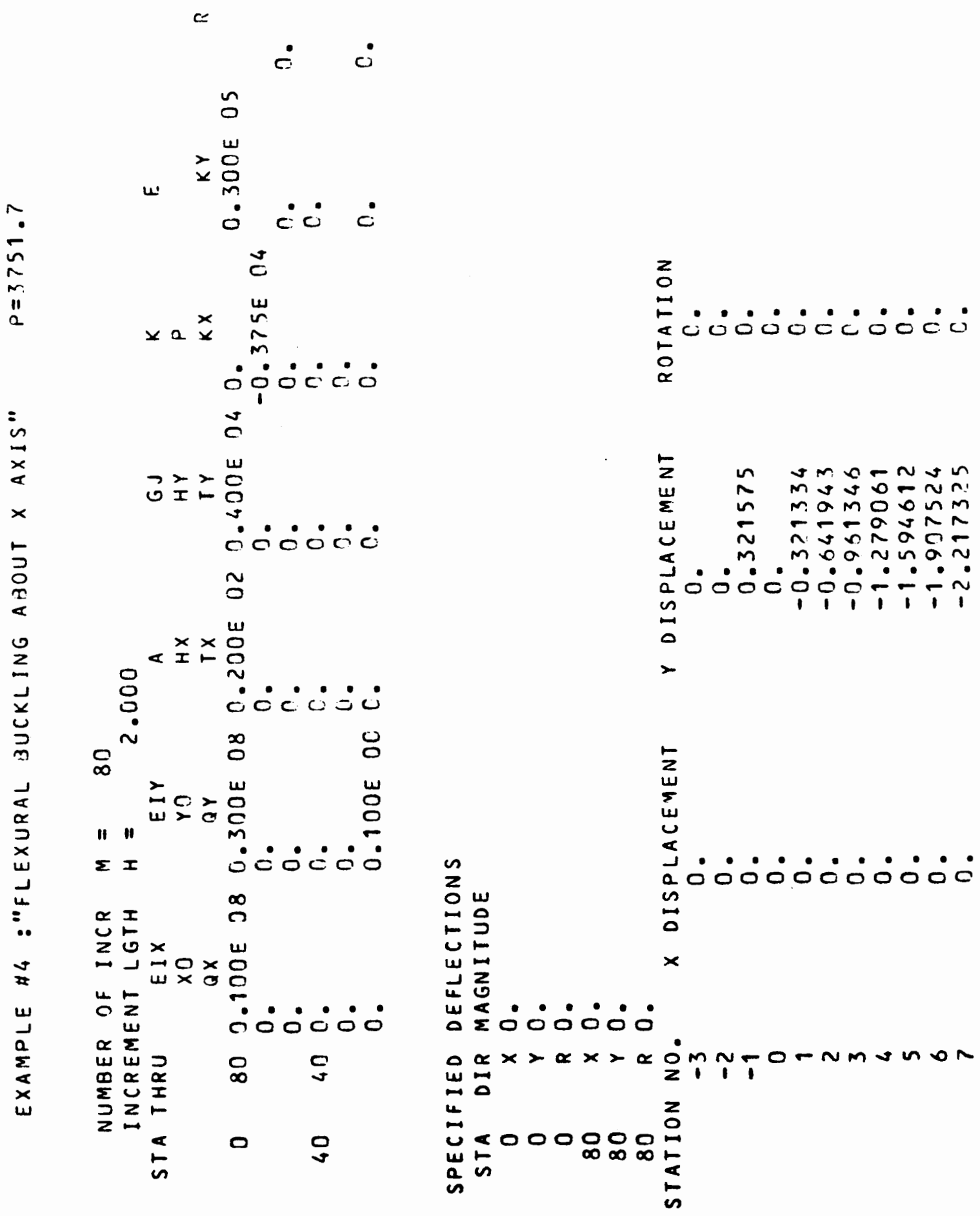


:

- Ca - no- 0 -

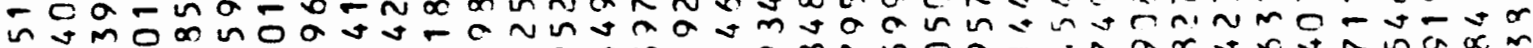

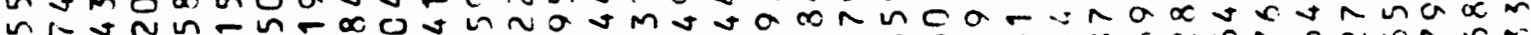

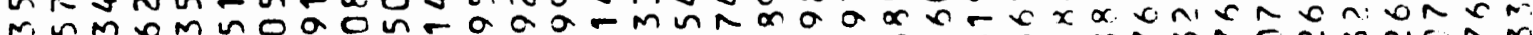

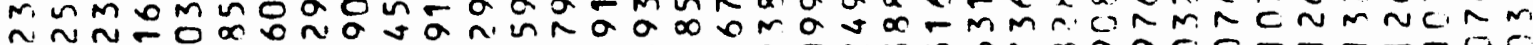

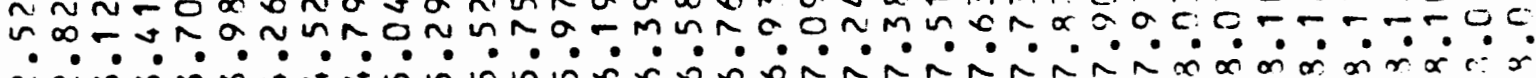

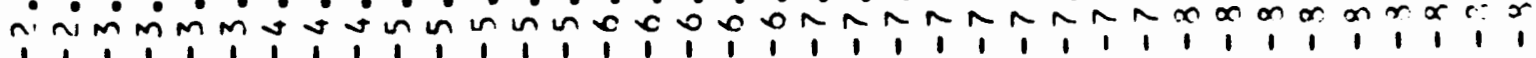

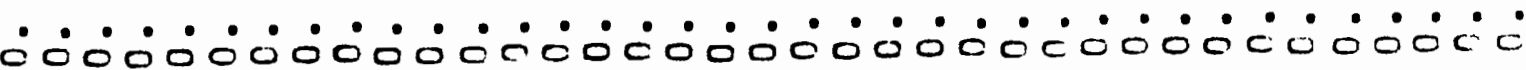
жа 


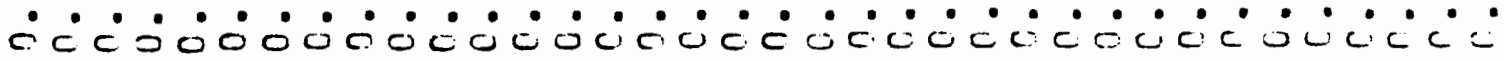

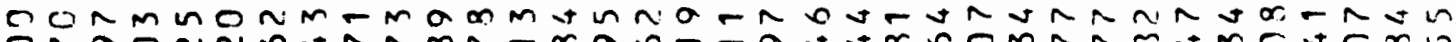
s. bumn-manm

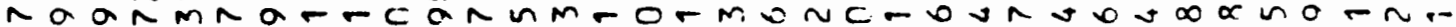

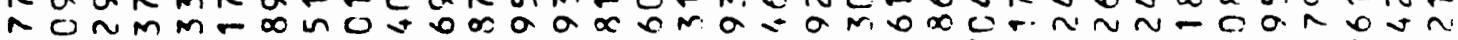

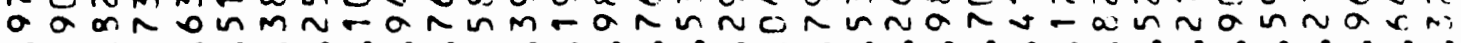

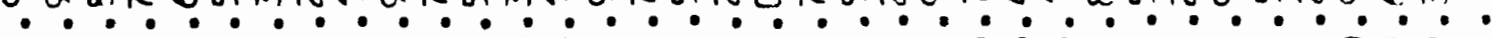

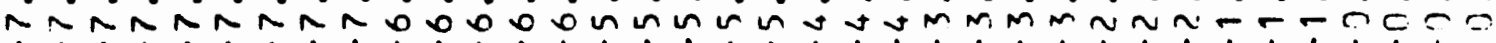

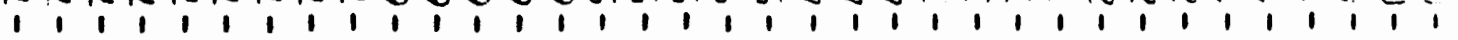

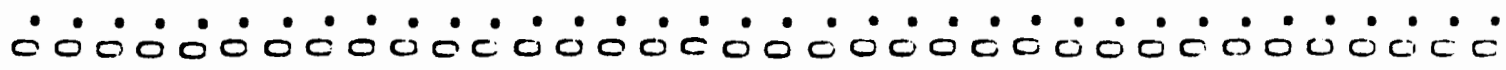

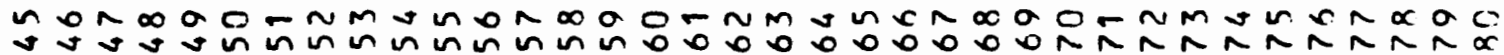


$\dot{0} \dot{c}$

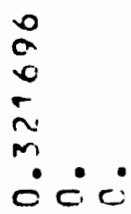

ن்

$\bar{\infty} \aleph^{m}$ 


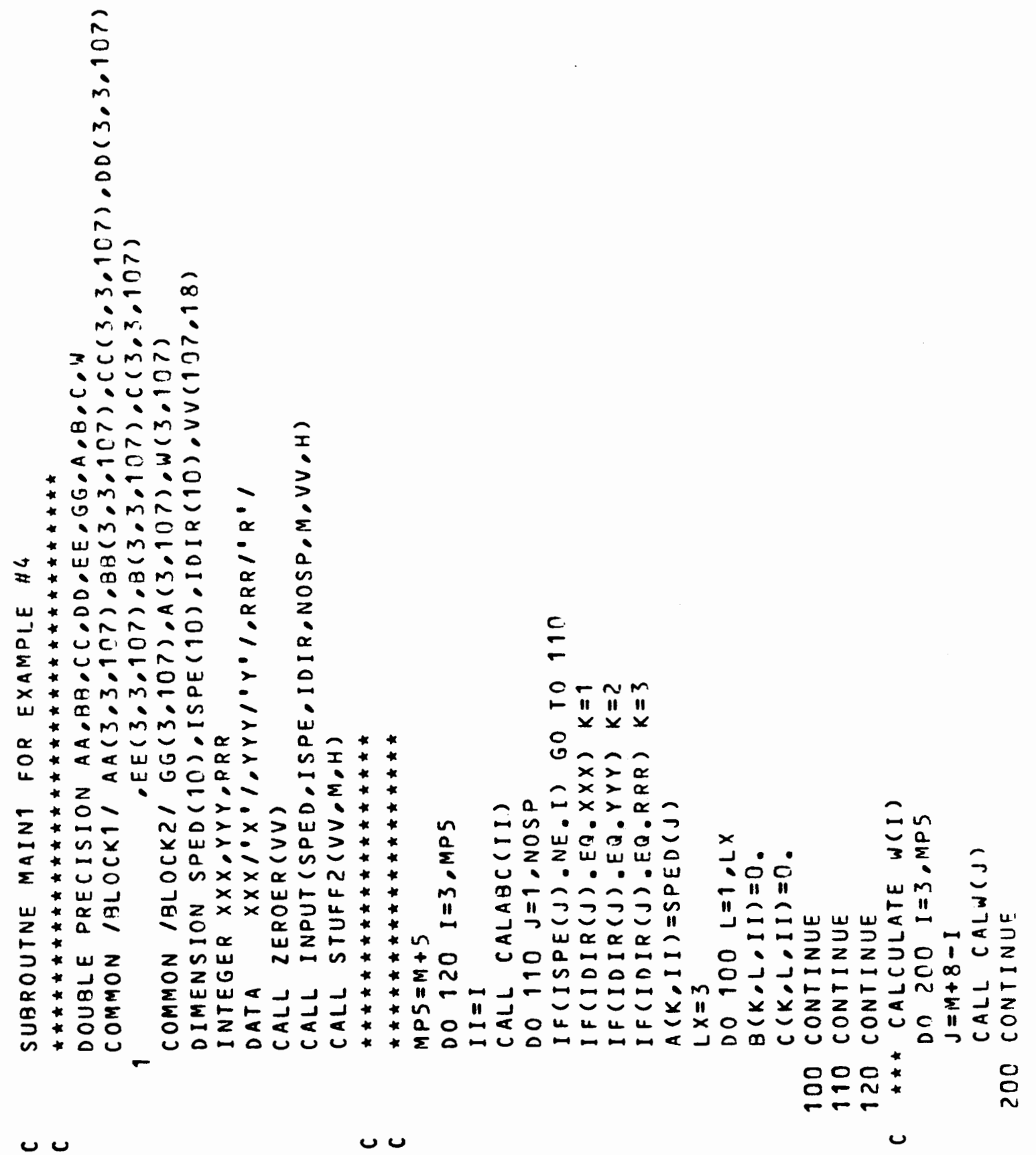


$\alpha$

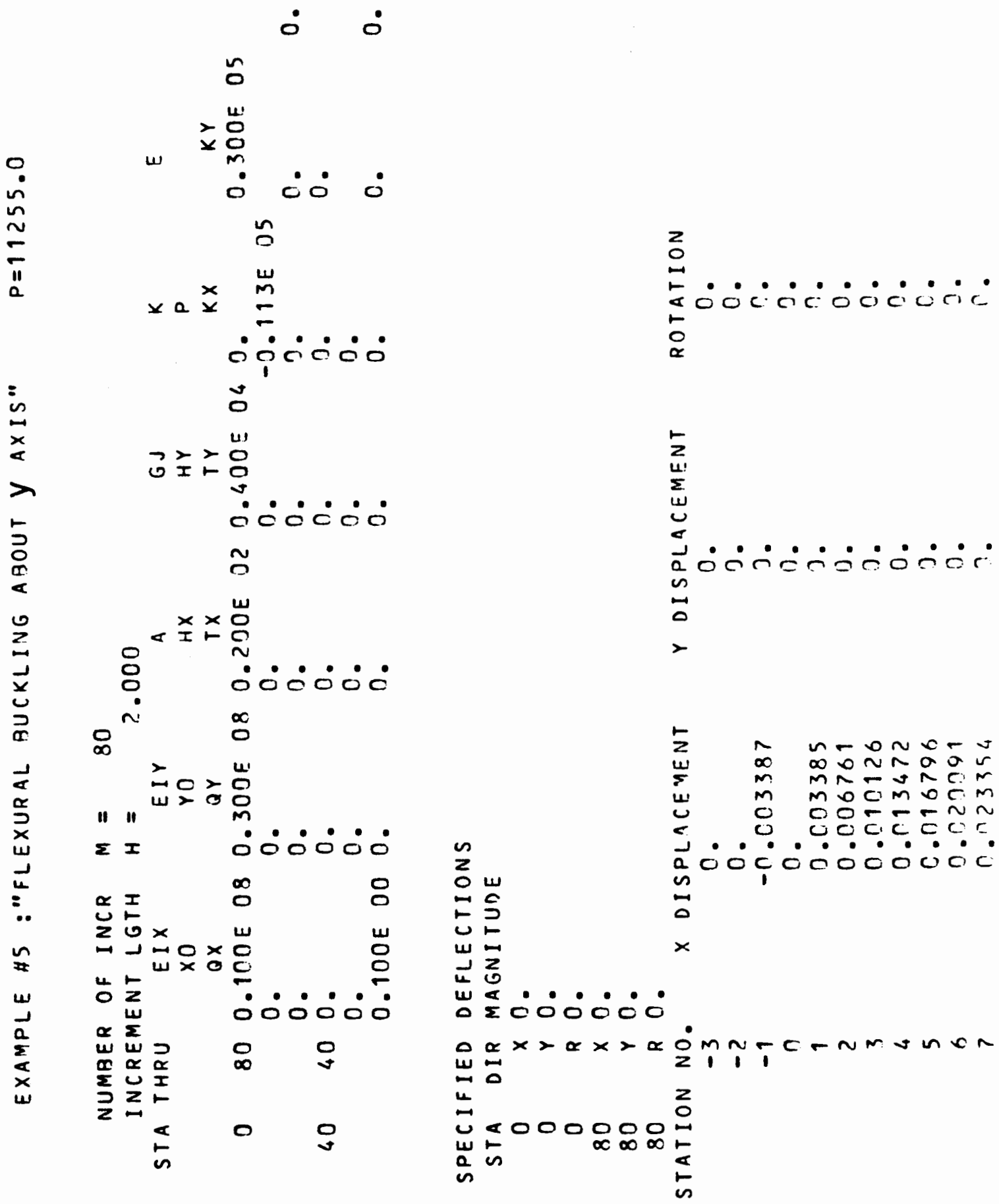




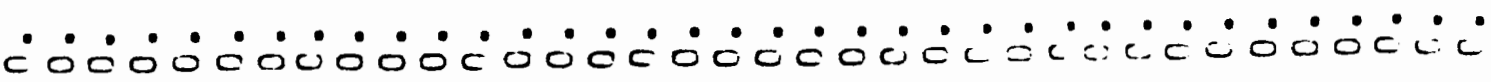

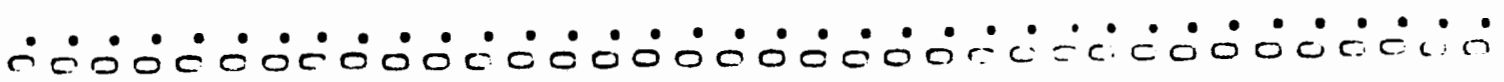

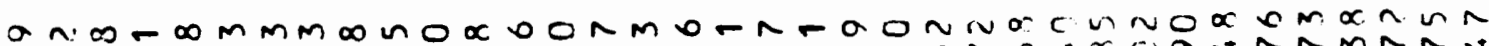

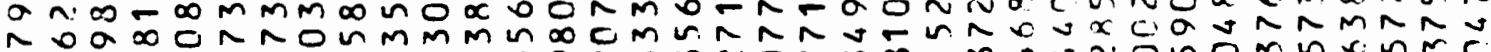

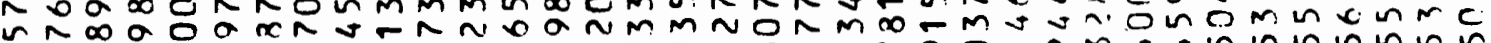

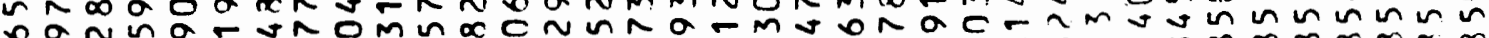

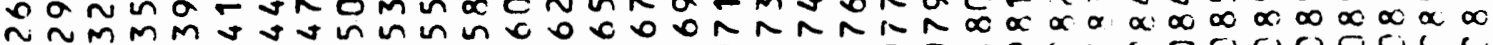
J :

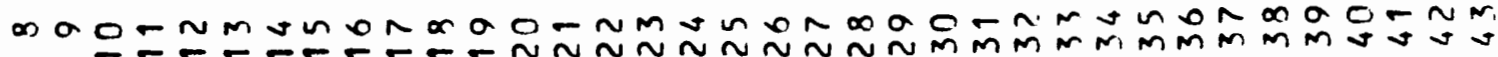




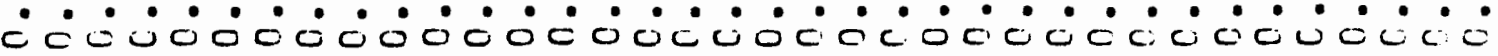

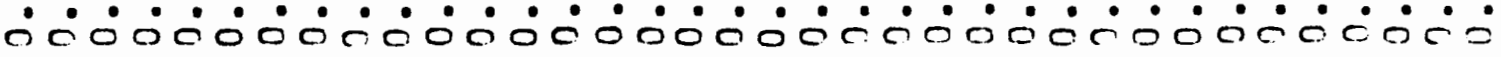

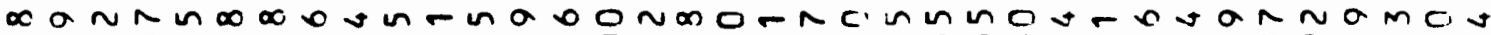

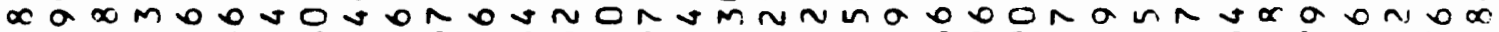

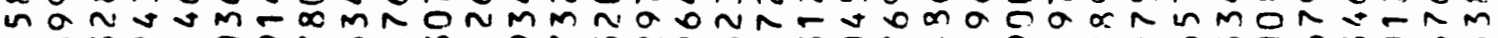

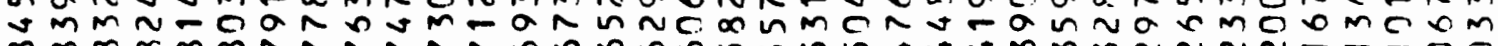

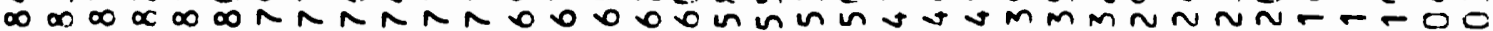

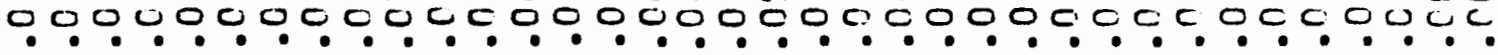

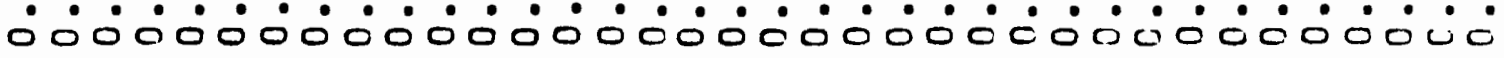

J m

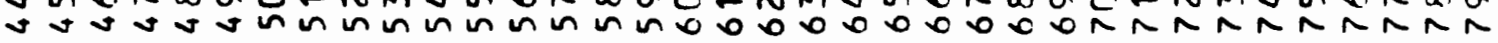


نं

هัல்

0
0
$m$
$m$
0
0
00
$i$

$\stackrel{\infty}{\infty} \underset{\infty}{\sim}$ 
$\propto$

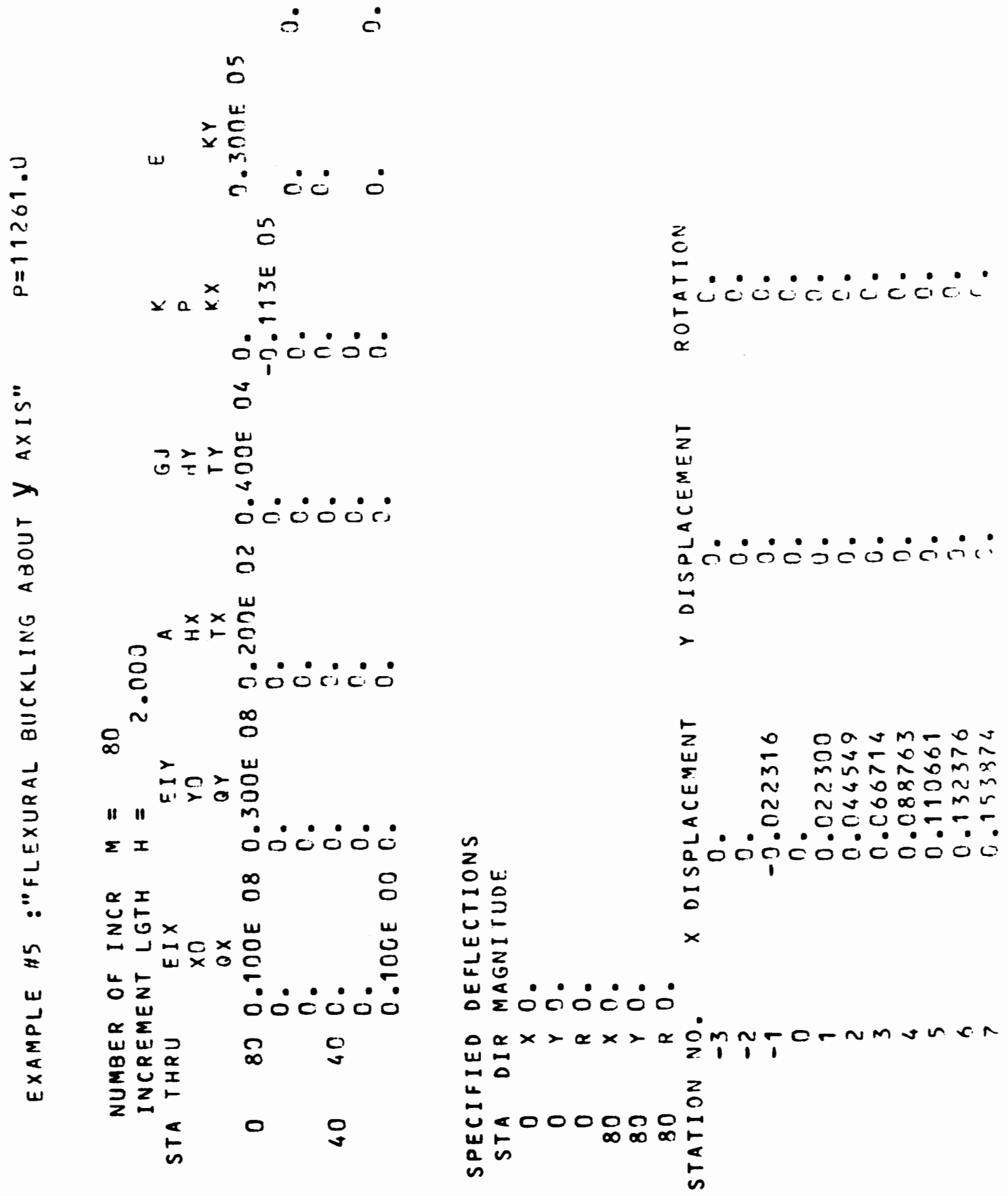




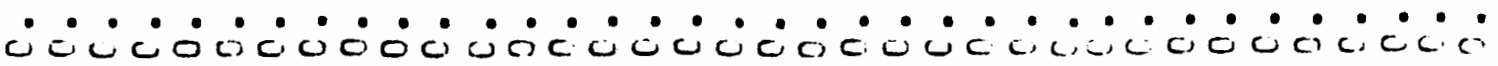

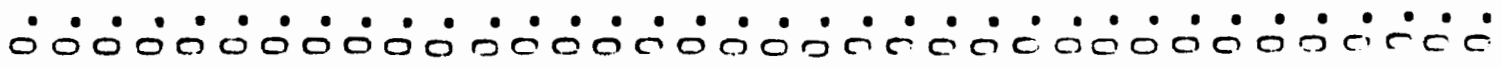

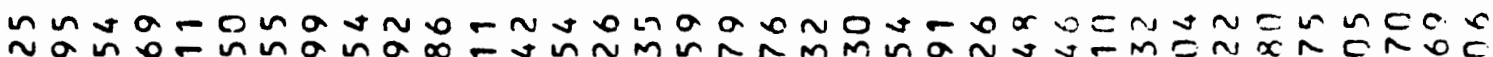

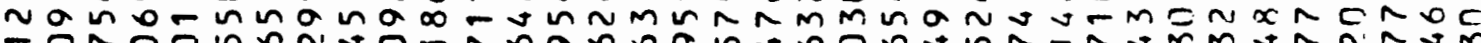

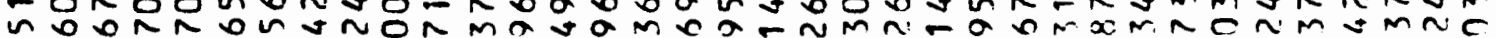

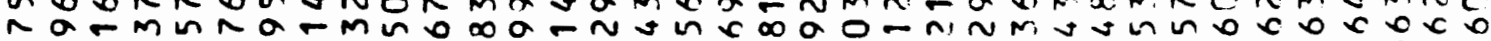

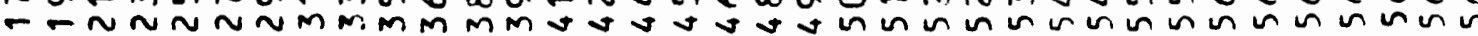

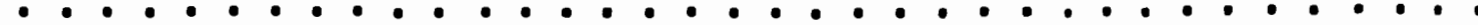
000000000000000000000000000000000000

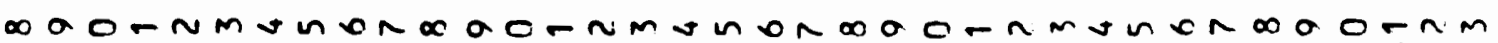

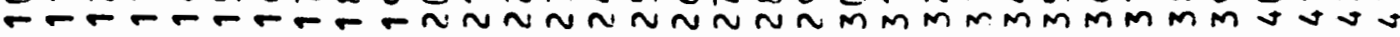


-

- $\dot{0} \dot{0} \dot{0} \dot{0} \dot{0} \dot{0} \dot{0} \dot{0} \dot{0} \dot{0} \dot{0} \dot{0} \dot{0} \dot{0} \dot{0} \dot{0} \dot{0} \dot{0} \dot{0} \dot{0} \dot{0} \dot{0} \dot{0} \dot{0} \dot{0}$

$m$ m

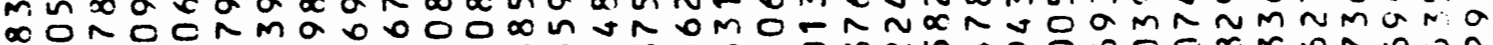

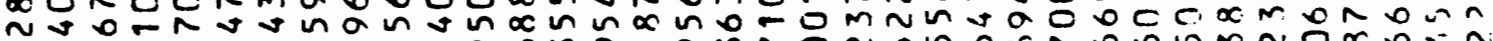

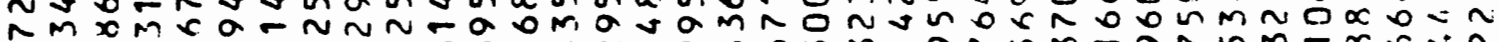

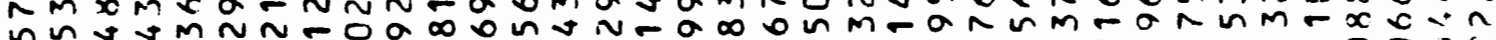
正 000000000000000000000000000000000000

va

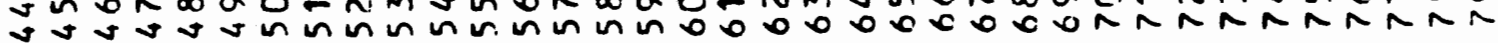


$\therefore \dot{0} \dot{0}$

வ0்

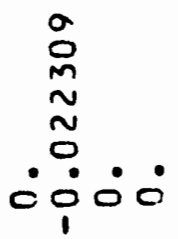

$﹎{\alpha}=\underset{\infty}{m}$ 
$\propto$

$$
\text { i c }
$$

n

岕

w

m

¿ंट

n

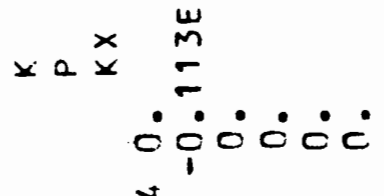

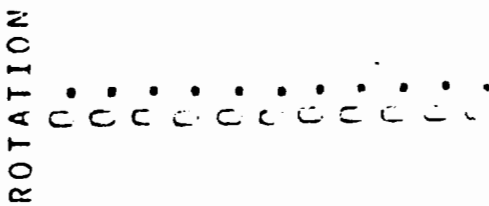

in

$\stackrel{\square}{0}$

งั>0

:00000

1
0
0
0

N

0
$z$
$\frac{1}{x}$
$\frac{1}{0}$

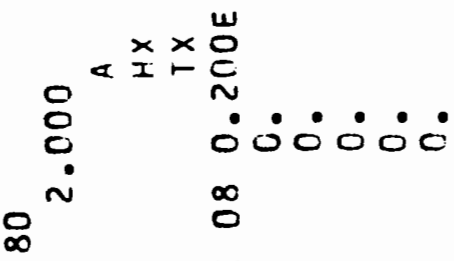

$\frac{1}{\alpha}$
$a$
$x$
$u$
$\vdots$
$\vdots$
$\vdots$

2

w

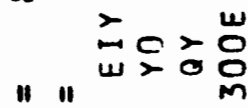

:0ं0ं0்

$\Sigma I$

$\infty \begin{array}{ll}\infty & 0\end{array}$

$\propto I$

$\sim$

2

$5 \Xi$

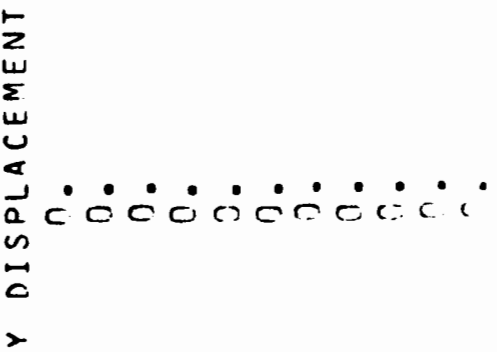

$>0 \times a \times 0 \times 0 \quad$ U $\quad$ U

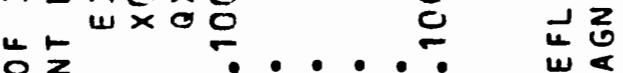

它

W

$\propto \Sigma$

$\begin{array}{lll}0 & 0 \\ \infty & & 0\end{array}$

ul

둔

$\sum_{z} \sum$

$\underset{5}{\infty} 0 \quad 0$

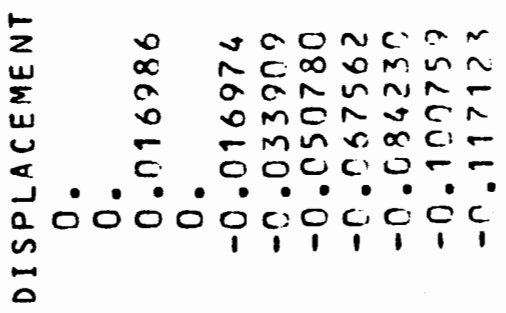

$x$

$\alpha x>\alpha x>\alpha \dot{0} m n-0-n m s m r$ $\omega \rightarrow$

$m 0$

$\ddot{m}<0000000$

U上

a s

$a$ 


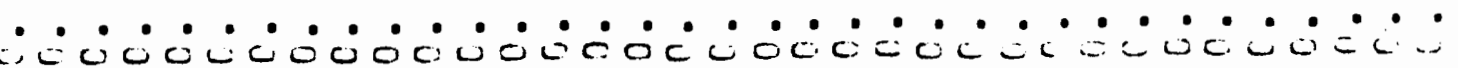

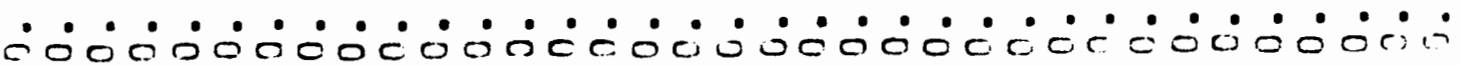

a $\alpha 0 \infty$ I 00 J

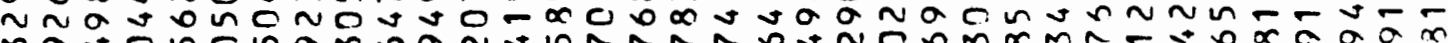
mave $\sigma$ a

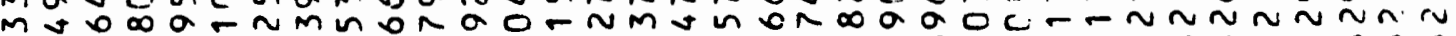
- $-F-\pi N$ -

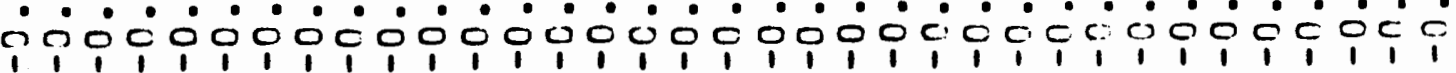

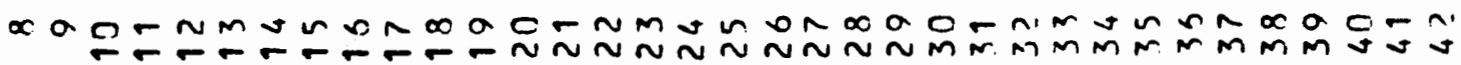




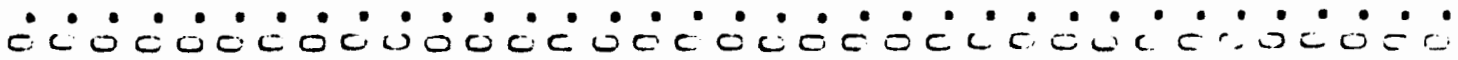
-

a - mo m o a gavecuna

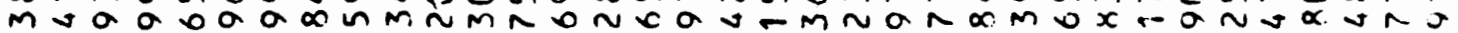

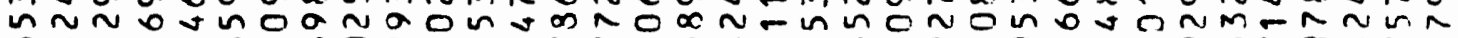

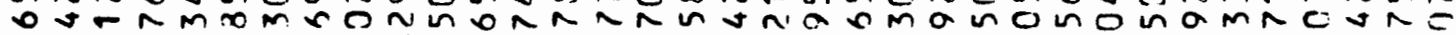

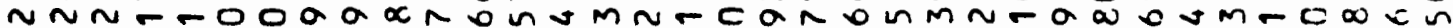

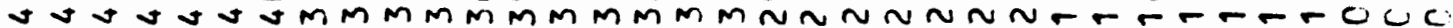
íc

mum o v

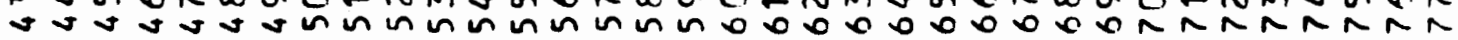


¿ن்ச்

ن்ட்ட்

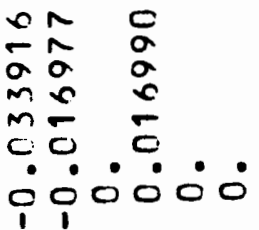

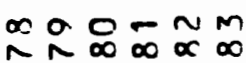




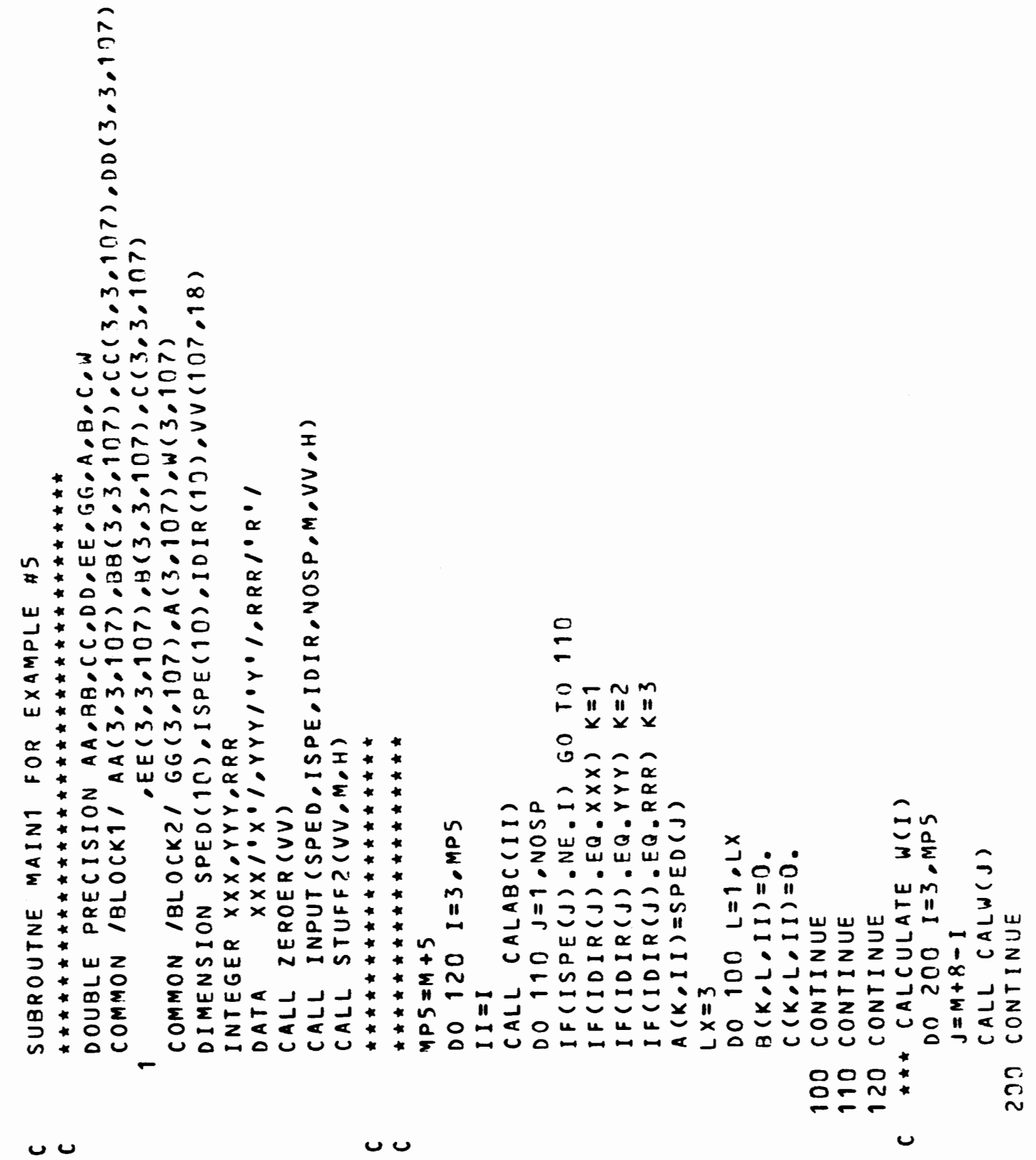


$\propto$

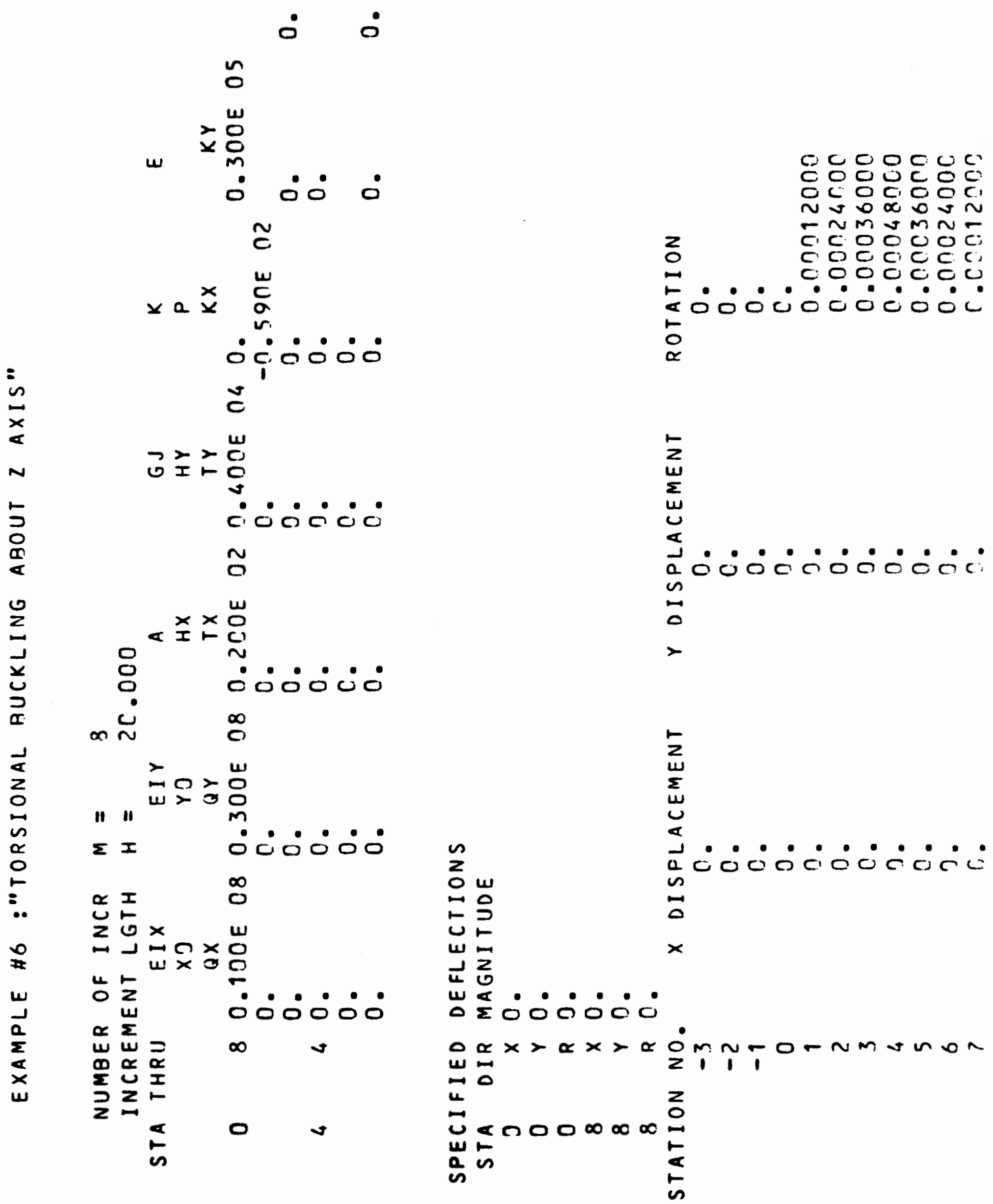


$\therefore 000$

هன்ல

نंتْه

no은 
$\alpha$

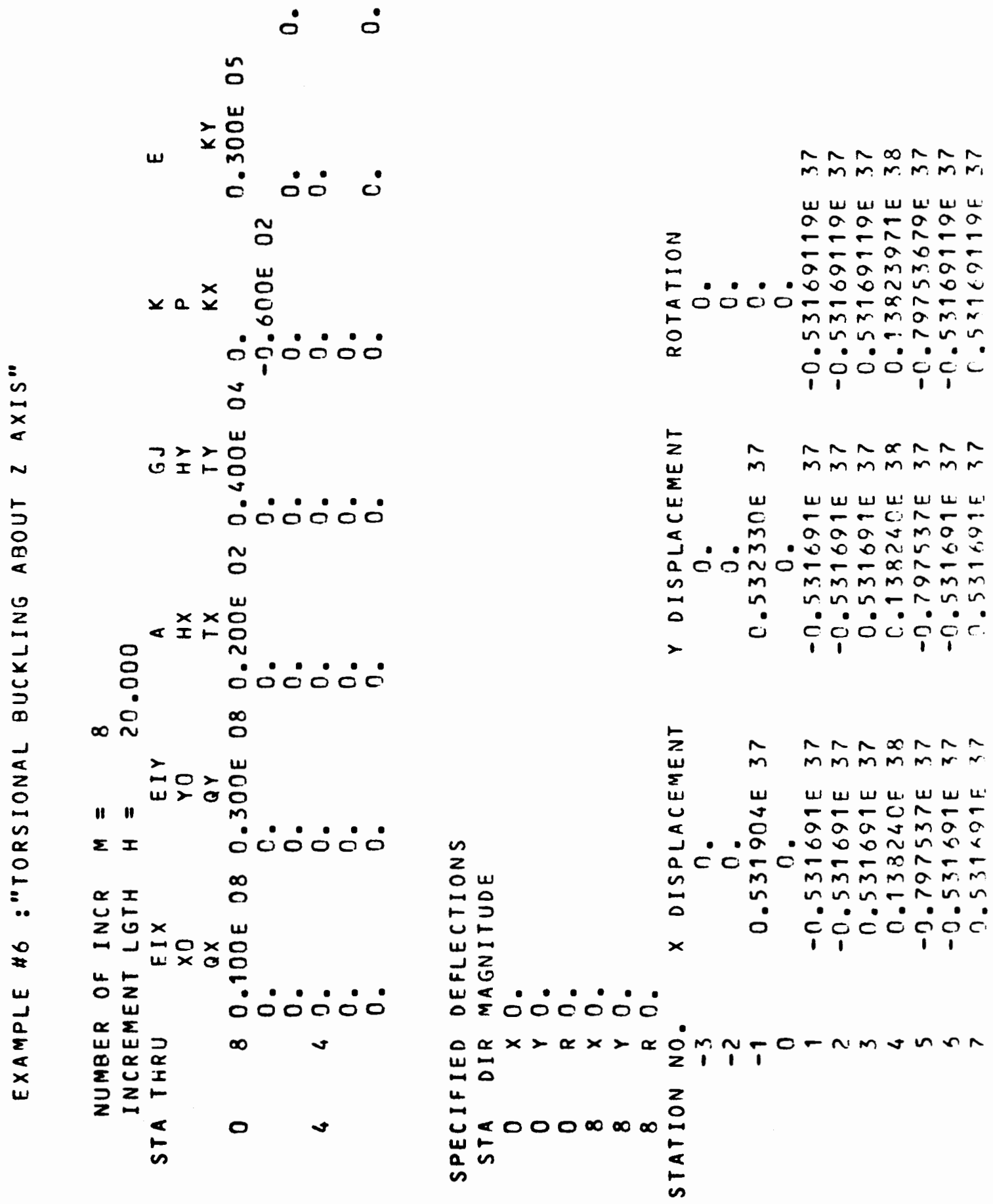



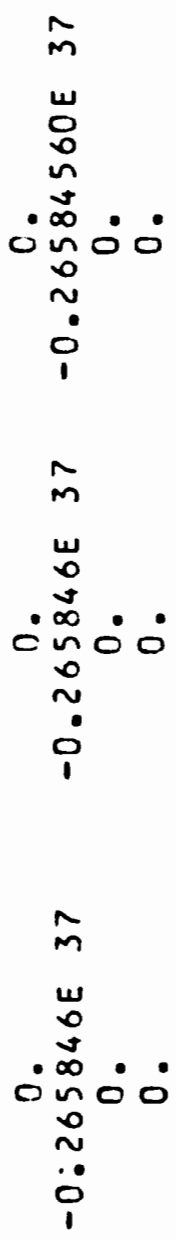

이음 
$\propto$

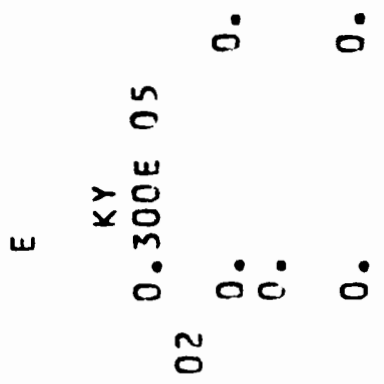

$\times \quad \frac{\omega}{0}$
0

ن்ட்

5
in
$x$
0
0
0
0

5

$\vec{I}>0$

ல்0ं0்

N

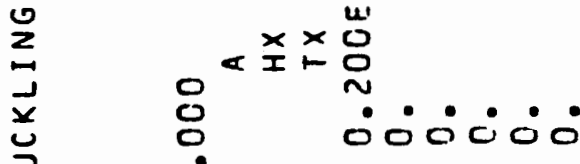

$\stackrel{\infty}{\infty}$

$\frac{1}{2}$
2
$\vdots$
$\vdots$
0

$\infty \stackrel{0}{n}$

i

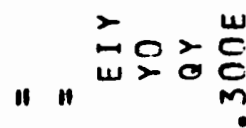

I I $\dot{0} \dot{0} \dot{0} \dot{0}$

$\propto I \leftarrow \infty$

$25 \times \omega$

ㄴ $\quad-40 \times 0$

wa

u

$\propto \Sigma$

$\omega \underset{0}{\omega} \overrightarrow{0}$

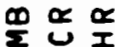

$\sum 2$

$$
\text { o }
$$

z

$2 w$

$\because 0$

บ

$w$

$\mathbb{2}$

:0்0ं0்

$\infty \quad$
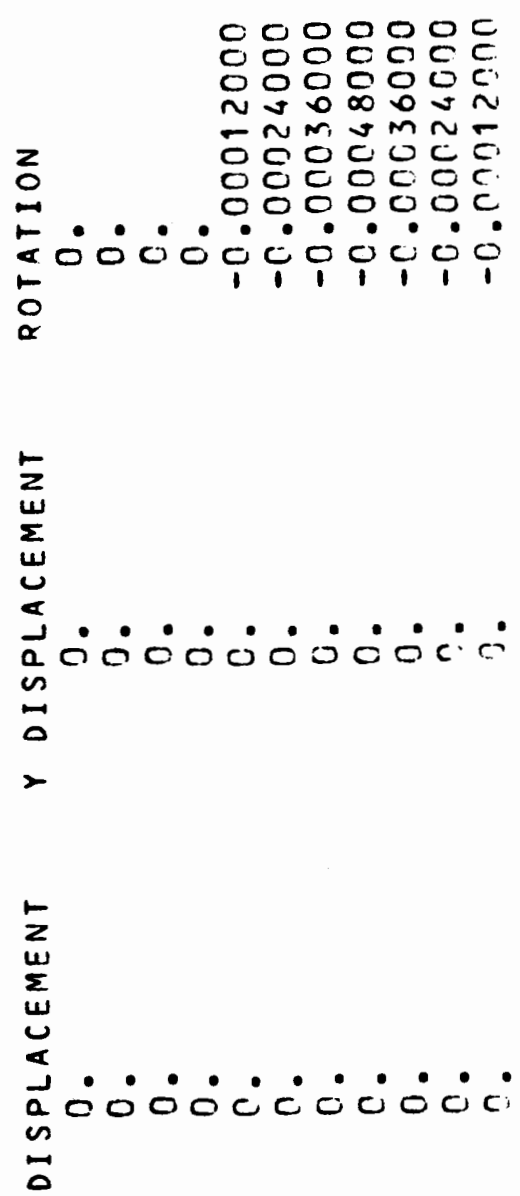

$0 \alpha x>\alpha x>\alpha \dot{0} m n-0-n m \sin n$ $\omega_{0}$

U⿺𠃊一

an 
$\dot{0} \dot{0} \dot{\circ}$

$\therefore \circ \circ 0^{\circ}$

ن்

- $0=$ 


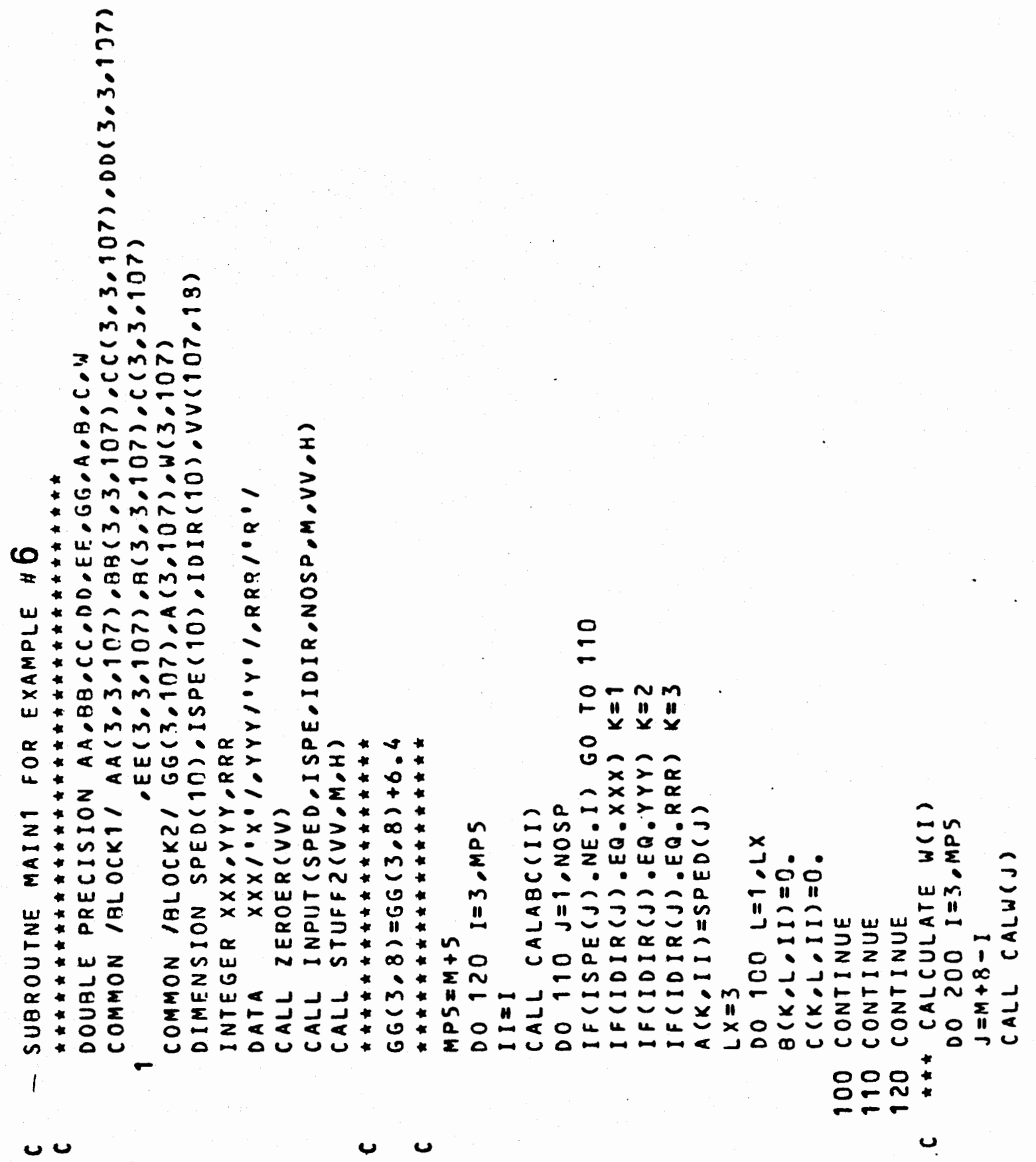




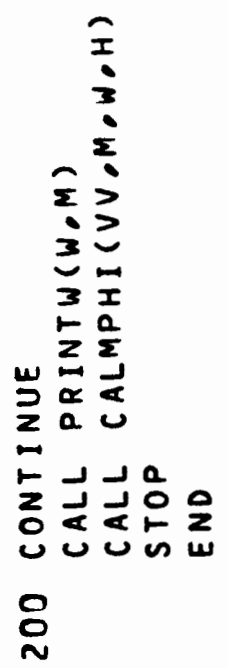


?

$\propto$

$$
\ddot{0} \quad \dot{0}
$$

2
$z$
0
$\vdots$
$w$
$w$
$w$
0
0
$z$
$\alpha$

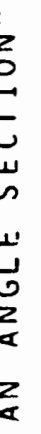

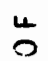

号

خ岕

$w$

$\because$ Oं்<smiles>[Mg]=[Mg]</smiles>
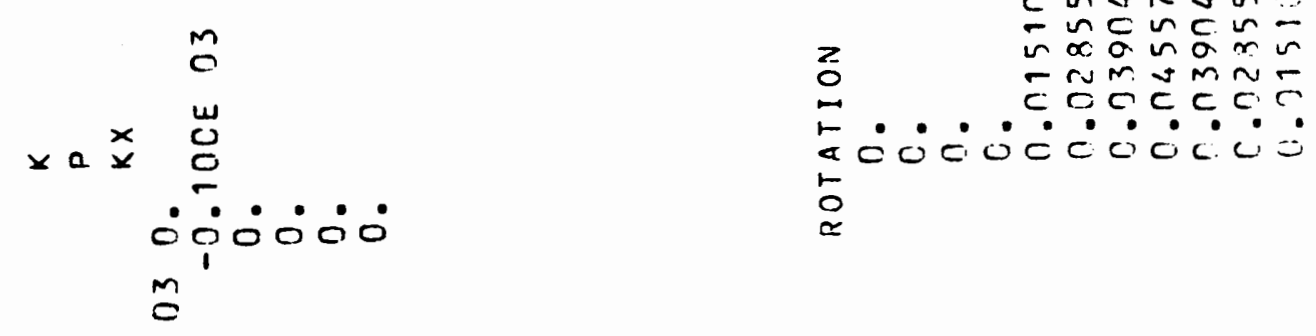

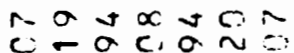

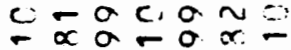
cintagin

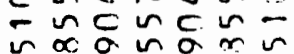

$5 \quad 0 \quad x \infty a n x \alpha$ u. in $\quad$ a

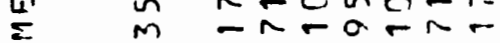
山 $\mathrm{y}$ a u $\quad c 0 F-c c$

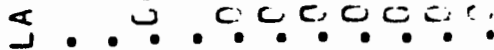
क a

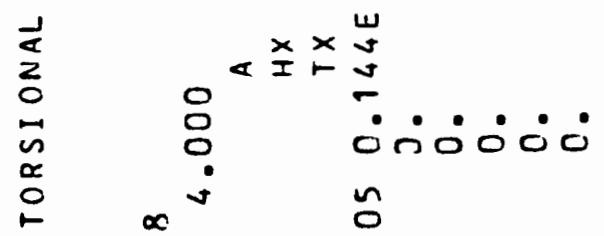
$\overrightarrow{0}$ $>$ n ¿ 든 웅 U

*

*

*

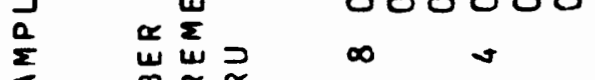

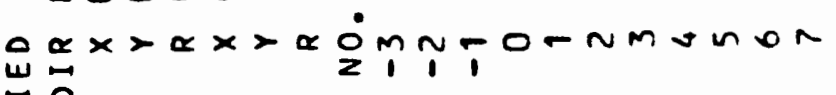
艎

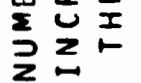
is

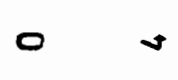

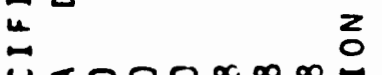

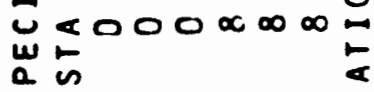

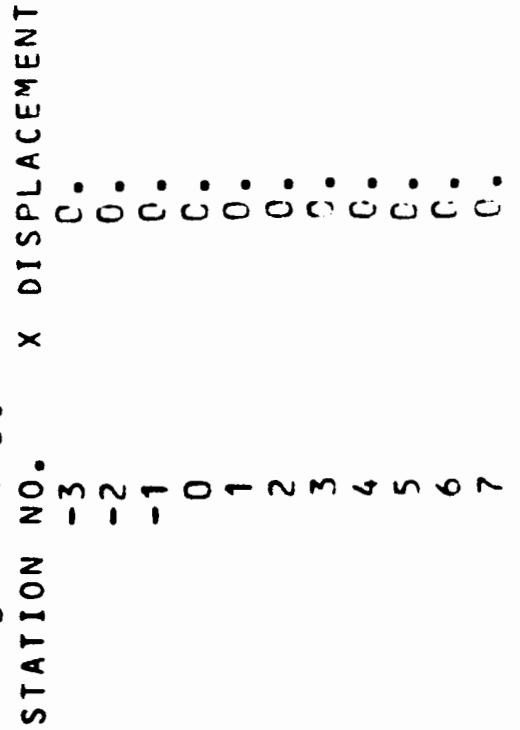


¿0்0

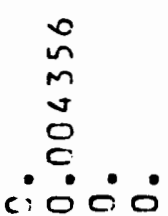

ن்

$\infty 00=$ 
$?$
$\vdots$
5
II

$\propto$

0ं

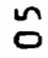

$\sum_{0}^{2}$

w

$\times 0$

(1) $\quad \times$

:0

So $\operatorname{sima\infty }$ an $n-C-t$ $m \sim n m \Delta \sim \sim$ cñOñ m

w<smiles></smiles>

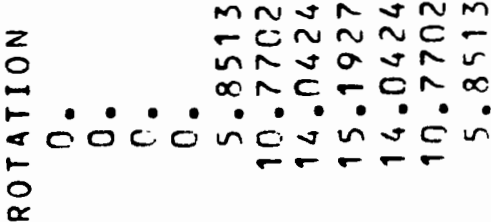

2

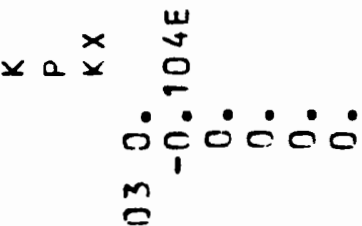

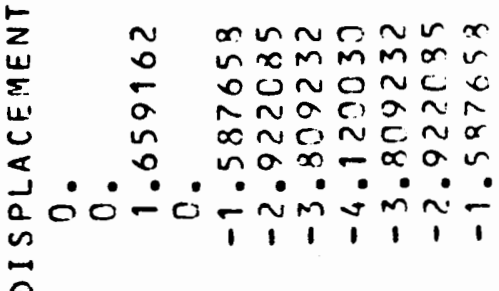

$\vec{I} 20$

¿0ं0்

o

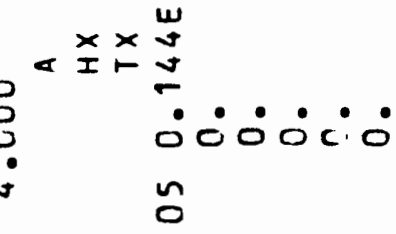

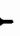

2

2

은

$\vdash \stackrel{5}{5}$

$\omega$

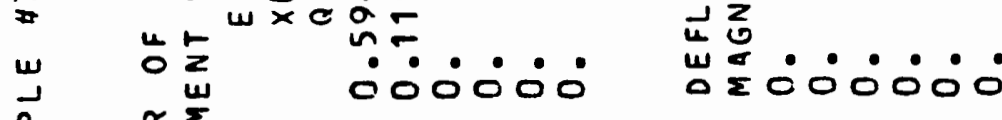

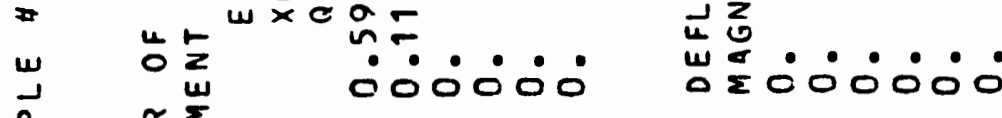

$\underset{x}{a}$

$\propto \stackrel{w}{\Sigma}$

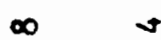

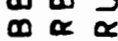

$\infty$

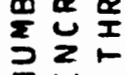

$\underset{r}{i} 0$

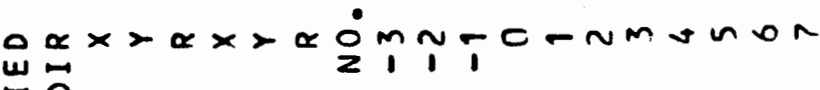

u

$m$

U

$\omega$

a $n$

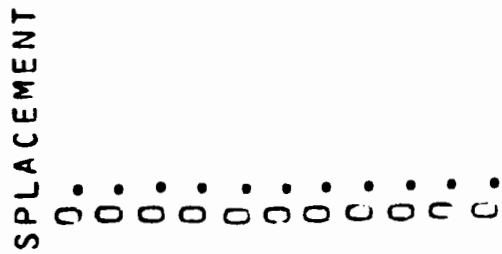

$\overrightarrow{0}$

$x$ 
¿ச்

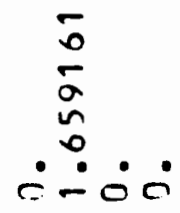

$\dot{0000}$

$\infty a=$ 
$\propto$

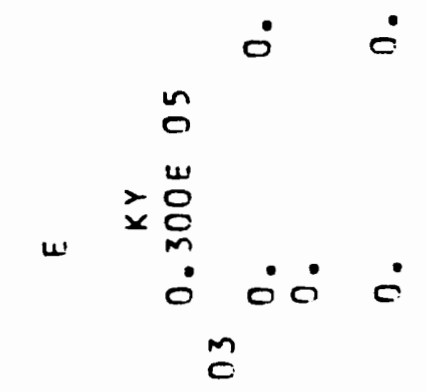

w
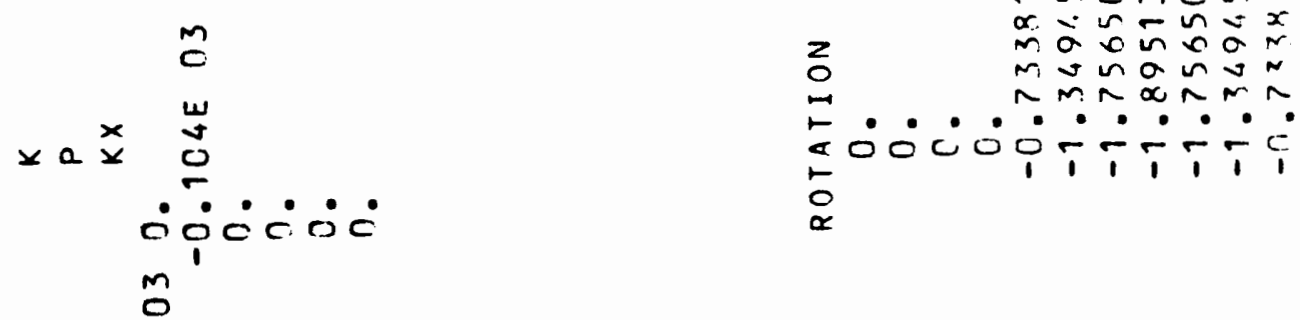

亗

כיב

$\vec{I} \underset{1}{2}$

m. $\cdot \dot{0} \cdot \dot{0}$

$=\quad 0 \quad n n-\pi n n$ u $\quad n \alpha n \in \cos \alpha$ $\sum \infty \infty 00000$

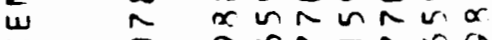
- 0 a $n \pi-r a a$ 000000

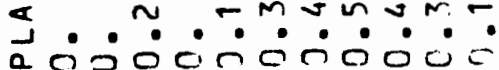
C

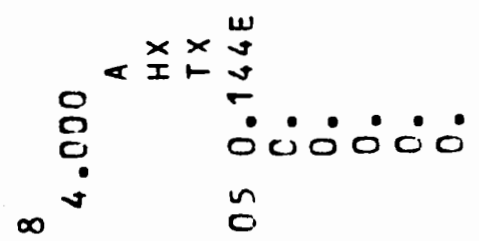

$\stackrel{n}{0}$

$>$

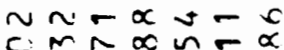

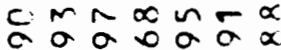
- nOMC n $x \dot{a} \sim n=x$ ma 0 a m $\operatorname{man} a \sin$ $0 \div \div \div \div \div$ isocinariog

$\sim$

2

음잉

$\leftarrow \stackrel{0}{5}$

แ๓

ए.

山 $4 \cdot \bullet \cdot \bullet \cdot \bullet$

प

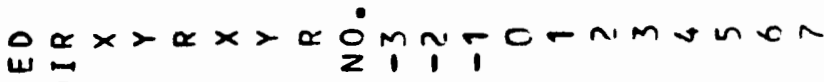
$\rightarrow 0$

in $4000 \times \infty \propto \stackrel{2}{2}$

$\omega \leftarrow$

a is

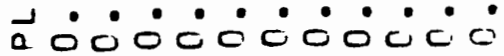
n

a

$x$

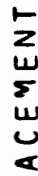

2

$$
\begin{gathered}
5 \\
0 \\
0 \\
0 \\
0 \\
0 \\
0 \\
0
\end{gathered}
$$

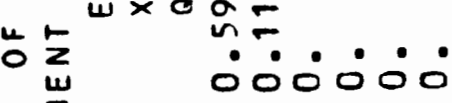

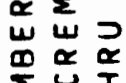$$
\infty
$$$$
0 \text { s }
$$ 
$\therefore 0^{\circ}$

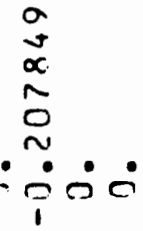

¿000

ar $0=$ 


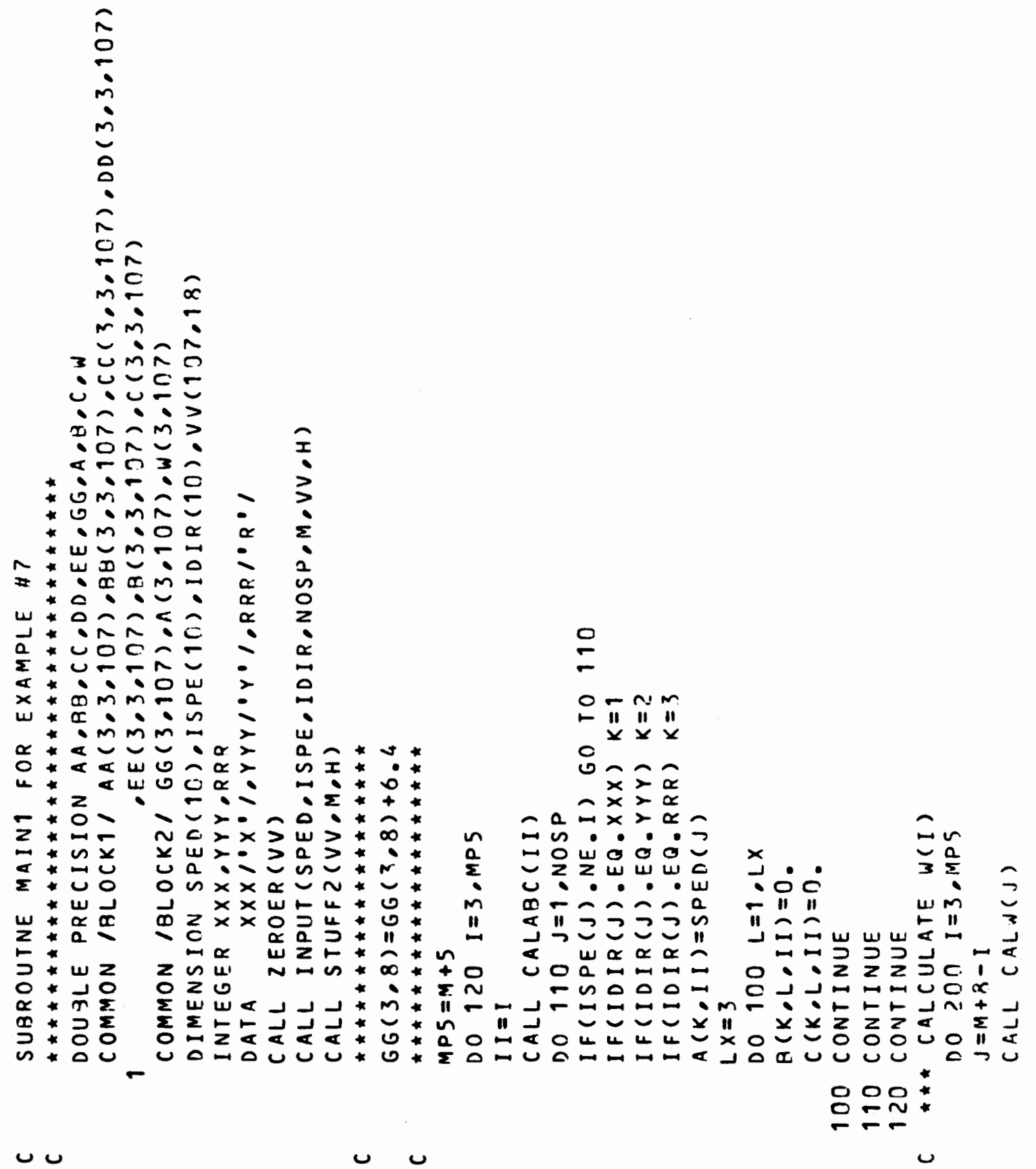




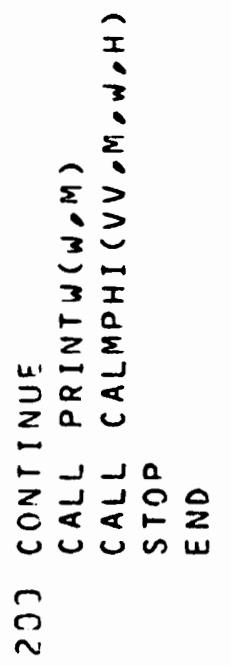




\section{APPENDIX D \\ DEFLECTION OF THE CROSS SECTION}

As the member buckles in flexural torsional buckling, the cross section undergoes translations $\mathrm{U}$ and $\mathrm{V}$ in the $\mathrm{X}$ and $\mathrm{Y}$ directions, respectively and a rotation $\varnothing$ about the $z$ axis. As the result of the rotation, each point of the cross section translates different amounts than $u$ and $v$ in the $X$ and $Y$ direction.

Shear center by definition is a point in the cross section through which a lateral load must pass to produce bending without twisting. Therefore, the cross section rotates about the shear center if a pure torque is applied to the cross section. In this discussion, the shear center is taken as the origin and $X$ and $Y$ axes are assumed to coincide with the principal axes of the section. $Z$ is assumed along the longitudinal axis through the shear center. During the translation, point 0 of Figure 20 , the shear center, moves to $0^{\prime}$ and point $C$, the center of gravity, moves to $C^{\prime}$. The final position of $C$ is $\mathrm{C}^{\prime \prime}$ as the cross section rotates about the shear center, $0^{\prime}$.

The shear center deflects $\mathrm{u}$ and $\mathrm{v}$ amount in the $\mathrm{X}$ and $\mathrm{Y} \operatorname{direc}-$ tion. The deflections of the center of gravity is $u+Y_{0} \varnothing$ and $v-x_{0} \varnothing$ in the $\mathrm{X}$ and $\mathrm{Y}$ direction. The proof of this follows: 


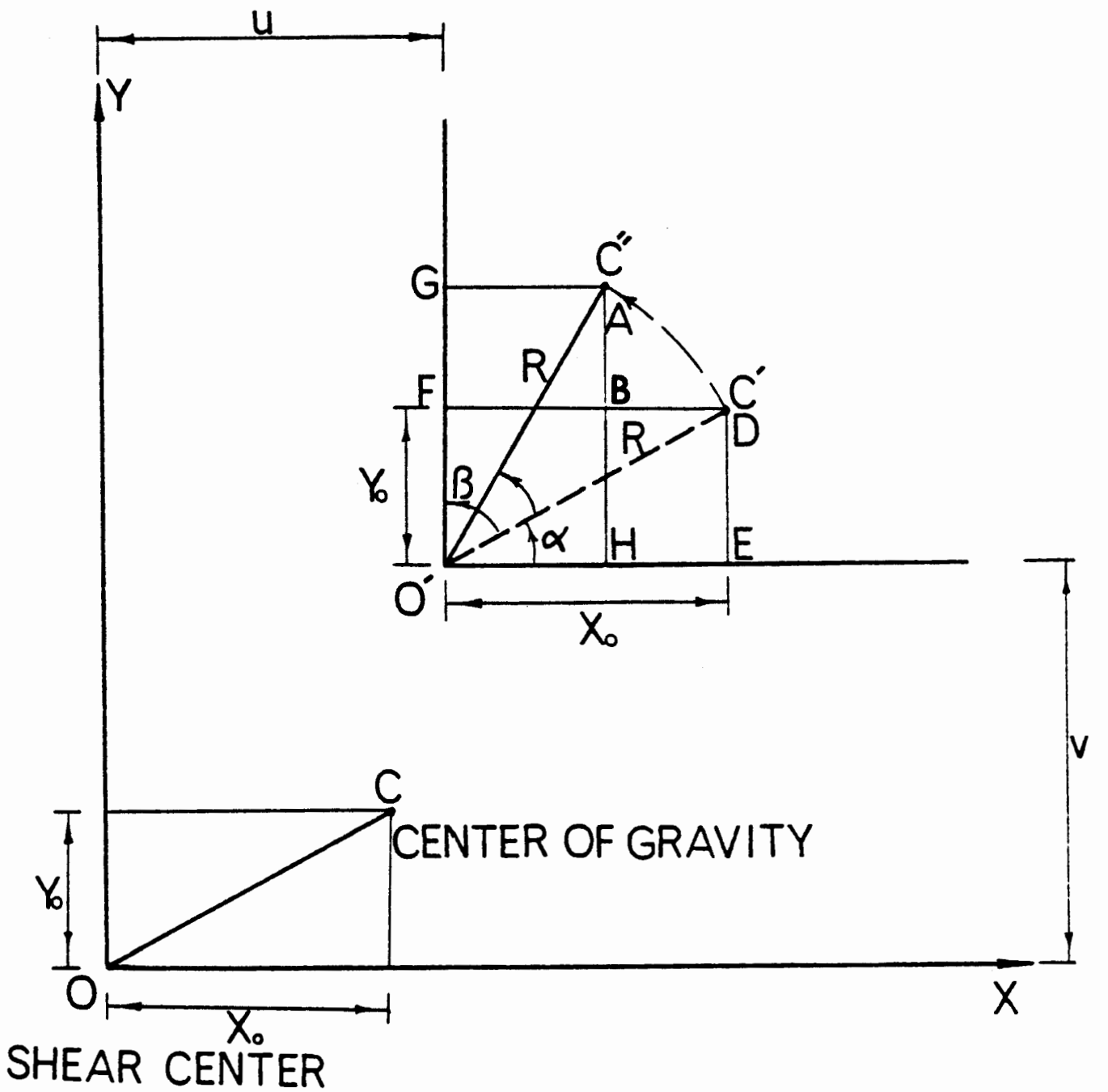

Figure 20 Displacement of the center of gravity 


$$
\begin{aligned}
& \bar{x}_{C C^{\prime}}=\bar{u} \text { (Distance from } C \text { to } C^{\prime} \text { in } X \text { direction) } \\
& \bar{x}_{C C^{\prime \prime}}=\bar{u}-\overline{D B} \text { (Distance from } C \text { to } C^{\prime \prime} \text { in } x \text { direction) } \\
& \overline{D B}=\overline{D F}-\overline{A G} \\
& \overline{D F}=x_{O} \\
& \overline{D B}=x_{O}-\overline{A G} \\
& \left.\overline{A G}=R \sin (\beta-\varnothing) \quad \text { (Triangle } 0^{\prime} A G\right)
\end{aligned}
$$

or

$$
\overline{A G}=R \sin \beta \cos \phi-R \operatorname{Cos} B \sin \phi
$$

$\phi$ is small angle, therefore assume $\cos \phi=1$ and $\sin \phi=0$

$$
\overline{\mathrm{AG}}=\mathrm{R} \sin \beta-(\mathrm{R} \cos \beta) \phi
$$

$R \sin \beta=x_{0}$ and $R \cos \beta=Y_{0} \quad$ (Triangle $\left.O^{\prime} D E\right)$

$\overline{\mathrm{AG}}=\mathrm{X}_{\mathrm{O}}-\mathrm{Y}_{\mathrm{O}} \varnothing$

$\overline{\mathrm{DB}}=\mathrm{X}_{0}-\left(\mathrm{X}_{0}-\mathrm{Y}_{0} \varnothing\right)=\mathrm{Y}_{0} \varnothing$

$\overline{\mathrm{x}}_{\mathrm{CC}^{\prime}}=\overline{\mathrm{u}}-\mathrm{Y}_{0} \phi$

$\overline{\mathrm{Y}}_{C C^{\prime}}=\overline{\mathrm{v}}$ (Distance from $\mathrm{C}$ to $\mathrm{C}^{\prime}$ in the $\mathrm{Y}$ direction)

$\overline{\mathrm{Y}}_{\mathrm{CC}^{\prime}}=\overline{\mathrm{v}}+\overline{\mathrm{AB}}$ (Distance from $\mathrm{C}$ to $\mathrm{C}^{\prime \prime}$ in the $\mathrm{Y}$ direction)

$\overline{\mathrm{AB}}=\overline{\mathrm{AH}}-\overline{\mathrm{BH}}$

$\overline{\mathrm{BH}}=\mathrm{Y}_{\mathrm{O}}$

$\overline{\mathrm{AB}}=\overline{\mathrm{AH}}-\mathrm{Y}_{\mathrm{O}}$

$\overrightarrow{\mathrm{AH}}=R \sin (\alpha+\varnothing) \quad$ (Triangle $O^{\prime} \mathrm{AC}$ )

$\overline{\mathrm{AH}}=\mathrm{R} \sin \alpha \cos \phi+\mathrm{R} \cos \alpha \sin \phi$

$\emptyset$ is small angle, therefore, assume $\cos \emptyset=1$ and $\sin \phi=0$

$\overline{A C}=R \sin \alpha+(R \cos ) \varnothing$

$R \sin \alpha=Y_{0}$ and $R \cos \alpha=X_{0} \quad$ (Triangle $O^{\prime} D E$ )

$\overline{A C}=Y_{0}+x_{0} \phi$ 


$$
\begin{aligned}
& \overline{A B}=\left(Y_{0}+x_{0} \phi\right)-Y_{0}=x_{0} \phi \\
& \bar{Y}_{C C^{\prime \prime}}=\bar{v}+x_{0} \phi
\end{aligned}
$$

As the beam deflects any point on the cross section which has $X$ and $Y$ coordinates, with respect to the shear center, translates $u$ - $Y \varnothing$ and $v+X \varnothing$ in the $X$ and $Y$ direction. This can be shown in the same manner as it was presented for the center of gravity. 